University of Tennessee Health Science Center

UTHSC Digital Commons

\title{
Investigating the Role of Dispatched in Hedgehog Ligand Transport and Delivery
}

\author{
William Bodeen \\ University of Tennessee Health Science Center
}

Follow this and additional works at: https://dc.uthsc.edu/dissertations

Part of the Chemicals and Drugs Commons, Genetic Processes Commons, Medical Biochemistry Commons, and the Medical Cell Biology Commons

\section{Recommended Citation}

Bodeen, William (http://orcid.org/0000-0002-0557-4826), "Investigating the Role of Dispatched in Hedgehog Ligand Transport and Delivery" (2017). Theses and Dissertations (ETD). Paper 432. http://dx.doi.org/10.21007/etd.cghs.2017.0437. 


\title{
Investigating the Role of Dispatched in Hedgehog Ligand Transport and Delivery
}

\begin{abstract}
During the development of all metazoans, the Hedgehog $(\mathrm{Hh})$ signaling pathway provides instructional cues influencing a variety of cellular processes. The pathway ligand, $\mathrm{Hh}$, is dually lipidated by cholesterol and palmitate, which effectively anchors the molecule to the lipid bilayer of the signal producing cell. To complicate the Hh pathway induction process, the $\mathrm{Hh}$ ligand is often produced at a significant distance from the cells it influences. Only one known conserved molecule, Dispatched (Disp), can alleviate the membrane tethering imparted by Hh lipidation. Underscoring the importance of Disp protein during development, knockout animals succumb to lethality at E9.5, an exact phenocopy of the knockout of the essential signal transducer of the pathway: Smoothened. Furthermore, mutations within Disp have been found in patients with Holoprosencephaly, the most common cause of human forebrain malformations, which is frequently caused by inhibition of Hh signaling during development. Very little is known regarding the functional or regulatory mechanisms enabling Disp to transport and release Hh ligand. This dissertation aimed to narrow this gap and began with investigation into the role of Disp in a largely ignored mechanism of $\mathrm{Hh}$ ligand transport known as cytoneme-mediated morphogen transport. This method of morphogen transport utilizes fragile, thin cytoplasmic extensions which deliver cargo directly from the source of production to ligand responding cells. Through the use of a modified electron microscopy fixative, which we named MEM-fix, to maintain cytonemes for traditional cell biological analysis, I established an in vitro cytoneme system capable of modeling in vivo cytoneme biology. This in vitro cytoneme system uses Schneider 2 cells, an embryonically derived Drosphila cell line, which demonstrate competency to produce and utilize cytonemes as a mechanism of Hh transport. Equipped with this tool, I investigated the relationship between cytonemes and $\mathrm{Hh}$ pathway components. In doing so, I uncovered a previously unknown Disp requirement in cytoneme-mediated transport of $\mathrm{Hh}$ ligand and subsequently a Disp-mediated cytoneme stabilizing effect. Through these studies into Disp-mediated cytoneme transport, I identified a Disp cleavage event of Disp that regulates the ability to release $\mathrm{Hh}$ ligand. The second part of this dissertation details a collaborative effort in which we discovered that the Furin family of proprotein convertases facilitate the cleavage of Disp at a conserved site of the first extracellular loop. The Furin family has been implicated in cleaving ligands and receptors of other developmental signaling pathways, but no reports exist linking the Furin family to regulation of the Hh pathway. Therefore, we investigated the functional consequence of this Disp cleavage event, and our results suggest that this cleavage likely influences the proper trafficking of Hh for efficient release both in vitro and in vivo. To our knowledge, this is the first report of a regulatory protein partner controlling the activity of Disp in releasing Hh.
\end{abstract}

\section{Document Type}

Dissertation

Degree Name

Doctor of Philosophy (PhD)

Program

Biomedical Sciences

Research Advisor

Stacey K. Ogden, Ph.D.

Keywords

Cytonemes, Dispatched, Hedgehog Signaling, MEM-fix, Morphogen, Morphogen Transport 


\section{Subject Categories}

Chemicals and Drugs | Genetic Processes | Medical Biochemistry | Medical Cell Biology | Medical Sciences | Medicine and Health Sciences 
Investigating the Role of Dispatched in Hedgehog Ligand Transport and Delivery

\author{
A Dissertation \\ Presented for \\ The Graduate Studies Council \\ The University of Tennessee \\ Health Science Center
}

In Partial Fulfillment

Of the Requirements for the Degree

Doctor of Philosophy

From The University of Tennessee

By

William Bodeen

May 2017 
Copyright (C) 2017 by William Bodeen. All rights reserved. 


\section{ACKNOWLEDGEMENTS}

I would like to thank my wife Rachael for her non-stop support to follow what I believe to be important and exciting; I could not have made it without you and love you dearly.

I would specifically like to acknowledge Drs. Daniel Stewart and Suresh Marada for their collaborations and contributions to Chapter 4 of this dissertation. Without Daniel's non-stop, over-the-top work ethic and Suresh's interests into all things that are science it would not have been possible. I also owe my fellow lab mates a word of thanks for all the discussion, advice and questions over the years. Without your friendship, words of encouragement, and of guiding criticism from the collective group I would not be the scientist I am today.

I owe a great deal of gratitude to my mentor, Dr. Stacey K. Ogden, for all the time and effort she devoted to the training I was given. Her viewpoints, guidance, and pressure were essential to my success. Countless hours of discussion on topics of interest led to the honing of my reasoning, which has propelled me down this path. To say you were indispensable would be a disservice.

Finally, none of this would be possible without the support of the University of Tennessee HSC, St. Jude Children's Hospital, ALSAC, and the NIH. Thank you for supporting this, as well as other, research. In times where factual evidence no longer appeals to reason and research-funding sources are under fire, student scientist should be particularly grateful for the opportunities provided to them. 


\begin{abstract}
During the development of all metazoans, the Hedgehog (Hh) signaling pathway provides instructional cues influencing a variety of cellular processes. The pathway ligand, $\mathrm{Hh}$, is dually lipidated by cholesterol and palmitate, which effectively anchors the molecule to the lipid bilayer of the signal producing cell. To complicate the Hh pathway induction process, the Hh ligand is often produced at a significant distance from the cells it influences. Only one known conserved molecule, Dispatched (Disp), can alleviate the membrane tethering imparted by Hh lipidation. Underscoring the importance of Disp protein during development, knockout animals succumb to lethality at E9.5, an exact phenocopy of the knockout of the essential signal transducer of the pathway: Smoothened. Furthermore, mutations within Disp have been found in patients with Holoprosencephaly, the most common cause of human forebrain malformations, which is frequently caused by inhibition of Hh signaling during development.

Very little is known regarding the functional or regulatory mechanisms enabling Disp to transport and release Hh ligand. This dissertation aimed to narrow this gap and began with investigation into the role of Disp in a largely ignored mechanism of $\mathrm{Hh}$ ligand transport known as cytoneme-mediated morphogen transport. This method of morphogen transport utilizes fragile, thin cytoplasmic extensions which deliver cargo directly from the source of production to ligand responding cells.

Through the use of a modified electron microscopy fixative, which we named MEM-fix, to maintain cytonemes for traditional cell biological analysis, I established an in vitro cytoneme system capable of modeling in vivo cytoneme biology. This in vitro cytoneme system uses Schneider 2 cells, an embryonically derived Drosphila cell line, which demonstrate competency to produce and utilize cytonemes as a mechanism of $\mathrm{Hh}$ transport. Equipped with this tool, I investigated the relationship between cytonemes and Hh pathway components. In doing so, I uncovered a previously unknown Disp requirement in cytoneme-mediated transport of Hh ligand and subsequently a Dispmediated cytoneme stabilizing effect.

Through these studies into Disp-mediated cytoneme transport, I identified a Disp cleavage event of Disp that regulates the ability to release Hh ligand. The second part of this dissertation details a collaborative effort in which we discovered that the Furin family of proprotein convertases facilitate the cleavage of Disp at a conserved site of the first extracellular loop. The Furin family has been implicated in cleaving ligands and receptors of other developmental signaling pathways, but no reports exist linking the Furin family to regulation of the Hh pathway. Therefore, we investigated the functional consequence of this Disp cleavage event, and our results suggest that this cleavage likely influences the proper trafficking of $\mathrm{Hh}$ for efficient release both in vitro and in vivo. To our knowledge, this is the first report of a regulatory protein partner controlling the activity of Disp in releasing $\mathrm{Hh}$.
\end{abstract}




\section{TABLE OF CONTENTS}

CHAPTER 1. INTRODUCTION ...............................................................................

The Hedgehog Signaling Pathway during Development and Disease .........................

Hh Pathway Components Overview .....................................................................2

Influences on the Range and Specificity of Hh Ligand Distribution.........................4

Conclusions and Aims of This Dissertation.......................................................... 8

CHAPTER 2. MATERIALS AND METHODS.........................................................10

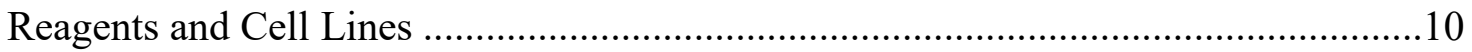

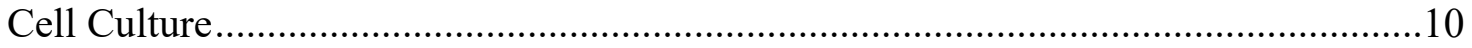

Expression Plasmids ......................................................................................... 10

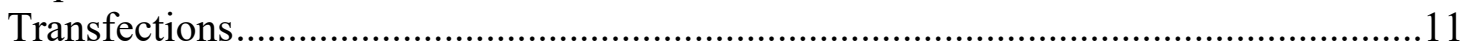

MEM-fix Immunofluorescence Protocol ............................................................. 11

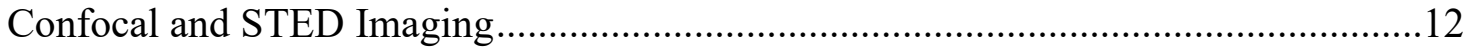

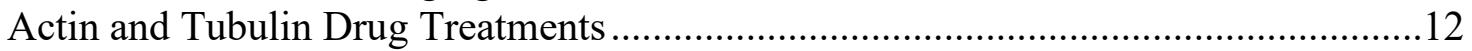

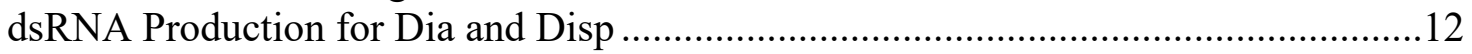

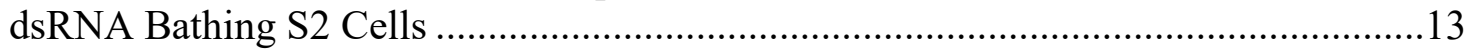

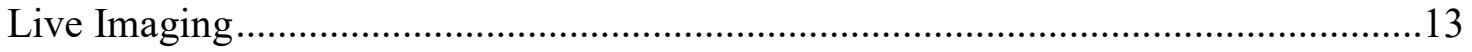

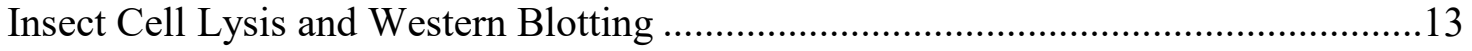

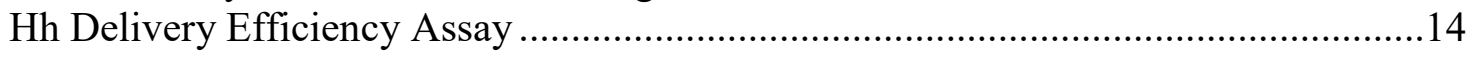

Quantification of Cytoneme Occurrence ................................................................. 14

Co-Culture Reporter Assay............................................................................... 15

Insect Hh Conditioned Media Generation, Collection, and Application ......................15

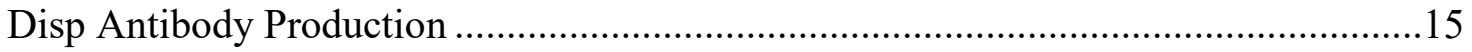

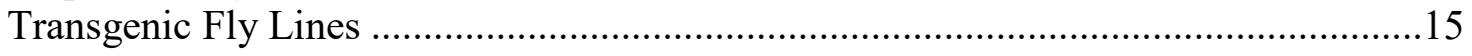

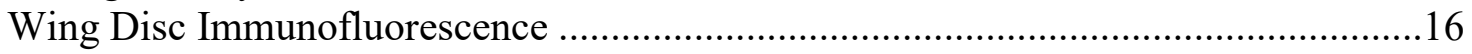

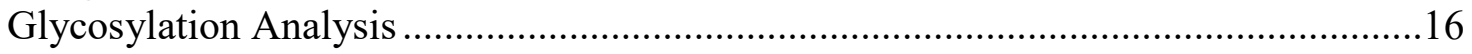

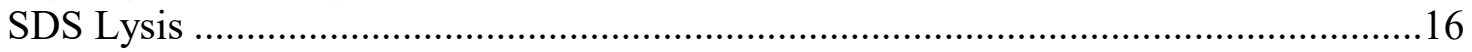

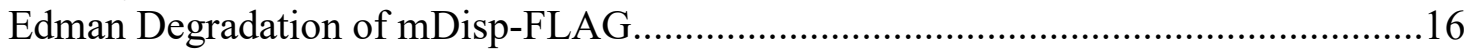

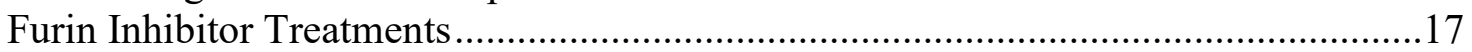

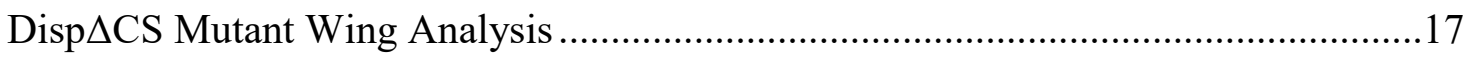

Disp Expression in Drosophila Follicle Cells ...................................................... 17

\section{CHAPTER 3. MEM-FIX: A NOVEL CYTONEME FIXATIVE REVEALS A} ROLE FOR DISP IN CYTONEME-MEDIATED HH TRANSPORT ......................18

Development of an In Vitro Cytoneme System..........................................................20

Live Imaging of GFP and CD8-mCherry (+) S2 Cytonemes .......................................24

Examining the Effect of Hh Pathway Components on Cytonemes ..............................24

Controlling for Lipid-Based Transfection and Membrane Protein Overexpression......27

Analysis of Density and Signaling on Cytoneme Occurrence.....................................34

Investigating Hh Lipidation on Cytoneme Outgrowth ............................................ 38

Live Imaging of GFP and Disp-mCherry (+) S2 Cytonemes ....................................41

Validating In Vitro Findings in Drosophila Wing Imaginal Discs .............................41 


\section{CHAPTER 4. DISP CLEAVAGE REGULATES RELEASE OF THE}

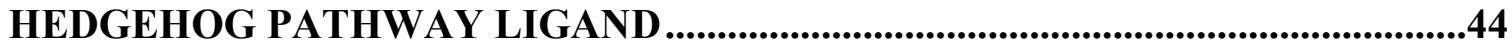

Disp Protein Banding Pattern Correlates with Activity .............................................44

Estimating the Cleavage Site of Drosophila Dispatched ........................................45

Testing Conservation of the Disp Lower Species Production ...................................48

Identifying the N-Terminus of the Lower Molecular Weight Disp............................48

Mutational and Pharmacological Inhibition to Block Disp Cleavage ..........................51

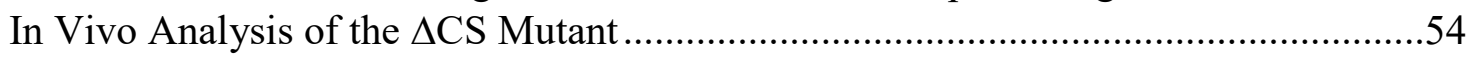

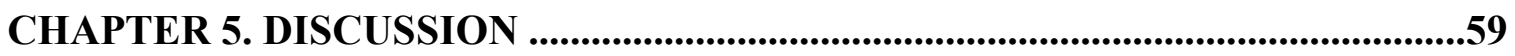

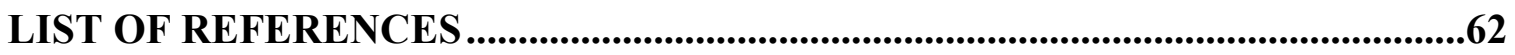

VITA 


\section{LIST OF FIGURES}

Figure 1-1. An overview diagram of the Hedgehog signaling pathway............................3

Figure 1-2. A diagram of the Drosophila wing imaginal disc separating posterior and

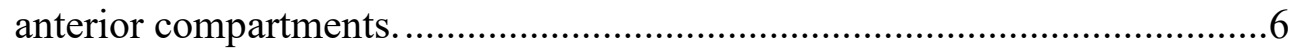

Figure 1-3. A diagram of the murine neural tube ……...................................................6

Figure 3-1. S2 cells treated with MEM-fix allows visualizing cytoneme structures.......19

Figure 3-2. Cytochalasin D treatment, but not Nocodazole, has a significant effect on cytoneme architecture.

Figure 3-3. S2 cell cytonemes control morphogen incorporation. ...................................21

Figure 3-4. Hh is found in producing cell neighbor cells contacted by cytonemes.........22

Figure 3-5. dia knockdown verified by western blot affects Hh delivery to neighbors.

Figure 3-6. Cl8 cells project cytoneme-like extensions containing Disp and the Hh morphogen.

Figure 3-7. NIH-3T3 cells project cytoneme-like extensions containing SHH morphogen.

Figure 3-8. Disp is present within outgrown cytonemes with Hh ligand ........................26

Figure 3-9. Cytoneme occurrence significantly increases with $\mathrm{Hh}$, Disp, and $\mathrm{Hh}+$ Disp. .28

Figure 3-10. The endogenous alpha-Spectrin protein is found in outgrown cytonemes...29

Figure 3-11. Lipid-based transfection effects play no role on cytoneme occurrence........29

Figure 3-12. Disp alignment of the GXXXD transmembrane four containing region......31

Figure 3-13. Disp TM4HA mutant has comparable protein levels to DispHA..................31

Figure 3-14. Disp TM4 mutant localizes similarly to wild-type Disp.................................32

Figure 3-15. Co-culture reporter assay design................................................................32

Figure 3-16. Co-culture reporter assay reveals TM4 mimics non-functional TM4/TM10. 
Figure 3-17. The membrane protein control, TM4, fails to increase cytoneme occurrence.

Figure 3-18. Increasing density does not significantly affect GFP cytoneme occurrence.

Figure 3-19. Pathway activity within receiving cells does not influence cytoneme occurrence.

Figure 3-20. HhN fails to enrich in cytonemes compared to dually lipidated Hh. .39

Figure 3-21. HhN producers do not match Hh cytoneme occurrence levels. .39

Figure 3-22. Endogenous Disp knockdown is verified using anti-Disp antibody.

Figure 3-23. Knockdown of Disp in S2 cells ablates Hh induced cytoneme occurrence.

Figure 3-24. Wing discs expressing GFP and mCD8-RFP extend cytonemes into the anterior signaling compartment.

Figure 3-25. Wing discs expressing Disp and mCD8-RFP extend cytonemes into the anterior compartment.

Figure 3-26. Wing discs expressing TM4 and mCD8-RFP sparsely produce cytonemes into the anterior compartment.

Figure 4-1. Glycosylation analysis of Disp reveals mature glycosylation on lower molecular weight species.

Figure 4-2. SDS lysis of C18 cells expressing Disp mimic banding pattern...................46

Figure 4-3. Endogenous Disp banding is similar to exogenous protein banding.

Figure 4-4. Estimation of cleavage site: Diagram.

Figure 4-5. Hh release assay with double-tagged Disp reveals $30 \mathrm{kDa}$ fragment.

Figure 4-6. Cl8 cells expressing a C-terminal V5-tagged mDisp produce similar banding pattern.

Figure 4-7. Cleavage site sequence diagram.

Figure 4-8. Mutation of fly Edman site fails to inhibit production of cleavage product.

Figure 4-9. Targeting an upstream region from predicted site ablates Disp cleavage. ...53 
Figure 4-10. Furin inhibitor I retards production of lower Disp molecular weight species.

Figure 4-11. Expression of Disp $\Delta \mathrm{CS}$ in the wing fails to induce blistering......................56

Figure 4-12. Polarized follicle cells in the Drosophila ovary reveal Disp $\Delta$ CS trafficking defect. .58 


\section{LIST OF ABBREVIATIONS}

$\begin{array}{ll}\alpha \text {-Spectrin } & \text { Alpha Spectrin } \\ \text { ANOVA } & \text { Analysis of Variance } \\ \text { Ap } & \text { Apterous } \\ \text { BMP } & \text { Bone Morphogenetic Protein } \\ \text { CD8 } & \text { Cluster of differentiation } 8 \\ \text { CDON } & \text { Cell Adhesion Molecule-Related/Down-Regulated By Oncogenes } \\ \text { Ci } & \text { Cubitus Interruptus } \\ \text { C18 } & \text { Clone 8 } \\ \text { CMLE } & \text { Classic Maximum Likelihood Estimation } \\ \text { Cyto D } & \text { Cytochalasin D } \\ \text { DAPI } & \text { 4'6-diamidino-2-phenylindole } \\ \text { DGRC } & \text { Drosophila Genomics Research Center } \\ \text { DHH } & \text { Desert Hedgehog } \\ \text { Dia } & \text { Diaphanous } \\ \text { Disp } & \text { Dispatched } \\ \text { Dpp } & \text { decapentaplegic } \\ \text { dsRNA } & \text { double stranded RNA } \\ \text { DTT } & \text { Dithiothreitol } \\ \text { En } & \text { Engrailed } \\ \text { Endo-H } & \text { Endoglycosidase H } \\ \text { ESCRT } & \text { endosomal sorting complexes required for transport } \\ \text { F-actin } & \text { Filamentous Actin } \\ \text { FGF } & \text { Fibroblast Growth Factor } \\ \text { FP } & \text { Floorplate } \\ \text { Gas1 } & \text { Growth Arrest Specific 1 } \\ \text { GFP } & \text { Green Fluorescent protein } \\ \text { Gli } & \text { Glioma-Associated Oncogene Family Zinc Finger } \\ \text { HA } & \text { Hemaggluttinin } \\ \text { HEK-293T } & \text { Human Embryonic Kidney cells 293T } \\ \text { Hh } & \text { Hedgehog } \\ \text { HHAT } & \text { Hedgehog Acetyl Transferase } \\ \text { HHIP } & \text { Hedgehog Interacting Protein } \\ \text { HhN } & \text { Hh N-terminal truncation lacking cholesterol } \\ \text { HPE } & \text { Holoprosencephaly } \\ \text { IHH } & \text { Indian Hedgehog } \\ \text { kDa } & \text { Kilodalton } \\ \text { mCherry } & \text { monomeric Cherry } \\ \text { mDisp } & \text { Mouse Disp 1 } \\ \text { MEM-Fix } & \text { modified Electron Microscopy fixative } \\ \text { NC } & \text { Notochord } \\ \text { Noco } & \text { Nocodazole } \\ \text { PBS } & \text { Phosphate Buffered Saline } \\ \text { PNGase F } & \text { Peptide:N-Glycosidase F } \\ \text { Ptc } & \text { Patched } \\ & \end{array}$




$\begin{array}{ll}\text { Rab4 } & \text { Ras-related protein } 4 \\ \text { Rab5 } & \text { Ras-related protein 5 } \\ \text { Rab9 } & \text { Ras-related protein 9 } \\ \text { RFP } & \text { Red Fluorescent Protein } \\ \text { RND } & \text { Resistance, Nodulation, and Cell Division } \\ \text { S2 } & \text { Schneider 2 } \\ \text { SHH } & \text { Sonic Hedgehog } \\ \text { ski } & \text { Skinny Hedgehog } \\ \text { Smo } & \text { Smoothened } \\ \text { SSD } & \text { Sterol Sensing Domain } \\ \text { STED } & \text { Stimulated Emission Depletion } \\ \text { TM4 } & \text { Transmembrane 4 GXXXD mutant } \\ \text { TM4/10 } & \text { Transmembrane 4 and 10 GXXXD mutant } \\ \text { UAS } & \text { Upstream activating sequence for Gal4 } \\ \text { UTR } & \text { Untranslated Region } \\ \text { v. } & \text { versus } \\ \text { Wg } & \text { Wingless } \\ \text { Wnt } & \text { Wingless-Type MMTV Integration Site Family, Member }\end{array}$




\section{CHAPTER 1. INTRODUCTION}

\section{The Hedgehog Signaling Pathway during Development and Disease}

The Hedgehog $(\mathrm{Hh})$ signaling pathway functions in all metazoans to provide instructional cues during development (1-8). In 1980, Nusslein-Volhard and Wieschuas performed a landmark forward genetic screen where Hedgehog pathway components were discovered as modulators of Drosophila embryogenesis (9). Genetic alteration of Hh pathway proteins resulted in a disruption of the segmental pattern of the developing embryo, which led to their classification as segment polarity genes. These segment polarity genes uncovered that the Hh pathway plays an important patterning role during morphogenesis as well $(10,11)$. In fact, most adult structures of the fly are patterned by the Hh pathway (12-18).

The adult wing and wing imaginal disc, a precursor tissue that gives rise to the adult wing, is one such tissue influenced by the Hh pathway (19). Within this tissue, the Hh pathway functions with other morphogen pathways, like Wingless (wg or Wnt in vertebrates) and Decapentaplegic ( $d p p$ or Bmp in vertebrates), to govern proper wing development (19-24). In some instances, disruptions which aberrantly activate the $\mathrm{Hh}$ pathway can cause wing overgrowth and in extreme cases, wing duplications (25-28). Conversely, loss of activity results in collapse of specific wing veins and contributes to reduced wing size $(26,29)$.

In a conserved role, the Hh signaling pathway is required during human and mouse development. In humans, the developmental disorders Pallister-Hall Syndrome, Gorlin Syndrome and Holoprosencephaly (HPE) are caused by alterations to Hh pathway members (10, 30-39). Both Pallister-Hall and Gorlin syndromes result from improper activation of the Hh signaling pathway. While caused by mutations in different $\mathrm{Hh}$ pathway components, the two disorders have similar presentations in patients, including craniofacial abnormalities $(38,39)$. HPE is the most common cause of forebrain malformation which often results from direct repression of Hh signaling through mutation of several pathway components which include: Sonic Hedgehog $(\mathrm{SHH})$, Dispatched (DISP1), Patched (PTCH1), Growth Arrest Specific 1 (GAS1), Cell Adhesion Molecule-Related/Down-Regulated By Oncogenes $(C D O N)$, and Glioma-Associated Oncogene Family Zinc Finger 2 (GLI2 and (34)). HPE is a spectrum disorder where the effects range from mild to severe. In the most severe cases, the forebrain fails to separate into two distinct hemispheres, which typically co-manifests with craniofacial abnormalities. These craniofacial defects include the collapse of the facial midline resulting in Cyclopia, a single central eye $(34,35)$. Multiple mouse models have been created by mutating components of the Hh pathway that recapitulate the presentations observed in these human developmental disorders (40-48).

In addition to being implicated in a number of developmental disorders, aberrant Hh pathway signaling can also lead to cancer. Basal-cell carcinoma, the most common adult skin cancer, frequently arises from mutations within the Hh pathway $(8,32,49)$. Two of the five most commonly mutated genes in Basal-cell carcinoma are Hh pathway 
components: Patched and Smoothened (Cosmic Database). Patients with Gorlin syndrome often present with recurring basal-cell carcinomas (38). Medulloblastoma, the most common pediatric malignant primary brain tumor, is also commonly caused by mutations in the Hh pathway. Furthermore, involvement of the Hh signaling pathway defines one of the subgroups of medulloblastoma $(50,51)$. In addition to driving cancer initiation, the Hh pathway often serves a secondary, supportive role in a large variety of cancer types $(8,49)$.

Underscored by the importance of the Hh pathway in development and disease, it is apparent that mechanistic study of the Hh pathway is essential to both our understanding of developmental disorders and prevention of disease. Numerous studies have investigated the mechanisms of Hh pathway components, with the vast majority focused on factors facilitating downstream Hh pathway signaling. However, few studies in comparison have concentrated on the components and the mechanisms upstream of initiating signaling. This area is not nearly as well explored and remains ripe for discovery.

\section{Hh Pathway Components Overview}

The Hh signaling pathway is composed of producing and receiving cells, which communicate using the signaling molecule Hh (Figure 1-1). In Drosophila, Hh is the only pathway ligand, while there are three in most vertebrates (excluding fish): Sonic Hedgehog ( $\mathrm{SHH})$, Indian Hedgehog, or Desert Hedgehog. SHH is the most widely expressed and as such will be referred to exclusively (11). In a dose dependent manner, the Hh ligand is able to act at both short and long range in order to correctly pattern developing tissues (52-55). The Hh molecule is produced as a full-length protein precursor which matures into a regulated signaling protein through several steps, which includes the addition of two lipid modifications (6). The C-terminal portion of the immature Hh form contains intervening protein sequences, or an intein, which are autocatalytically spliced out post translationally. The process involves the covalent addition of a cholesterol moiety to the new C-terminus generated from splicing (56). The second lipid modification occurs after the signal sequence of Hh is cleaved. A palmityl acid group is then covalently linked to the amino-terminal cysteine by Skinny Hedgehog (ski or HHAT in vertebrates and (57)). This dual lipidation effectively anchors the molecule to the plasma membrane of cells (58). Interaction with Dispatched (Disp), the essential Hh pathway component dedicated to release, relieves the plasma membrane anchoring of the Hh molecule (or of all three in mammals and (40, 53, 59-61)). Consistent with Disp alleviating lipid mediated tethering, genetic loss of Disp in both invertebrates and vertebrates results in the retention of the pathway ligand within producing cells, which induces embryonic lethality during development.

Disp is a twelve pass transmembrane protein which contains a Sterol-Sensing domain (SSD) and a Resistance, Nodulation, and Cell Division (RND) transporter domain (59). Proteins that contain SSDs are typically involved in lipid homeostasis, biogenesis, and trafficking (62-66). Mutations within the SSD domains can alter the association with lipid binding partners and as a result, ablates the SSD containing protein 


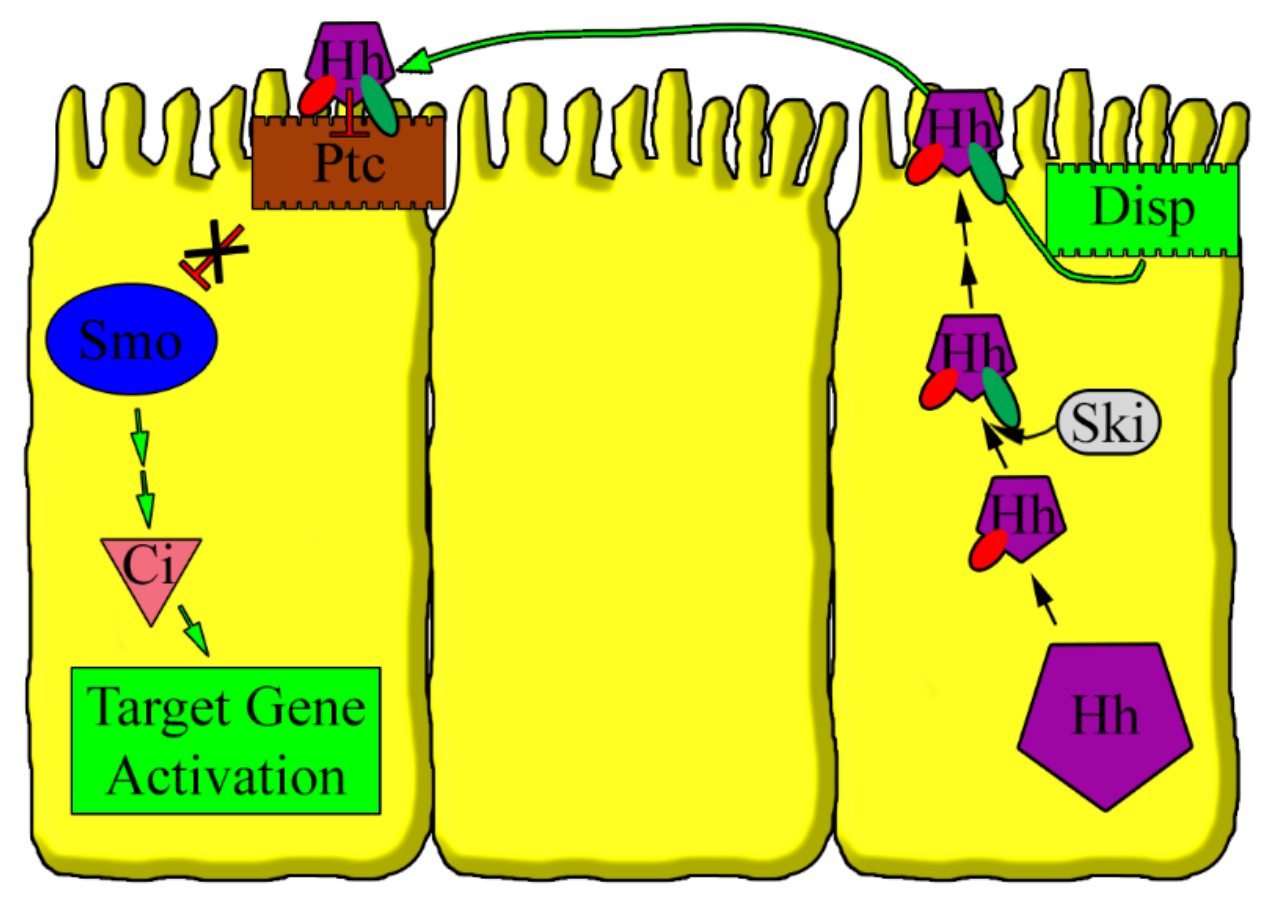

Figure 1-1. An overview diagram of the Hedgehog signaling pathway.

The Hedgehog (Hh) molecule is produced as a full length precursor (large magenta pentagon). In an autocatalytic cleavage event a cholesterol moiety (red oval) is added to Hh (small magenta pentagon). An additional enzyme, Skinny Hedgehog (Ski and grey oval) links a palmitic acid (green oval) to the Hh morphogen completing the maturation process. Hh localizes to the surface of the cell where it remains tethered until Disp (green rectangle) facilitates release. The Hh molecule is transported across a tissue until interacting with the Hh receptor Patched (Ptc and brown rectangle). The Hh molecule inhibits Patched activity (red inhibitory symbol) by triggering internalization and degradation of the two molecules. This alleviates the Patched inhibition (crossed out inhibitory signal) on Smoothened (Smo and blue circle). This allows Smoothened to initiate signaling and induce target gene activation through the transcription factor Cubitus Interuptus ( $\mathrm{Ci}$ and pink triangle). 
function $(59,62,63,67,68)$. RND domains are found within an ancient class of bacterial proton-substrate antiporters ((69-71). RND transporter containing proteins typically have twelve transmembranes and target a variety of substrates for efflux. Substrate specificity is predicted based on the highly conserved transmembrane four amino acid residues surrounding a centralized GXXXD motif (71). The GXXXD motif is responsible for the proton-substrate antiporter function and works in cooperation with a second GXXXD motif within RND domain containing proteins (69-71). As such, mutation of the aspartate(s) in the GXXXD motifs of bacterial transporters ablate their efflux function. Consistent with bacterial studies of RND transporters, the GXXXD motifs in Disp proteins are essential to the release of the membrane-bound Hh ligand $(40,54,59,72)$.

While the precise mechanism by which Disp alleviates the tethering of Hh from the cell membrane remains unclear, it has been reported Hh undergoes a Disp-dependent trafficking process in polarized cells of the wing imaginal disc prior to release. Initially, Hh localizes to the apical surface of wing imaginal disc cells through a Disp-independent mechanism, while the Disp protein localizes to a sub-apical compartment $(54,59)$. The two then internalize through a Disp-, Dynamin- and Rab5-dependent process (54). The molecules then re-localize, either back apically or basolaterally, through a Rab 4, 5, and 8 mediated process $(54,55)$. Loss of Disp, or inhibition of internalization by Dynamin, trapped Hh on the apical surface of wing imaginal disc cells. While the mechanism facilitating recycling by Disp is unclear, it depends on the GXXXD motifs of the RND transporter domain within Disp. Following these recycling events, Hh is released from the producing cell, either at the apical or basolateral surface and is then able to interact with Hh receiving cells $(54,55)$.

Once the ligand arrives at the receiving cell surface, the Hh receptor Patched (Ptc), another essential SSD and RND containing protein, binds $\mathrm{Hh}$ and the signaling process is initiated $(62,69,73)$. Upon binding $\mathrm{Hh}$, the Ptc receptor internalizes with the ligand for degradation $(74,75)$. The internalization of Ptc alleviates the poorly understood inhibition on the G-protein coupled receptor Smoothened (Smo) which functions as the essential signal transducer of the pathway (76-79). Consequently, Smo initiates a series of events driving pathway activation and subsequent target gene induction through the transcription factor Cubitus Interruptus ( $\mathrm{Ci}$ or $\mathrm{Gli}-1,-2$, or -3 in vertebrates and $(1,80))$.

During development, the aforementioned signaling cascade is absolutely dependent on the mechanisms facilitating successful, concentration-dependent transport of the Hh ligand across fields of cells. Delivering an essential ligand to receiving cells several distances away provides a substantial challenge when employing a membrane bound morphogen. As such, a variety of proposed methods attempt to address this problem.

\section{Influences on the Range and Specificity of Hh Ligand Distribution}

Within developing tissues of metazoans, Hh signaling occurs at long distances from the source of ligand. In the wing disc, transcriptionally controlled compartmental 
organization restricts the expression of the ligand to the posterior portion of the disc and receptor Ptc to the anterior (Figure 1-2). While Hh expression is restricted to the posterior compartment, the highest level of signaling occurs at the anterior-posterior compartmental border and at a lower level throughout the remaining portions of the anterior compartment in a graded manner $(1,52,81)$. In this tissue, in the most extreme case the Hh ligand has to travel approximately $100 \mu \mathrm{m}$ before reaching a Patched expressing receiving cell. In vertebrate neural tube development, the ventrally located notochord is the initial source of SHH (Figure 1-3). A second site of SHH production is induced in the neighboring floorplate $(40,53,60)$. With the ventral localized floorplate serving as the only source of SHH for the neural tube, the molecule must then act in a high to low ligand gradient to induce or repress transcription factors driving cellular fate decisions on cells positioned at progressive distances dorsal from the source. During the development in both tissues, the signaling molecule has to traverse the expanse of a tissue to trigger downstream signaling in a concentration dependent manner.

Several mechanisms of how $\mathrm{Hh}$ is transported throughout a tissue have been proposed $(7,10,52,82,83)$. The first proposed mechanism involves the release of the Hh ligand into the extracellular space whereby diffusion alone distributes the molecule. Ptc receptor expressing cells closest to the source would capture the majority of the diffusing Hh ligand, while cells furthest from the source would obtain the least amount of Hh. The cells positioned along the morphogenetic gradient induce a ligand concentration dependent signaling output dictating differential cell fates. However, a shortcoming to this proposed mechanism is that release of a dually-lipidated ligand into the extracellular environment would drive exposed lipids to interact with cellular membranes, which would impede distribution. Through very elegantly performed studies, Porter et. al in 1995 and Pepinsky et. al in 1998 have definitively shown that extracellular, soluble $\mathrm{Hh}$ ligand is indeed modified by cholesterol and a palmitic acid $(84,85)$. With the presence of both lipids on the secreted ligand, additional modifications or protein associations would be necessary to solubilize the molecule. The discovery that $\mathrm{SHH}$, and subsequently Hh, could exist as a dimer or multimeric complex explained how a dually lipidated molecule could solubilize in the extracellular space (86-88). It was proposed that shielding the lipid moieties in an internal hydrophobic pocket with the protein domains on the outsides would allow such solubilization $(87,89)$. Alternatively, discovery of $\mathrm{Hh}$ ligand associated with apolipoproteins provided another mode in which to solubilize the morphogen (83, 90-94). Apolipoproteins typically bind lipids to form lipoproteins. This lipoprotein molecule can then solubilize the lipids and allow for the distribution of the lipid through hydrophilic environments (95). As such, Apolipoproteins are proposed to interact with the lipid modifications on the Hh molecule in order to solubilize the ligand (83). In either Hh multimerization or Hh lipoprotein formation, the dually lipidated $\mathrm{Hh}$ ligand would be solubilized and free to diffuse throughout the entire tissue until bound by the Ptc receptor.

The second proposed mechanism of Hh transport involves the soluble secretion of Hh followed by membrane bound proteins facilitating or impeding the diffusion process to form a concentration dependent gradient $(7,10,52,82,83)$. Discovery of the Hh ligand present within exosomes, SHH interaction with Megalin, and the inhibitory actions of the Hedgehog interacting protein (HHIP) provide evidence supporting this model 


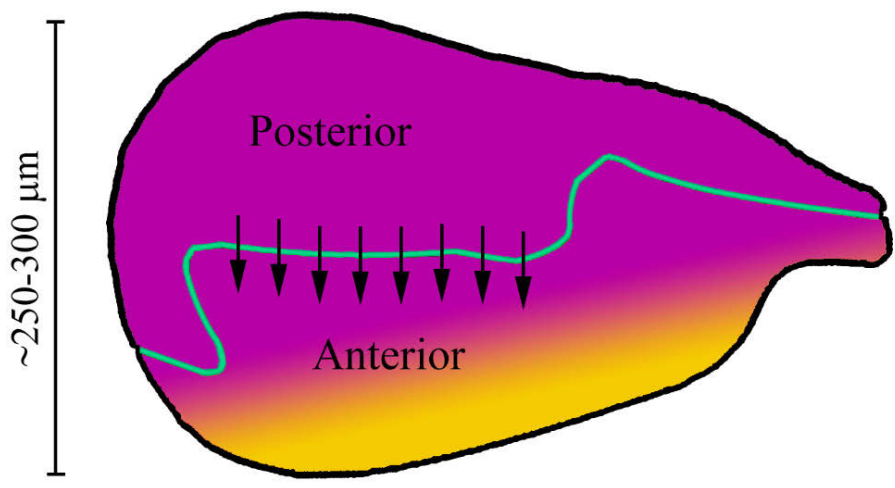

Figure 1-2. A diagram of the Drosophila wing imaginal disc separating posterior and anterior compartments.

The wing imaginal disc from a third instar larva is approximately $250-300 \mu \mathrm{m}$.

Transcriptionally regulated compartments separate regions of the disc. The Hh ligand is produced in the posterior portion and signals throughout the anterior compartment (arrow indicated direction of Hh ligand progression). The border between the anterior and posterior compartments is indicated by the teal line and signifies the expression boundary of Hh. The gradient of magenta to yellow indicates the concentration gradient of the $\mathrm{Hh}$ ligand.

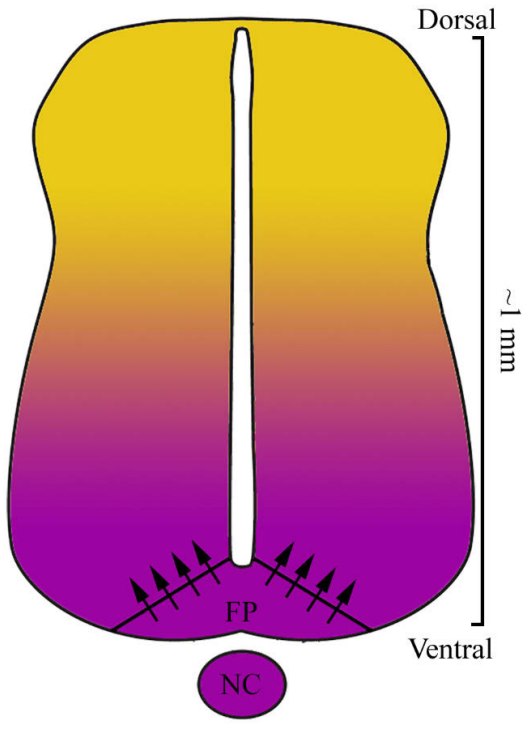

Figure 1-3. A diagram of the murine neural tube.

The neural tube of a developing mouse embryo can extend approximately $1 \mathrm{~mm}$ in length. The SHH molecule is initially produced in the notochord (NC) before inducing expression in the floor plate (FP). The floor plate provides the source of SHH which travels throughout the tissue (indicated by the arrows emanating from the floor plate). The magenta to yellow gradient represents the concentration gradient of the SHH ligand. 
(96-100). Exosomes are vesicles produced in the multivesicular bodies of cells which are subsequently released into the extracellular space. Intracellular cargo internalized from the plasma membrane and specifically trafficked through an endosomal sorting complex required for transport (or ECSRT) dependent mechanism make up the majority of components present in multivesicular bodies. These exosomes within the multivesicular bodies contain $\mathrm{SHH}$ as well as other morphogens (100). Notably, exosomes have been shown to contain apolipoprotein family members in vertebrate cells (101). These secreted, SHH containing exosome vesicles, sometimes referred to as exovesicles, then interact with the receptor Megalin. Megalin mediates the internalization of the SHH exosomes to be recycled and released again in a process called transcytosis. Transcytosis actively transports the ligand through tissues to Hh receiving cells $(97,98,102)$. Alternatively, interaction with HHIP restricts the progression of release SHH ligand through the extracellular space (103). As such, this model of Hh ligand transport proposes a balance in the interaction between facilitating and hindering extracellular factors to setup a concentration dependent gradient during morphogenesis.

A third proposed model of distributing the membrane bound morphogen $\mathrm{Hh}$ involves the utilization of cytoplasmic containing, thin cellular projections named cytonemes $(52,104-107)$. These structures extend from the site of ligand production directly to Hh receiving cells $(108,109)$. Multiple independent groups working in a variety of organisms and their developing tissues have identified cytonemes transporting and delivering morphogens $(24,54,55,96,105,109-114)$. Studies into cytoneme regulation have demonstrated a reliance on actin and actin binding proteins for their formation and function. Furthermore, an actin specific motor protein, Myosin X, has been implicated in the transport of SHH morphogen through cytonemes in the Chicken limb bud, a vertebrate tissue patterned by Hh signaling (111). Within the Drosophila wing imaginal disc, cytonemes incorporate morphogens specific for the direction in which they extend. This directionality and morphogen inclusion for Hh specific cytonemes is controlled by the production of the Drosophila Fibroblast growth factor (FGF) homologue, Branchless, at the anterior posterior border where the highest level of $\mathrm{Hh}$ signaling occurs $(105,107,109)$. Of note, a Hh mutant that is deficient in inducing $\mathrm{Hh}$ signaling when exposed to excessive temperature blunted and disorganized cytonemes extending from the posterior compartment at the restrictive temperature. Cytonemes formed and extended normally at the permissive temperature in these mutant animals $(105,109)$. This finding suggests a requirement of $\mathrm{Hh}$ for proper cytoneme growth from the posterior compartment towards Hh responsive anterior compartment cells. Growth rates of cytonemes have been observed at nearly $25 \mu \mathrm{m} / \mathrm{min}$ in the wing imaginal disc, a tissue which is roughly 250-300 $\mu \mathrm{m}$ wide at the third and final larval stage (Figure 1-2 and $96,105,109)$. Cytonemes observed in ex vivo organ cultures could extend as far as $300 \mu \mathrm{m}$ from certain cell types $(52,110)$. Notably, in a variety of tissues and species the average cytoneme length and growth rates observed in vivo were approximately $5 \mu \mathrm{m}$ and $5 \mu \mathrm{m} / \mathrm{min}$, respectively $(24,52,105,109,110,113)$. Evidence from Gradilla et. al in 2014 demonstrated Hh containing exosomes localized and traveled along cytonemes towards $\mathrm{Hh}$ receiving cells in the wing imaginal disc (96). Taken together, this form of ligand transport may function as a precursor transport mechanism before release of a solubilized Hh ligand. Compensating for the deficiencies of the other models, cytonememediated transport provides efficient, rapid distribution of morphogenetic signals from 
their site of production directly to ligand responsive cells. Thus, understanding the regulatory mechanisms of this model of Hh transport could be informative in how the concentration gradient is formed during development.

While a novel and efficient mechanism in morphogen dispersion, these structures have been largely ignored since their discovery in 1999 (105). Only a handful of research groups have published data demonstrating the importance of cytonemes delivery of morphogens in developing tissues $(24,96,110,113,114)$. Primarily due to their fragile and transient nature, these structures are difficult to study $(105,115)$. Traditional fixatives for cell biological analysis fail to maintain cytonemes and laser based confocal microscopy can damage them. As such, the study of cytonemes in morphogen transport has been limited to extremely careful, extended live imaging studies with fluorescent fusion proteins. The ability to visualize these structures using standard cell biological techniques would most likely accelerate the investigations into their regulation, formation, and function.

Of the transport mechanisms discussed, it is currently unknown if Disp plays a regulatory role in cytoneme-mediated transport. With the requirement of Disp in long range Hh transport, we hypothesized that Disp was essential to cytoneme-mediated transport of the Hh ligand $(40,53-55,59,72)$. Furthermore, relatively recent studies detail the localization of Disp within cytonemes containing $\mathrm{Hh}$, lending support to a role for Disp in this transport mechanism (113). Therefore, an investigation into the function of Disp in cytoneme-mediated Hh transport could provide mechanistic insight into the Disp-dependent release of Hh to receiving cells.

\section{Conclusions and Aims of This Dissertation}

Although Disp was discovered over 15 years ago, the published literature consists of $\sim 40$ publications, with very little information regarding regulatory or functional data (PubMed). To address this gap in knowledge, these studies were first focused on identifying regulatory partners to give mechanistic insight into Disp function. These efforts lead to the discovery of a novel role for Disp in cytoneme-mediated transport. To further explore this finding and as a second aim, a fixable in vitro system that recapitulates cytoneme-mediated morphogen delivery was developed. This novel in vitro cytoneme system demonstrated the requirement of Disp for the stabilization of outgrown cytonemes which was verified in vivo. Furthermore, this method of fixation allowed cytoneme visualization within multiple cell types and in wing imaginal disc tissues. This method, which we name MEM-fix, has potential to impact the field because it will enable other groups to overcome a major roadblock in studying these fragile structures for a variety of signaling pathways.

Finally, another finding that arose from these studies on Disp in cytoneme biology, was the discovery and characterization of a regulatory cleavage event of Disp protein. We hypothesized that cleavage of Disp played a regulatory role on function. The site of cleavage and responsible protease for mediating this cleavage were identified and 
then subsequently used to interrogate the functional importance of Disp cleavage fulfilling the first aim of these studies.

In combination, these studies detail a novel, highly tractable system amenable to fixation that models cytoneme biology, a previously undiscovered role for Disp in cytoneme transport, and a regulatory partner responsible for cleaving Disp into an active form. It is my hope that these tools and studies further our understanding of mechanisms controlling Hh ligand release and downstream signaling in the context of development and disease. Through these efforts our understanding of developmental patterning and formation of the $\mathrm{Hh}$ morphogen gradient will be further expanded. 


\section{CHAPTER 2. MATERIALS AND METHODS}

\section{Reagents and Cell Lines}

Cytochalasin D was purchased from Calbiochem now EMD Millipore (Darmstadt, Germany). Nocodazole was purchased from Sigma (Saint Louis, MO). Furin Inhibitor I (chloromethylketone) was purchased from Enzo (Farmingdale, NY). All cDNAs were purchased from the DGRC (Bloomington, IN). Gal4 and UAS-CD8-RFP fly lines were obtained from the Bloomington Stock Center (Bloomington, IN).

Schneider 2 (S2) cells were purchased from Invitrogen (Carlsbad, CA), Clone 8 (c18) cells were from the DGRC (Bloomington, IN), NIH-3T3 and HEK-293T cells were from ATCC (Manassas, VA), and Disp ${ }^{-/}$MEFs were a gift from Dr. Phil Beachy. $p M T$ Puro-V5dispHA cl8 cells were generated using standard techniques.

\section{Cell Culture}

$\mathrm{S} 2, \mathrm{C18}$, and NIH-3T3 cells were maintained as previously described $(26,116)$. pMT-Puro-V5dispHA cl8 cells were cultured as normal cl8 cells with the addition of Puromyocin $(1 \mu \mathrm{g} / \mathrm{mL})$ to the media. Disp ${ }^{-/-}$MEFs were cultured and maintained in DMEM (Invitrogen) supplemented with 10\% Fetal Bovine Serum, 1 mM Sodium Pyruvate (Invitrogen), 2 mM L-glutamine (Invitrogen), 1X Pen/Strep (Millipore), and G418 (0.1 g/mL, Invitrogen). HEK-293T cells were grown in similar conditions to Disp ${ }^{-/}$ MEFs with the following differences: $0.1 \mathrm{mM}$ nonessential amino acids (Invitrogen) and no G418. LoVo and HCT-15 cells were cultured similarly to HEK-293T cells with the substitution of F-12K Nutrient media (Invitrogen) instead of DMEM.

\section{Expression Plasmids}

CD8-mCherry was amplified from $p Q U A S p$-mCD8mCherry (Addgene) and inserted into $p A c 5.1$ using Not1-Xba1 restriction sites to generate $p A c-C D 8$-mCherry. $p A c$-dispHA was generated by inserting disp cDNA amplified from $p F L C$-I-disp (DGRC) into a $p A c 5.1-H A$ using the Kpn1 restriction site. To make the double tagged Disp construct, sequence encoding the V5 epitope tag was introduced following V108 of $p A c$ dispHA to generate $p A c-V 5$ dispHA.

$p A c-m C h e r r y$ was generated by amplifying the coding region for mCherry from pmCherry-N1 (Clonetech) into the Xbal site of $p A c 5.1$. pAc-disp-mCherry was produced by replacing the $\mathrm{C}$-terminal $\mathrm{HA}$ tag in $p A c$-dispHA with mCherry coding sequence from pmCherry-N1.

Wingless (wg) was amplified from wg cDNA (DGRC) and inserted into $p A c-5.1$ using Kpn1-Xbal digestion sites to produce $p A c-w g$. 
$p C D N A 3-m D i s p$ was generated by introducing mDisp1 cDNA from the RIKEN library (http://dna.brc.riken.jp/) into Not1-Xbal sites of $p C D N A 3$ (Invitrogen). The HA tag was introduced as an annealed oligo into the Xho1-Xbal site in $p C D N A 3 . p C D N A 3$ $m D i s p H A$ was generated by introducing mDisp 1 cDNA amplified from cDNA into the Not1-Xho1 sites in $p C D N A 3-H A$. To generate double-tagged mDisp, V5 epitope tag coding sequence was introduced behind amino acid Alanine106 of $p C D N A 3-m D i s p H A$.

All mutagenesis performed in these studies was done so using the QuikChange II XL mutagenesis kit (Agilent).

\section{Transfections}

For insect cell transfections, approximately $4 \times 10^{6} \mathrm{cl} 8$ or S2 cells were plated in 60 $\mathrm{mm}$ dishes the day before transfection. The following morning, cells were transfected with $2 \mu \mathrm{g}$ of $p A c 5.1$ expression vectors for Disp or Hh proteins using Lipofectamine 2000 (Invitrogen). DNA content was normalized with empty pAc5.1 vector.

For mammalian cell transfection, NIH-3T3 mouse embryo fibroblasts were seeded at a density of $1 \times 10^{6}$ cells $/ 60 \mathrm{~mm}$ dish in DMEM plus $10 \%$ fetal bovine serum (FBS), respectively. Empty $p C D N A 3(2 \mu \mathrm{g})$ or $p C D N A 3-S h h(2 \mu \mathrm{g})$ constructs were transfected into NIH3T3 using Fugene 6 Transfection Reagent (Promega).

\section{MEM-fix Immunofluorescence Protocol}

For fixed cell fluorescence microscopy, $4 \times 10^{6} \mathrm{~S} 2$ or $\mathrm{C} 18$ cells were plated into 60 $\mathrm{mm}$ dishes the day before transfection. Cells were transfected with $5 \mu \mathrm{g}$ of $p A c 5.1-G F P$, $\operatorname{dispHA}$, -dispTM4HA, $-H h$, or $-h h N$ as indicated using Lipofectamine 2000

(ThermoFisher). Forty-eight hours post transfection, cells were resuspended by pipetting, and then plated into chamber slides (LabTek) at a density of $\sim 1$ million cells/well. Cells were allowed to settle for 1.5 hours. Adherent cells were washed gently 3 times with $1 \mathrm{X}$ phosphate buffered saline (PBS), then immediately subjected to fixation at $4 \mathrm{oC}$ for 7 minutes using a freshly prepared MEM-fix (0.1 M Sorensen's Phosphate Buffer ( $\mathrm{pH} 7.4)$, $4 \%$ Formaldehyde (Polysciences) and $0.5 \%$ Gluteraldehyde (Electron Microscopy Sciences)). Fixed cells were washed three times using 1X PBS for 5 minutes each, then permeabilized for one hour at room temperature in permeabilization buffer $(0.1 \%$ Triton X-100, 5\% Goat Serum (Jackson ImmunoResearch), $1 \mathrm{mg} / \mathrm{mL}$ of sodium borohydride in distilled H2O). The permeabilization buffer was replaced with staining buffer $(0.1 \%$ Tween-20 and 5\% Goat Serum in 1X PBS containing anti-HA.11 (Covance), anti-Hh (SCBT), and Actin Green (Invitrogen)) and incubated overnight at $4 \mathrm{oC}$ in the dark unless otherwise noted. The next morning, cells were washed three times for 5 minutes each using $1 \mathrm{X}$ PBS. Secondary antibodies were incubated in staining buffer for one hour at room temperature protected from light. Following secondary antibody incubation, cells were washed five times for 10 minutes each in $1 \mathrm{X}$ PBS, then mounted using ProLong Gold with DAPI for confocal analysis or Diamond for STED experiments (Invitrogen). Slides were allowed to cure for 72 hours before imaging. 
For NIH3T3 fibroblast analysis, approximately $2 \times 10^{5}$ were plated into 6 well dishes containing coverslips the day before transfection. NIH3T3 cells were transfected with $5 \mu \mathrm{g}$ of $p C D N A 3-S h h$ using Lipofectamine 3000 (ThermoFisher).

Samples prepared in this method were stained with Actin Green/Red (1:500, Invitrogen), Mouse anti-alphaSpectrin (1:250, DSHB), mouse anti-HA (1:1,000, Covance), rat anti-HA 3F10 (1:1,000, Sigma), rabbit anti-Hh (1:500, SCBT), rabbit antiSHH (1:100, SCBT), and or mouse anti-wg (1:1,000, DSHB). Alexa fluor corresponding secondaries were used at 1:500 dilutions (Invitrogen).

\section{Confocal and STED Imaging}

Data for cytoneme occurrence was collected on a 3i Marianas Spinning Disc confocal automated for Z-stack collection of randomly selected, positively transfected or stained cells. Collected images were subsequently analyzed using Slidebook analysis software.

Representative confocal images were captured on a Leica TCS SP8 system. STED images were captured with the 3D STED module by utilizing 770, 660, and 592 depletion lasers on Alexa 633 Phalloidin (Invitrogen), CD8-mCherry, and GFP, respectively. STED derived width measurements were obtained using pAc-mCherry with the 660 depletion laser.

Deconvolution was performed on images obtained from the Leica TCS SP8 using the Huygens Professional software package. Deconvolution calculations were performed using Classic Maximum Likelihood Estimation (CMLE) limited to 5 iterations using default settings for the remaining parameters. Figures were compiled using Adobe Photoshop CS4.

\section{Actin and Tubulin Drug Treatments}

$4 \times 10^{6} \mathrm{~S} 2$ cells were plated and transfected the following morning with $5 \mathrm{ug}$ of pAc-mCherry using Lipofectamine 2000 (ThermoFisher). Approximately 48 hours post transfection, cells were collected by centrifugation of cell-containing media at $250 \mathrm{x} \mathrm{g}$, then resuspended in complete $\mathrm{S} 2$ media containing a $10 \mu \mathrm{M}$ final concentration Nocodazole, $10 \mu \mathrm{M}$ final concentration Cytochalasin-D or DMSO control. After resuspension, treated cells were immediately plated into chamber slides and incubated for 1.5 hours before subjecting to the MEMF-Fix immunofluorescence protocol detailed above.

\section{dsRNA Production for Dia and Disp}

disp 3'UTR dsRNA was generated by amplifying bases 4980 to 5547 of $p F L C-I-$ disp using forward T7 primer (5'-GAATTAATACGACTCACTATAGGGAGATATGC TGGCGGTG) and reverse T7 primer (5'-GAATTAATACGACTCACTATAGGGAGA 
GGGATATAACACTATGTCTG) with Phusion High-Fidelity DNA Polymerase (NEB). Control dsRNA was generated from the Xenopus elongation factor template provided with the T7 Megascript Kit (Thermofisher). Production of dia specific dsRNA was generated by amplifying bases 3037 to 3599 of $p B S K$-dia (DGRC) using the forward T7 primer (5'-GAATTAATACGACTCACTATAGGGAGAGCAGACATTGCTGCACTA $\mathrm{CC}$ ) and reverse T7 primer (5'-GAATTAATACGACTCACTATAGGGAGACCAACA GACTGTCCATCACG) with Phusion High-Fidelity DNA Polymerase (NEB). The dsRNA was then generated using the T7 Megascript Kit using standard methods (26).

\section{dsRNA Bathing S2 Cells}

Approximately $4 \times 10^{6} \mathrm{~S} 2$ cells were plated into $60 \mathrm{~mm}$ dishes the day before initiating knockdown. The following morning, S2 cells were bathed with $15 \mu \mathrm{g}$ of control, disp, or dia dsRNA for two 5 day periods by collecting and centrifuging cells at $250 \mathrm{x}$ g for 5 minutes then resuspended in $1.5 \mathrm{mLs}$ of serum free media containing the indicated dsRNA. Cells were incubated for 1 hour before adding $3 \mathrm{mLs}$ of S2 complete media.

\section{Live Imaging}

For live imaging, $\mathrm{S} 2$ cells were plated and transfected with $p A c-G F P, p A c$-disp$m C h e r r y$, or $p A c-C D 8-m C h e r r y$ as described above. After $\sim 48$, hours cells were washed twice with serum-free S2 media, resuspended in fresh S2 media supplemented with $10 \%$ FBS and then plated into glass bottom dishes (MatTek). Cells were allowed to settle for 1.5 hours before imaging using Leica TCS SP8 resonance scanner mode. Entire Z-stacks were taken at $\sim 12$ second intervals using the $100 \mathrm{X}$ objective. Images were processed as detailed above before constructing the maximum intensity projection. Movies were encoded to match timeframes between GFP co-expressed with CD8-mCherry or DispmCherry captures. Representative movies are provided.

\section{Insect Cell Lysis and Western Blotting}

For insect cells, cell lysates were isolated using either a modified HK buffer ( 20 mM Hepes, $10 \mathrm{mM} \mathrm{KCl,} 1$ X Complete Protease Inhibitor Cocktail (PIC) - EDTA Free (Fisher), and $150 \mathrm{mM} \mathrm{NaCl}, \mathrm{pH} 7.9)$ or 1\% NP-40 (1\% NP-40, $150 \mathrm{mM} \mathrm{NaCl}, 50 \mathrm{mM}$ Tris base, $50 \mathrm{mM} \mathrm{NaF}, 1 \mathrm{X}$ Complete PIC - EDTA Free, and $0.5 \mathrm{mM}$ DTT, pH 8.0) buffer.

For samples isolated with modified HK Buffer, samples were dounce homogenized 20 times using the tight pestle. Homogenates were then centrifuged at 2000 $\mathrm{x} g$ for 10 minutes at $4^{\circ} \mathrm{C}$. Supernatant was then subjected to a $100,000 \mathrm{x}$ g spin for 30 minutes at $4{ }^{\circ} \mathrm{C}$. Cell pellets were resuspended using $1 \% \mathrm{NP}-40$ buffer. 
For samples isolated with 1\% NP-40 buffer, samples were incubated with lysis buffer for 10 minutes at $4{ }^{\circ} \mathrm{C}$ before centrifuging at $2,000 \mathrm{x}$ g for 10 minutes at $4{ }^{\circ} \mathrm{C}$. Supernatants were taken as lysates.

Equal amounts of protein were loaded on $7.5 \%$ or $15 \%$ Criterion Tris Glycine gels (BioRad) then transferred to Nitrocellulose membranes (Amersham) using Tris/Glycine/SDS Buffer (Biorad) at $100 \mathrm{~V}$ for one hour at RT. Membranes were ponceauS stained to confirm equal loading, then blocked in $1 \mathrm{X}$ TBS containing $5 \%$ milk and $0.01 \%$ Tween-20 for 1 hour before probing for 1 hour at room temperature with rabbit anti-Disp $(1: 15,000)$ or overnight at $4^{\circ} \mathrm{C}$ with rabbit anti-Dia $(1: 30,000$ and (117)), rat anti-HA 3F10 (1:15,000, Sigma), mouse anti-HA (1:15,000, Covance), rabbit anti-Hh (1:10,000, SCBT), rabbit anti-Kinesin (1:50,000, Cytoskeleton), mouse anti-Actin (1:15,000, Millipore), or mouse anti-Tubulin (1:15,000, Cell Signaling). Antibodies were multiplexed when possible using corresponding Li-Cor IR and Jackson ImmunoResearch HRP conjugated secondaries (1:15,000) for 30 minutes.

\section{Hh Delivery Efficiency Assay}

The day before transfection, $4 \times 10^{6} \mathrm{~S} 2$ cells were plated in $60 \mathrm{~mm}$ dishes. The cells were either: 1) bathed in control or dia specific dsRNA for 10 days, or 2) transfected with $p W I Z$-empty (DGRC) or $p W I Z$-dia-RNAi vectors (114) every five days for a total 10 days before transfecting with 5 ug of $p A c 5.1$-empty or -Hh. After 48 hours post Hh transfection, cells were separated to be lysed or processed and fixed using MEM-fix as discussed above. Delivery efficiency was calculated by counting the number of cells positive for background corrected $\mathrm{Hh}$ signal that were in contact with a Hh-containing cytoneme. Percent positivity was used to determine fold change relative to control dsRNA treated cells. Statistical significance was determined using a student's T-test.

\section{Quantification of Cytoneme Occurrence}

For all quantification, percent occurrence was calculated using transfected cells that stained positive for Actin and the appropriate transfection markers. The following requirements were used to identify cytonemes for quantification: filopodia 1) were at

least $2 \mu \mathrm{m}$ in length, 2) were less than $500 \mathrm{~nm}$ thick, 3) originated from the upper half of the cell, and 4) did not target back to the cell of origin. The number of cells that had any cytoneme in the total population of positively marked cells was used to determine cytoneme occurrence. Two lab members, with one "blinded" for the experimental condition to ensure unbiased analysis, independently determined occurrence.

For baseline cytoneme occurrence levels, fields of cells were imaged with each cell within examined for cytonemes. The percent with a cytoneme within the total population is presented.

Statistical significance was determined with One-way or Two-way ANOVA as appropriate, using a multiple comparison correction with Prizm (Graphpad). 


\section{Co-Culture Reporter Assay}

For the co-culture reporter assays, Hh producing cells were generated by cotransfecting $4 \times 10^{6} \mathrm{Cl} 8$ cells in a $60 \mathrm{~mm}$ plate with $5 \mu \mathrm{g}$ control or disp specific 3'UTR dsRNA with $p A c$-empty, $-H h(5 \mu \mathrm{g})$, or -dispHA $(1 \mu \mathrm{g})$ as indicated. Empty vector was used to normalize DNA content. To generate Hh receiving reporter cells, a $10 \mathrm{~cm}$ dish containing $1 \times 10^{7} \mathrm{Cl} 8$ cells was transfected with $600 \mathrm{ng}$ ptc-136-luciferase and $60 \mathrm{ng}$ $p$ Ac-renilla. Hh producing and reporter cells were resuspended approximately 24 hours post-transfection by pipetting, and re-plated into a 12 well dish at a 1:3 ratio of reporter to producing cells. Cells were co-cultured for $\sim 48$ hours at $26^{\circ} \mathrm{C}$ and reporter assays performed using the Dual Luciferase Assay kit (Promega) as described (26).

\section{Insect Hh Conditioned Media Generation, Collection, and Application}

$\mathrm{S} 2$ cells were plated into $100 \mathrm{~mm}$ plates at $1 \times 10^{7}$ cells/plate the day before transfection. Cells were transfected with $10 \mathrm{ug}$ of either $p A c-e m p t y,-H h$, or $-h h N$ the following morning and incubated for 24 hours in complete media. The cells were then washed using serum free S2 media three times before resuspending the cells in $10 \mathrm{mLs}$ of serum free media to incubate for 48 hours.

Conditioned media was collected from each of the conditions by removing the producing cells by light centrifugation at $250 \mathrm{x} g$ for 5 minutes. The cell free media was concentrated with Amicon Ultra-15 3K centrifugal filter units (Millipore) down to $3 \mathrm{~mL}$. The concentrated media was then spun at $100,000 \mathrm{xg}$ for 1 hour at $4^{\circ} \mathrm{C}$ to remove any cellular debris. The supernatant was combined with $3 \mathrm{~mL}$ of complete $\mathrm{S} 2$ media.

A single $10 \mathrm{~cm}$ dish of GFP transfected cells incubated for 48 hours were equally separated into $60 \mathrm{~mm}$ dishes. The media from the cells was removed and replaced with $3 \mathrm{mLs}$ of conditioned media for the indicated type. Cells were incubated for 48 hours before analysis by Western blot and Cytoneme Occurrence.

\section{Disp Antibody Production}

To generate antisera against Drosophila Disp, the coding region of the predicted fourth extracellular loop (amino acids: 694-959) was introduced into $p E T-28 b$ in frame with a carboxyl terminal $6 \mathrm{X}$ His tag. Protein was expressed in BL-21 cells and affinity purified on nickel resin by the St. Jude Protein Production Facility. Antisera were produced in rabbits using the Covance custom antibody service.

\section{Transgenic Fly Lines}

Engrailed (en)-GAL4 and UAS-CD8-RFP lines were obtained from the Blooming Stock Center and used to generate recombinants per standard technique. UAS-dispHA, V5dispHA, -dispTM4HA, -V5dispTM4HA, -V5dispHAACS and -GFP transgenic lines were generated using the PhiC31/attB system. Transgenes were targeted to the ZH-51D 
landing site using Best Gene embryo injection services. All transgenes were balanced over $\mathrm{CyO}$, and expressed under control of apterous (ap)-Gal4 or en-Gal4 as indicated.

\section{Wing Disc Immunofluorescence}

For visualizing wing disc cytonemes, imaginal discs were collected from wandering third instar larva and then immediately fixed using MEM-fix for 15 minutes at RT. Primary antibody staining was done overnight at $4^{\circ} \mathrm{C}$ while rocking. Secondary antibodies were incubated for 1 hour at RT while rocking. Stained discs were mounted directly on the coverslip in ProLong Gold or Diamond mounting media (Invitrogen).

\section{Glycosylation Analysis}

Deglycosylation analysis was performed exactly as previously described (116).

\section{SDS Lysis}

$60 \mathrm{~mm}$ dishes containing $4 \times 10^{6} \mathrm{cl} 8$ cells were transfected with 1 ug of $p A c$ dispHA the day after plating. Cells were incubated for 48 hours before lysing in $200 \mathrm{uL}$ of SDS buffer with DTT in a 4:1 ratio for 10 minutes at room temperature. Lysates were centrifuged at $10,000 \mathrm{x} g$ for 10 minutes and supernatants were taken and equal volumes were run for Western blotting.

\section{Edman Degradation of mDisp-FLAG}

HEK293T cells were seeded in thirty $100 \mathrm{~mm}$ plates at a density of $8 \times 10^{6}$ cells/plate in DMEM plus 10\% Fetal Bovine Serum and transfected the following morning with $10 \mu \mathrm{g}$ of $p c D N A 3-m D i s p$-Flag per plate according to Fugene HD (Promega) instructions. Cells were incubated for an additional 48 hours prior to lysis in $1 \%$ Triton X-100 Buffer (50mM Tris-HCl, $\mathrm{pH} 8.0,150 \mathrm{mM} \mathrm{NaCl}, 1 \%$ Triton X-100, and 1X Protease Inhibitor Cocktail). Lysates were pooled and centrifuged at $14,000 \mathrm{x} \mathrm{g}$ at $4^{\circ} \mathrm{C}$ for 45 minutes. Supernatant was pre-cleared with $400 \mu 1$ of $50 \%$ EZ View Red Protein A Affinity Gel (Sigma) for 1 hour at $4^{\circ} \mathrm{C}$. Pre-cleared supernatant was transferred to a new tube and incubated with $400 \mu 1$ of EZ view Red ANTI-FLAG M2 Affinity Gel (Sigma) for 3 hours at $4^{\circ} \mathrm{C}$. Beads were washed with $1 \%$ Triton X-100 Lysis Buffer with increasing amounts of $\mathrm{NaCl}(0.25 \mathrm{M}, 0.5 \mathrm{M}, 0.75 \mathrm{M}$, and $0.150 \mathrm{M})$ before eluting with $3 \mathrm{x}$ Flag Peptide (Sigma) according to instructions. Protein was TCA precipitated for 6 hours at $4^{\circ} \mathrm{C}$ before pelleting and resuspending in TCA Resuspension Buffer (2\% w/v SDS, $0.42 \mathrm{M}$ Tris-HCl, $\mathrm{pH} 7.4,4 \% \mathrm{v} / \mathrm{v}$ glycerol, $0.01 \% \mathrm{w} / \mathrm{v}$ Bromophenol Blue and $0.05 \mathrm{M}$ DTT). Samples were electrophoresed on a NuPage gel using NuPage MOPS running buffer (Invitrogen) then transferred to Immobilon-PSQ PVDF (Millipore) with NuPage Transfer Buffer without Methanol (Invitrogen). The PVDF membrane was stained with coomassie blue and allowed to air dry. The band of interest was excised and sent to Tufts 
University Core Facility (http://tucf.org/protein-f.html) for protein sequence identification.

\section{Furin Inhibitor Treatments}

For Furin inhibition in insect cells, $4 \times 10^{6} \mathrm{cl} 8$ cells stably transfected with $p M T-$ Puro-V5dispHA were plated into a 6 well dish. The following day cells were treated with the indicated concentrations of Furin Inhibitor I and induced with $\mathrm{CuSO}_{4}$ for 48 hours in complete media at $26^{\circ} \mathrm{C}$. Cells were lysed and membrane fractions were isolated using modified HK buffer.

\section{Disp $\Delta$ CS Mutant Wing Analysis}

Wings from male apterous-GAL4;UAS-V5dispHA (WT or $\triangle \mathrm{CS}$ ) flies were mounted and imaged using a Zeiss ICc3 camera and processed using Adobe Photoshop. Multiple progeny from at least two independent crosses were analyzed. Representative wings are presented.

\section{Disp Expression in Drosophila Follicle Cells}

For immunofluorescence analysis of Drosophila ovaries, tissue was dissected from 2-3 day old c204>V5dispHA (WT or $\triangle \mathrm{CS}$ ) females using standard methods. Samples were imaged on a Leica TCS SP8 confocal microscope with a $63 \mathrm{X}$ objective. Images were deconvolved using Huygens Professional software (theoretical PSF, Classic Maximum Likelihood Estimation (CMLE) algorithm, with 5 iterations max) and processed using LAS X and Adobe Photoshop CS6. V5 and HA epitope tags were detected using Anti-V5 (1:500; Life Technologies) along with Alexa Fluor 488 (1:1000; Life Technologies) and anti-HA (1:250; Roche) along with Alexa Fluor 555 (1:1000; Life Technologies) respectively. Phalloidin conjugated with Alexa Fluor 633 (1:100; Life Technologies) was used to mark F-actin. 


\section{CHAPTER 3. MEM-FIX: A NOVEL CYTONEME FIXATIVE REVEALS A ROLE FOR DISP IN CYTONEME-MEDIATED HH TRANSPORT}

Schneider 2 (S2) cells are an embryonically derived Drosophila line commonly used for in vitro studies. When beginning these studies investigating Dispatched, S2 cells were transiently transfected with an expression vector encoding the full-length form of the Hh ligand. These cells were fixed and examined for Hh ligand localization by immunofluorescent microscopy. The Hh ligand localized to the plasma membrane of these cells with a portion of the protein resident in intercellular puncta, likely secretory vesicles or recycling endosomes, consistent with previous reports. In addition, Hh containing fine cellular extensions projected away from the cell body. Fine cellular processes were also observed emanating from cells only expressing GFP. With S2 cells having an average size of approximately seven micrometers, these structures stretched a cell diameter in some cases and did not exceed an average thickness of 500 nanometers. The extensions were reminiscent of cytoneme structures proposed to be a mechanism of direct cell-cell delivery of morphogens. Cytonemes were previously described as unamenable to fixation impeding traditional immunostaining based studies. Through optimization of a modified electron microscopy fixative (MEM-fix), cytoneme-like structures could be consistently maintained and visualized by traditional immunofluorescence techniques. In Figure 3-1, an S2 cell co-expressing cytoplasmic GFP and the membrane marker CD8-mCherry extended thin cellular projections containing actin and both fluorescent proteins when visualized by confocal and STED microscopy. With the ability to visualize these extensions we wanted to determine if the lengths and widths were similar to cytonemes identified in vivo. To these ends, the length of approximately 40 cytoneme-like, cytoplasmic GFP containing, actin positive structures measured at an average of $5 \mu \mathrm{m} \pm 0.24 \mu \mathrm{m}$ with a range of approximately $2 \mu \mathrm{m}$ to $12 \mu \mathrm{m}$. To determine an accurate width STED microscopy was applied.

In STED microscopy, an additional laser is projected in a ring pattern around the normal excitation laser used in confocal microscopy $(118,119)$. The fluorophore targeted by the excitation laser absorbs energy from the laser photons and causes the elevation of a fluorophore electron to increase from a ground state to an excited state. After a known amount of time the electron returns to the ground state and in this process it releases the absorbed energy of the fluorophore in the form of fluorescence. With the addition of the STED laser ring, extra laser energy is applied after fluorophore activation and this causes the excited electron to transition to the ground state significantly faster than normal. This time difference is then utilized by integrating time gated detection of the fluorescence signal. In doing so, the STED ring and gated detection allows only a defined area of a sample to be excited and subsequently detected. With STED microscopy, normal confocal microscopy xy resolution limits of $200 \mathrm{~nm} /$ pixel can be theoretically decreased to as low as $20 \mathrm{~nm} / \mathrm{pixel}$ in the $\mathrm{xy}$. Using this significant resolution improvement we performed gated STED on cytoplasmic fluorescent proteins within the fixed, outgrown extensions. From measurements of approximately 20 extended cytoneme-like structures, the average observed width of these structures was approximately $230 \mathrm{~nm} \pm 75 \mathrm{~nm}$ with a range from $\sim 120 \mathrm{~nm}$ to $380 \mathrm{~nm}$. With the length and width averages similar to reports of cytonemes in vivo, we sought to validate this in vitro system as a predictive tool for 


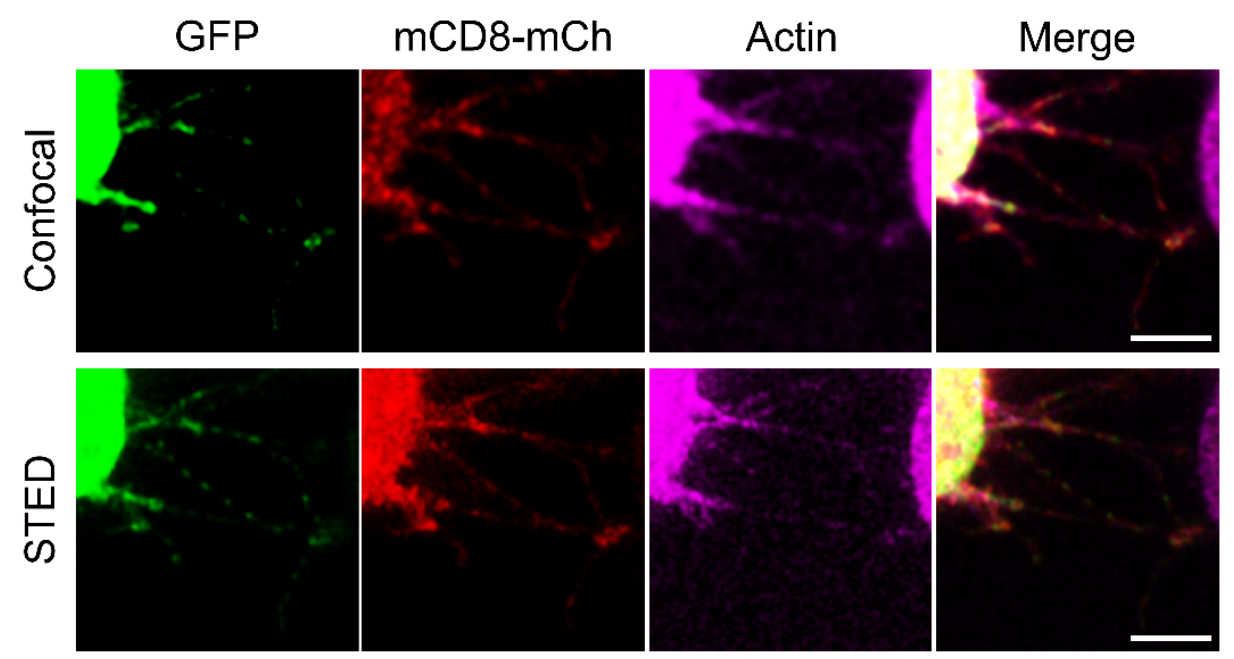

Figure 3-1. S2 cells treated with MEM-fix allows visualizing cytoneme structures. S2 cell expressing GFP and mCD8-mCherry extend cytoneme-like extensions. Red represents the $\mathrm{mCD} 8$-mCherry, green corresponds to GFP, and magenta is Actin. Images were taken by confocal and Stimulated Emission Depletion (STED) microscopy. Image was taken at $100 \mathrm{X}$ magnification. Scale bar represents $5 \mu \mathrm{m}$. 
cytoneme biology and utilize the system to determine a role, if any, for Disp in cytoneme-mediated transport of the Hh ligand.

\section{Development of an In Vitro Cytoneme System}

In vivo cytonemes have been reported to: 1) contain cytoplasm indicated by the presence of cytoplasmic GFP, 2) transport morphogens, 3) show specificity to morphogens, 4) rely primarily on actin, and 5) extend more than 2 micrometers from the cell with a diameter less than 500 nanometers $(105,109-112,114)$. To rule out cellular adhesions meant to anchor the cell to the slide in which the cells were plated, only extensions reaching from portions of the cell not in contact with the plate were considered. Furthermore, extensions which doubled-back to the cell of origin or formed ruffle-like structures were also disregarded.

To address these requirements and validate our system, we began by testing the role actin played. S2 cells expressing mCherry (or GFP) were treated at the time of plating with the actin or tubulin polymerization blocking compounds, Cytochalasin D and Nocodazole, respectively. As expected, mCherry expressing cells extended thread-like projections that contained cytoplasm and matched dimensional descriptions previously observed (Figure 3-2, top panel). Nocodazole had no noticeable effect on the structure of cytonemes (Figure 3-2, bottom panel). Alternatively, treatment with Cytochalasin D caused the thickening of cytoplasmic filled extensions extending from the cell body of expressing cells (Figure 3-2, middle panel).

To test whether S2 cytoneme-like extensions are able to organize specific morphogens within outgrown cytonemes, S2 cells were transiently co-transfected with expression plasmids encoding Hh and the Drosophila Wnt pathway ligand Wingless (Wg). As was seen in previous in vivo reports, Hh freely localized in while Wg was segregated from the outgrown extensions (Figure 3-3 and (107)).

While localization of Hh within outgrown cytonemes indicated an ability to transport morphogens in the structures, delivery of the ligand to adjacent cells was still in question. From confocal images of Hh producing cells, intracellular Hh was visible in cells in contact with cytonemes extended from Hh producers, which suggested cytonememediated Hh delivery possibly occurred (Figure 3-4, arrows). To test this possibility, we targeted a primary component of the actin polymerization machinery, the Formin protein Diaphanous (Dia), to inhibit morphogen transport to surrounding cells (114). Dia was targeted for knockdown in Hh expressing S2 cells and the effectiveness of knockdown was verified by Western Blot (Figure 3-5 and 114, 117). In Hh expressing cells treated with Dia specific dsRNA, the endogenous levels of Dia protein detected by Dia antiserum show a decrease in protein levels demonstrating the efficiency of knockdown. From the analysis of $\sim 60$ cells per condition in contact with a Hh producing cell cytoneme, there was a significant decrease of intracellular Hh present in receiving cells when Dia was knocked down in Hh producers. This is indicated by a decrease in the relative delivery efficiency levels quantified in Figure 3-5. 


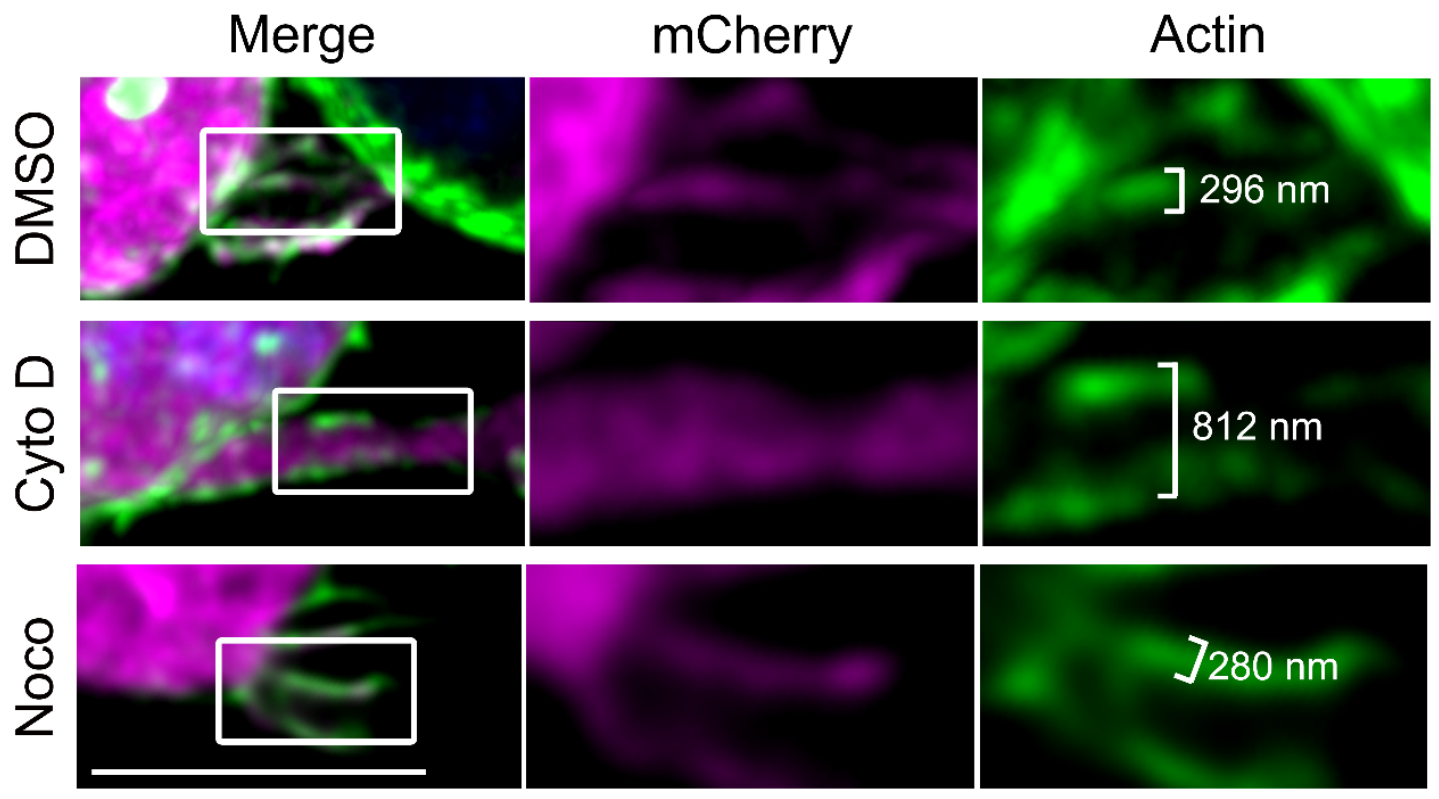

Figure 3-2. Cytochalasin D treatment, but not Nocodazole, has a significant effect on cytoneme architecture.

$\mathrm{S} 2$ cells expressing cytoplasmic mCherry were subjected to pharmacological inhibition of actin using $10 \mu \mathrm{M}$ final concentration of Cytochalasin D. To interfere with microtubule polymerization cells were treated with a $10 \mu \mathrm{M}$ final concentration of Nocodazole. Treatments were done 48 hours after transfection at plating of cells. Image was taken at $63 \mathrm{X}$ magnification. Scale bar represents $3 \mu \mathrm{m}$.
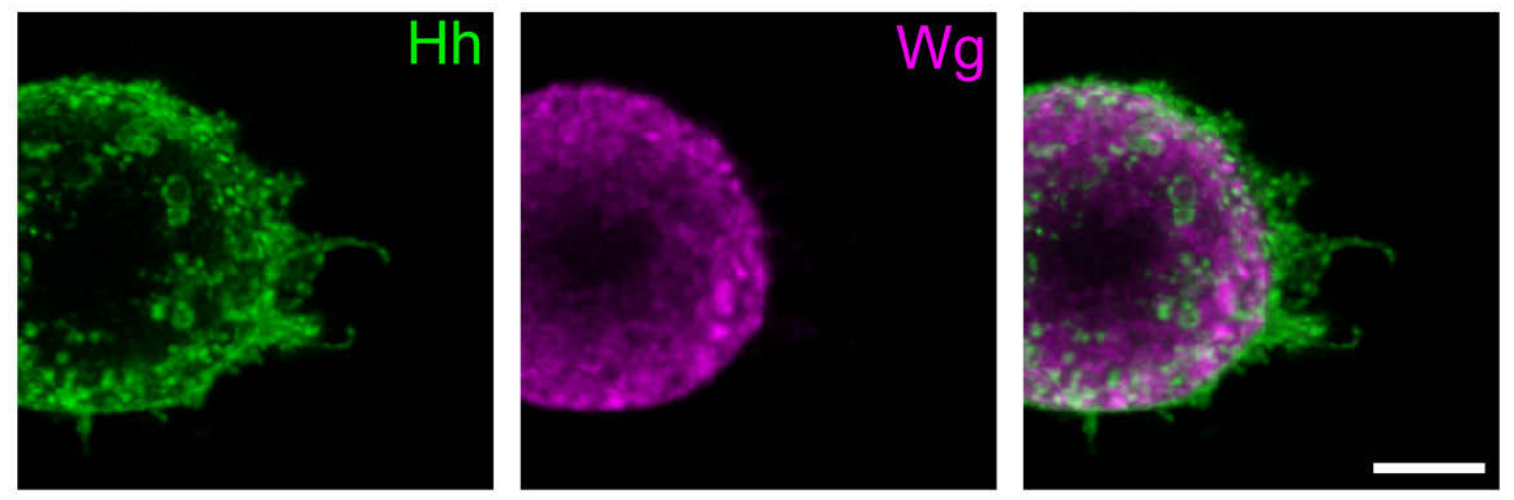

Figure 3-3. S2 cell cytonemes control morphogen incorporation.

An S2 cell co-transfected with expression plasmids for Hh (Green) and Wingless (Wg in pink) shows an active incorporation of Hh into outgrown cytonemes with the retention of $\mathrm{Wg}$ with the cell body. Image was taken at $63 \mathrm{X}$ magnification. Scalebar represents $5 \mu \mathrm{m}$. 


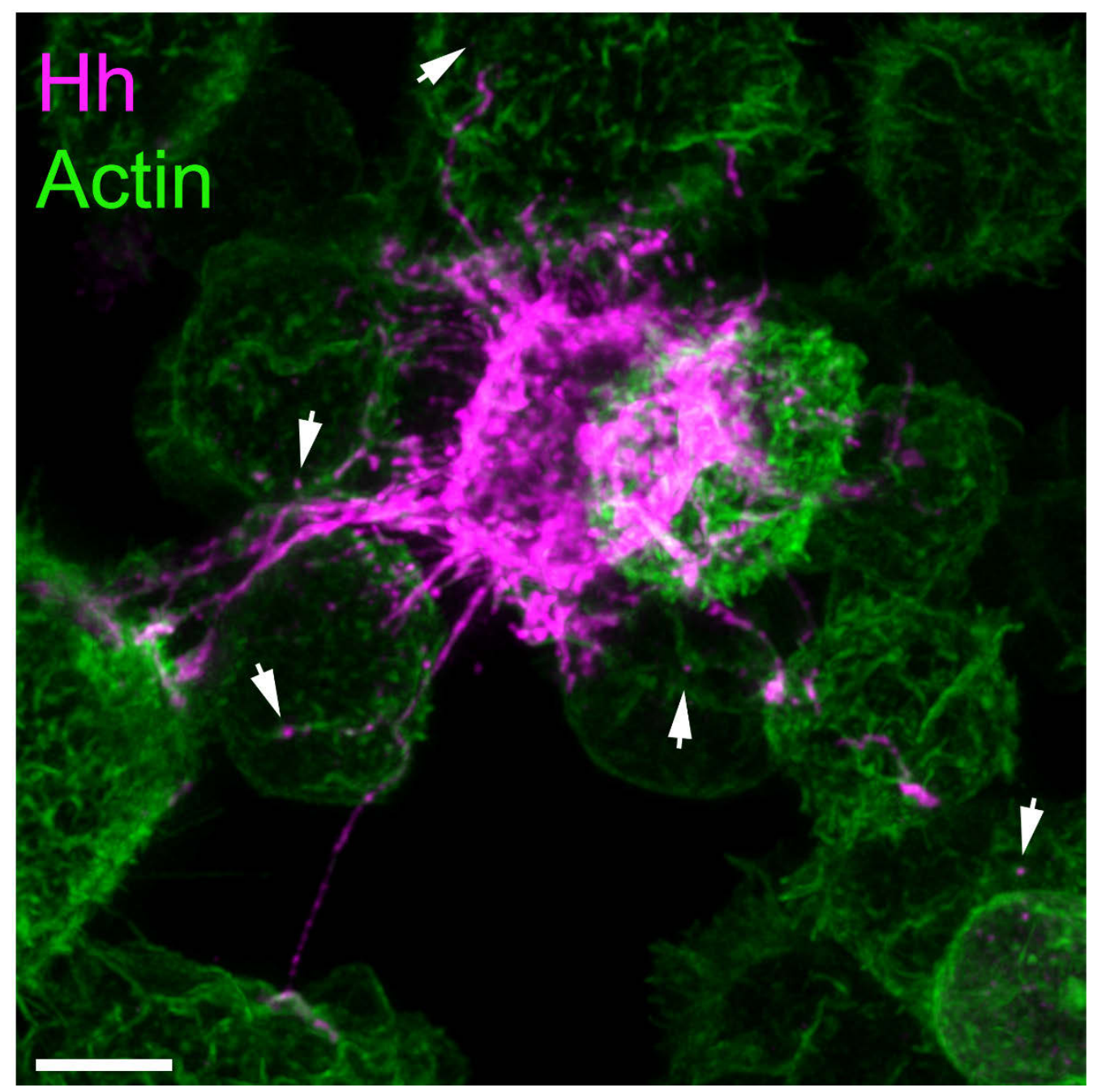

Figure 3-4. Hh is found in producing cell neighbor cells contacted by cytonemes. An S2 cell transfected with Hh projects cytonemes away from the producing cell body towards neighboring cells. Within the neighboring cells, distinct Hh (pink) puncta can be observed. Image was taken at $63 \mathrm{X}$ magnification. Scale bar represents $5 \mu \mathrm{m}$. 

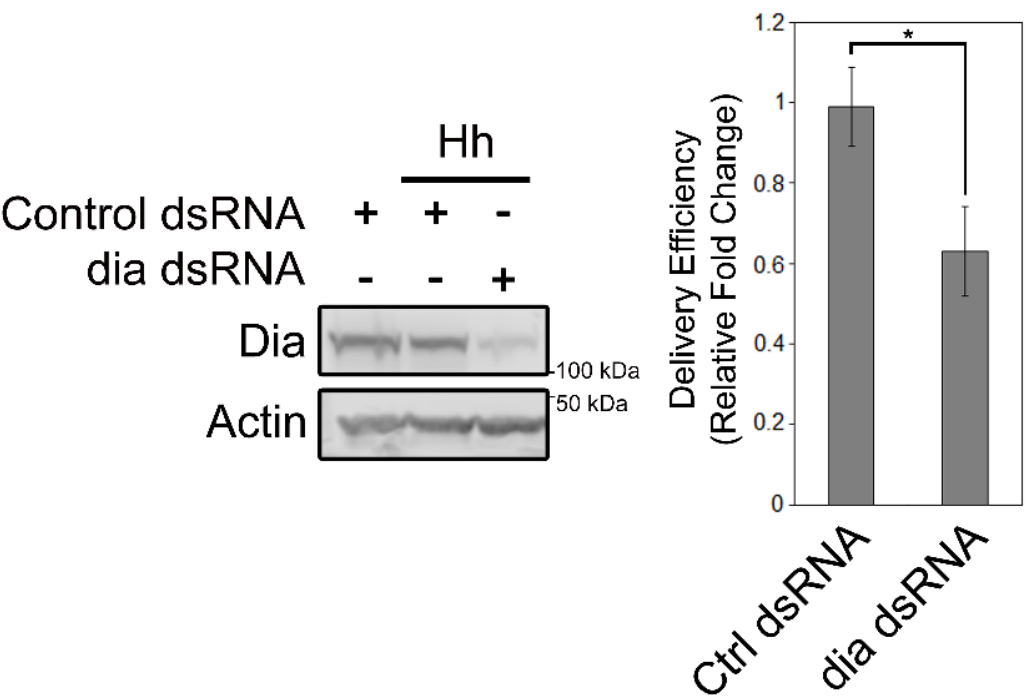

Figure 3-5. dia knockdown verified by western blot affects Hh delivery to neighbors.

S2 cells were either transfected with RNAi constructs or bathed in dsRNA targeting dia transcripts for ten days. Lysates from the cells were collected and probed by Western Blot using a Dia specific antibody. Dia levels were reduced in RNAi or dsRNA treated samples. Representative Western is shown. Performed in tandem, the presence or absence of Hh puncta was measured in Hh producing cell neighbors contacted by a cytoneme. Treatment with RNAi or dsRNA targeting dia significantly reduced the efficiency of $\mathrm{Hh}$ delivery. ${ }^{*} \mathrm{p} \leq 0.05$. 
To determine whether the MEM-fix protocol could be successfully applied to other cell types, we tested the ability of MEM-fix to maintain and visualize cytonemelike structures in Clone $8(\mathrm{Cl} 8)$ and $\mathrm{NIH}-3 \mathrm{~T} 3$ cells overexpressing the Hh or SHH ligand, respectively. $\mathrm{Cl} 8$ cells derived from the wing imaginal disc tissue and the mouse embryonic fibroblast NIH-3T3 cell line were chosen based on tissue origin and the ability to release Hh. In Figure 3-6 and Figure 3-7, cytoneme-like structures extending from $\mathrm{Cl} 8$ or NIH-3t3 cells are present and contain their respective Hh morphogen.

Based on these studies, the MEM-fix protocol is capable of preserving cytonemes for visualization by immunofluorescence microscopy in a variety of cell types. S2 cells produce functional cytonemes that match the majority of the existing criteria. Taken together, the data support that in vivo characteristics are measurable by images of fixed S2 cells. One integral characteristic of cytoneme biology not capable of being analyzed in fixed cells or tissues is the ability to achieve growth rates capable of rapidly transporting morphogens.

\section{Live Imaging of GFP and CD8-mCherry (+) S2 Cytonemes}

In order to determine whether S2 cell cytonemes are capable of achieving documented growth rates we turned to live fluorescent imaging. S2 cells co-expressing cytoplasmic GFP and the fluorescently-tagged mouse membrane protein CD8-mCherry were examined for cytonemes in live cultures. Consistent with cytonemes in a variety of organisms and tissues $(105,109,111-114)$, GFP and CD8-mCherry positive cells projected cytonemes with an average duration of $\sim 80$ seconds (-+ 7.91 seconds) and average growth and retractions rates of $6.03 \mu \mathrm{m} / \mathrm{min}(-+0.61 \mu \mathrm{m} / \mathrm{min})$ and $7.53(-/+1.01$ $\mu \mathrm{m} / \mathrm{min}, \mathrm{n}=23)$. Additionally, S2 cell cytonemes often demonstrated a "snap-back" characteristic documented previously (Movie $1 \&(96)$ ).

These measurements taken together with results from experiments utilizing MEM-fix demonstrate that the S2 cell cytonemes recapitulate the essential characteristics of in vivo cytonemes. Moreover, utilizing MEM-fix allows traditional immunofluorescent cell biology based studies to be performed on structures previously thought to be unfixable.

\section{Examining the Effect of Hh Pathway Components on Cytonemes}

With the establishment of the S2 cytoneme system, we then examined the regulatory mechanisms governing cytoneme-mediated Hh transport. Based on our previous observation that Hh localized to outgrown cytonemes, we hypothesized that Disp, the essential regulator of $\mathrm{Hh}$ release, would co-localize within cytonemes. To test this, S2 cells were transfected with expression plasmids encoding GFP, Hh, a Cterminally HA-epitope tagged version of Disp (referred to as Disp), or the latter two together and processed with MEM-fix. Antibody staining detecting the HA epitope visualized the presence of Disp (green) in the extended cytonemes with puncta of $\mathrm{Hh}$ (magenta) distributed in cytonemes (Figure 3-8). The Hh molecule was relatively uniform on the plasma membrane of the cell body in comparison to the punctate $\mathrm{Hh}$ 

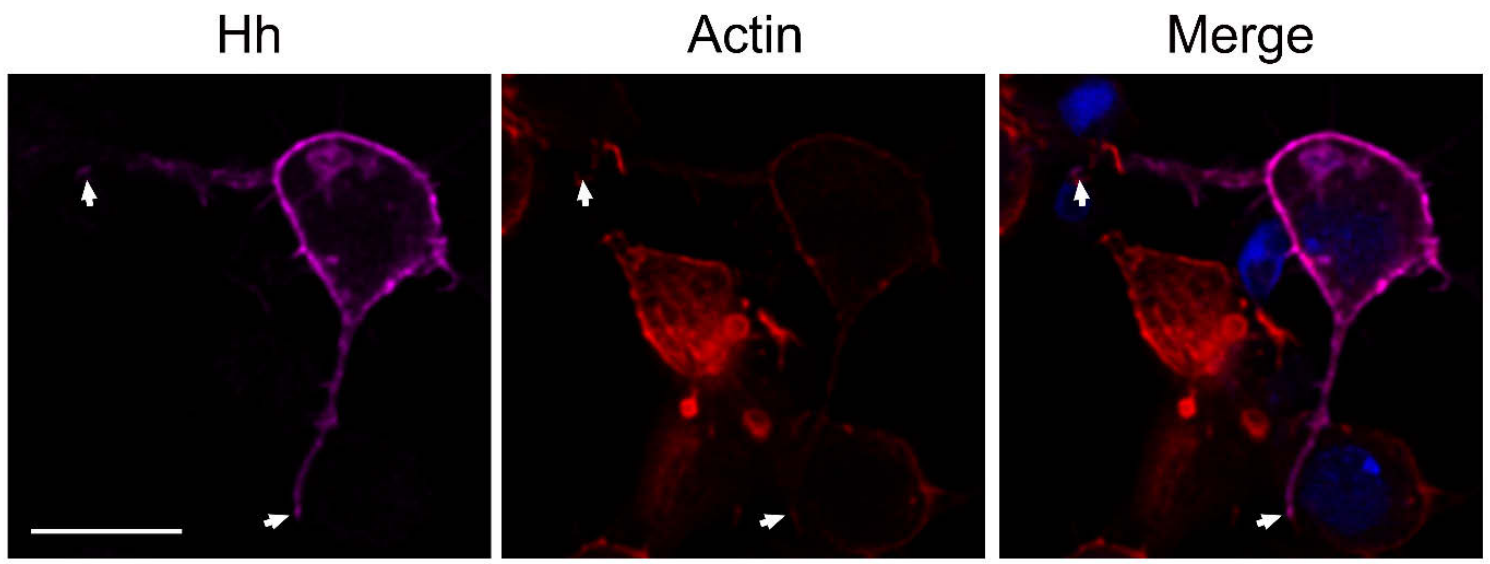

Figure 3-6. Cl8 cells project cytoneme-like extensions containing Disp and the Hh morphogen.

Cl8 cells co-expressing Hh and Disp treated with the MEM-Fix protocol allows for the visualization of cytoneme-like structures matching criteria set forth by previous publications. Cytonemes were positive for Hh (magenta) and Actin (red). DAPI is blue in merge. Image was taken with $63 \mathrm{X}$ magnification. Scale bar represents $7.5 \mu \mathrm{m}$.
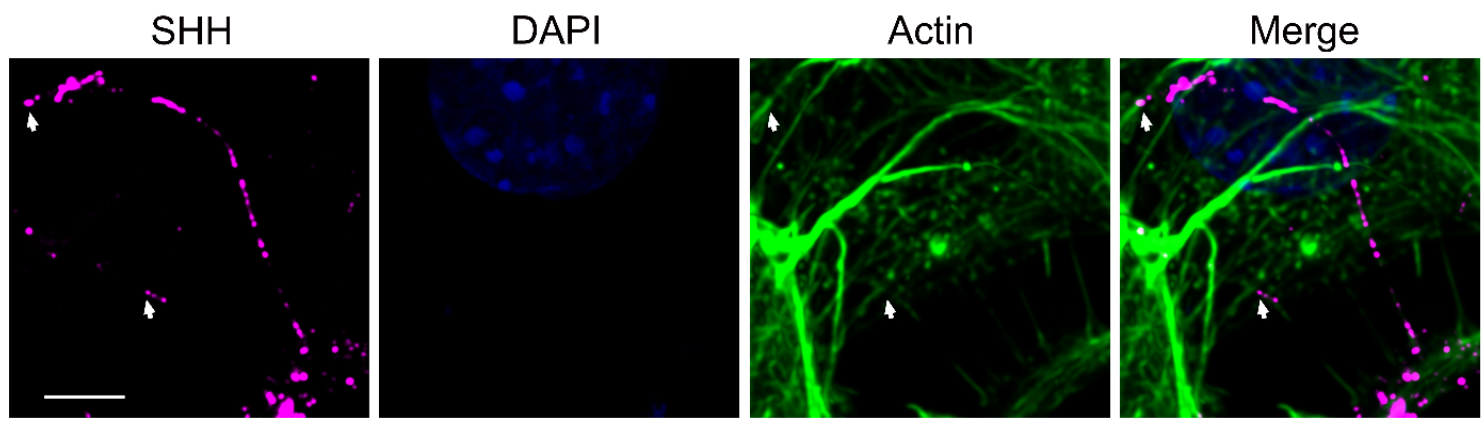

Figure 3-7. NIH-3T3 cells project cytoneme-like extensions containing SHH morphogen.

NIH-3T3 cells expressing SHH treated with the MEM-Fix protocol allows for the visualization of cytonene-like structures which are positive for SHH ligand (Magenta). Actin (green) and DAPI (blue) are also shown. Image was taken at 63X magnification and scale bar represents $5 \mu \mathrm{m}$. 

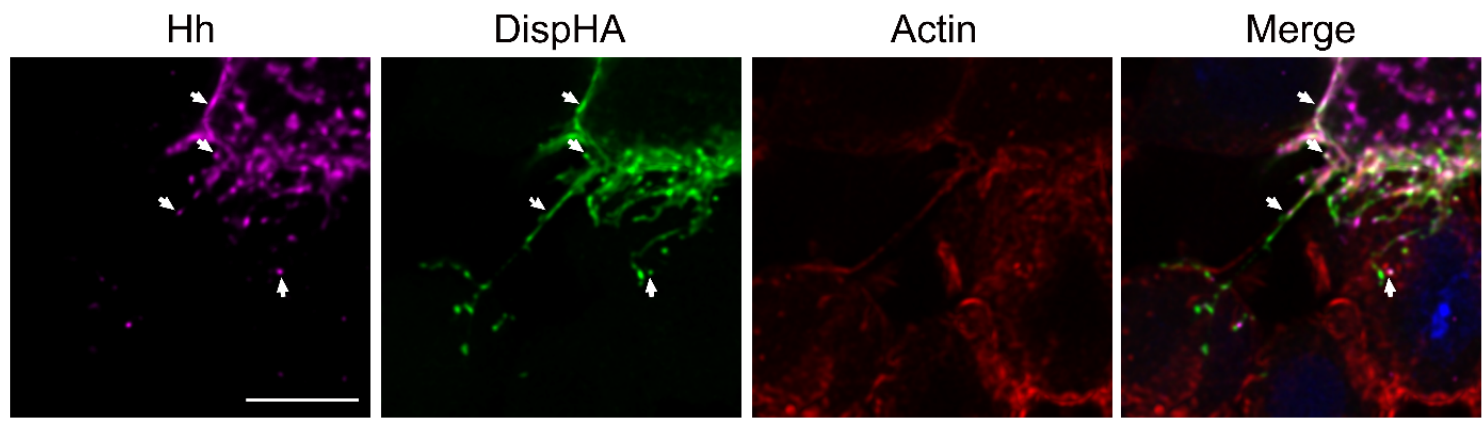

Figure 3-8. Disp is present within outgrown cytonemes with Hh ligand.

An S2 cell co-transfected with DispHA (Green) and Hh (Magenta) extend actin positive cytonemes towards a neighboring cell. Distinct Hh puncta can be observed in extended cytonemes. 
within cytonemes (Figure 3-8, upper arrow compared to lower arrows). This lack of Hh accumulation within the outgrown cytonemes could indicate a rapid release of the $\mathrm{Hh}$ ligand from the structures. Additionally, in the absence of exogenous Hh expression Disp localized within outgrown cytonemes. These findings suggested that Disp localized to cytonemes independently of Hh since S2 cells do not endogenously express $\mathrm{Hh}$ (modENCODE database). This supported the hypothesis that Disp plays a regulatory role in cytoneme-mediated Hh transport.

From this cell biological analysis, it was observed that Disp and/or Hh expressing cells had a higher abundance of cytonemes compared to GFP expressing cells visualized with MEM-fix. To test this, fifty individual cells per condition were imaged in 3D of GFP, Hh, Disp, or Hh + Disp expressing cells. The images were then quantified for the presence of any actin-containing cytoneme extending $\geq 2 \mu \mathrm{m}$ from the portion of the cell not in contact with the plating surface. To prevent interference by non-transfected cells in the quantification of any effect, only cells positive for the expressed proteins were included in the analysis. Over multiple independent experiments, there was a significant increase of cytoneme occurrence when expressing Hh, Disp, or the two together compared to GFP expressing cells (Figure 3-9). In GFP expressing cell populations, approximately 25 percent of cells extended a cytoneme. Expression of Hh significantly raised this level to $\sim 60$ percent compared to GFP. The expression of Disp alone or with $\mathrm{Hh}$ lead to similar increases in cytoneme occurrence. This finding suggested that $\mathrm{Hh}$ pathway components could modulate cytoneme biology to influence this increase.

\section{Controlling for Lipid-Based Transfection and Membrane Protein Overexpression}

Transfections of S2 cells utilize a liposome based delivery system in order to introduce expression plasmids to the translation machinery within the cells. Liposomes are vesicles that can easily fuse with the bilayer of the cell to introduce their cargo within the cell (120). As such, introduction of lipids in the liposome bilayer to the membranes of S2 cells could cause alterations in membrane curvature, budding, or organization (121123). To ensure that the process of transfecting $S 2$ cells played no role in cytoneme formation, untransfected and empty vector-transfected cells were stained for the endogenous Drosophila membrane marker $\alpha$-Spectrin and Actin then quantified for cytoneme occurrence. $\alpha$-Spectrin is a constitutive membrane protein present in Drosophila S2 cells (124). A representative cell shows $\alpha$-Spectrin stain colocalizing with Actin in a cytoneme (Figure 3-10, arrow). In this quantification of cytoneme occurrence, three independent experiments were performed where fields of cells were imaged then analyzed. Within the fields, individual cells totaling $\sim 150$ individual cells per sample were analyzed for cytoneme presence. Untransfected cells had an occurrence of approximately 25\%, similar to levels observed of GFP (Figure 3-11 compared to Figure 3-9, GFP). Empty expression vector transfected cells had similar occurrence rates which suggested introduction of the lipid based transfection reagent had no effect on cytoneme occurrence.

We next sought to rule out that the observed increase in cytoneme occurrence resulted from over expression of a membrane protein. To test this, we attempted to utilize 


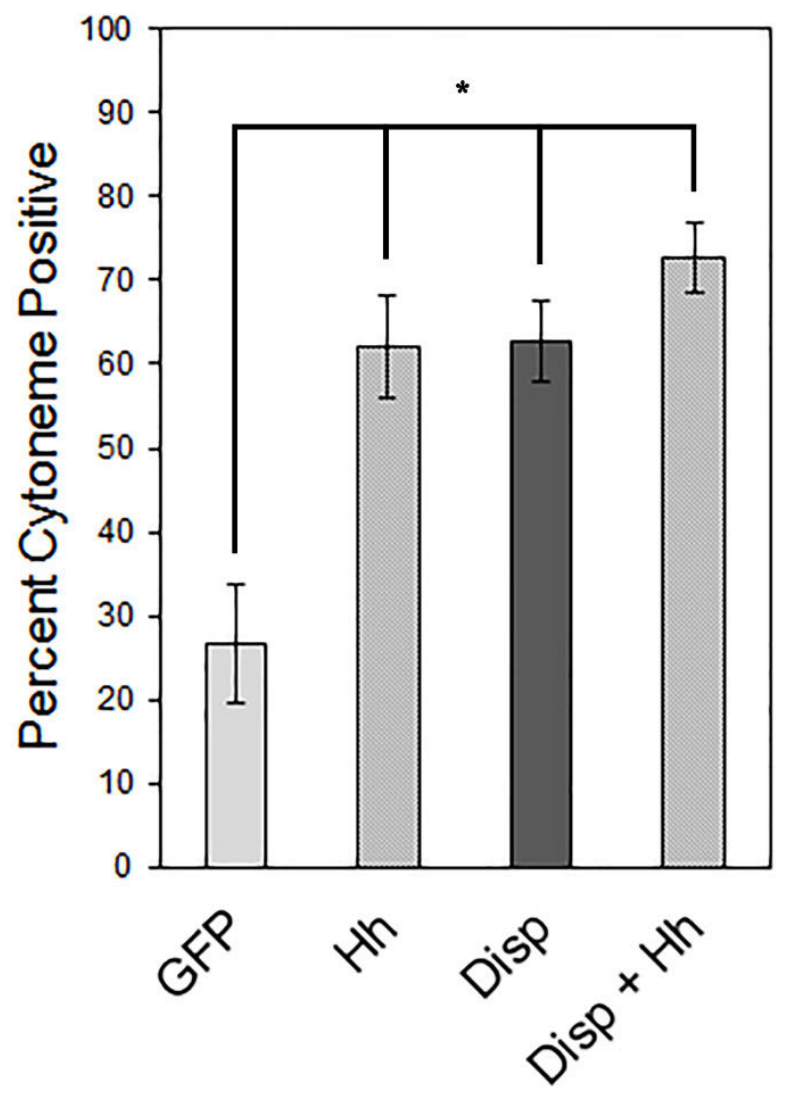

Figure 3-9. Cytoneme occurrence significantly increases with Hh, Disp, and $\mathrm{Hh}+$ Disp.

S2 cells expressing GFP, Hh, Disp, or Hh + Disp were analyzed for the presence of a cytoneme in the top half of the cell, thinner than $500 \mathrm{~nm}$, extended more than $2 \mathrm{um}$, contained their respective expressed proteins, and did not "double-back" to the producing cell. Based on this criteria Hh, Disp, and the two together significantly increased the presence of cytonemes extended from producing cells. Graph represents the average of multiple independent experiments. Error bars represent standard error of the mean (s.e.m). ${ }^{*} \mathrm{p} \leq 0.01$. 


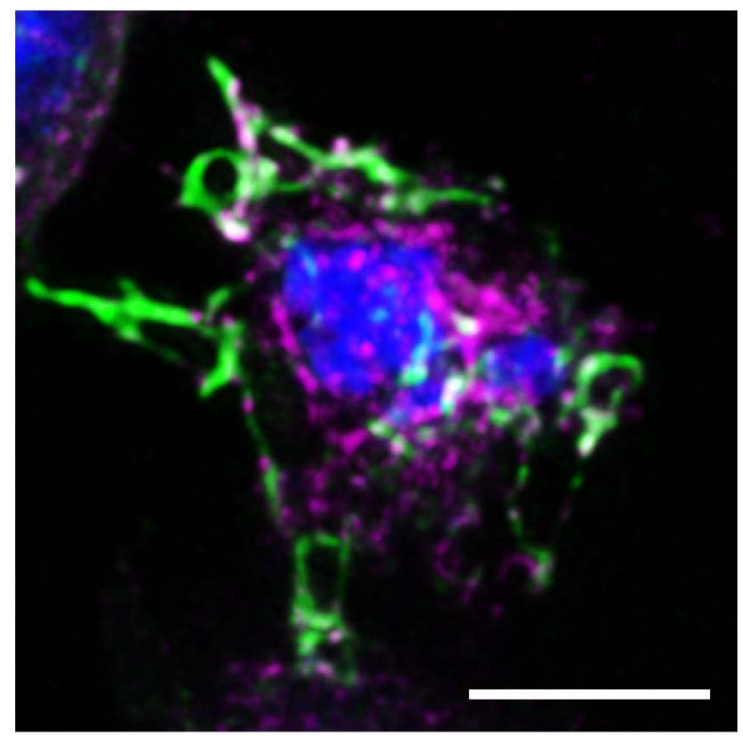

Figure 3-10. The endogenous alpha-Spectrin protein is found in outgrown cytonemes.

An S2 cell was stained for alpha-Spectrin (magenta) and Actin (green) revealed the presence of endogenous alpha-Spectrin in outgrown cytonemes containing Actin. DAPI is marking the nucleus. Image was taken at $63 \mathrm{X}$ and scale bar represents $5 \mu \mathrm{m}$.

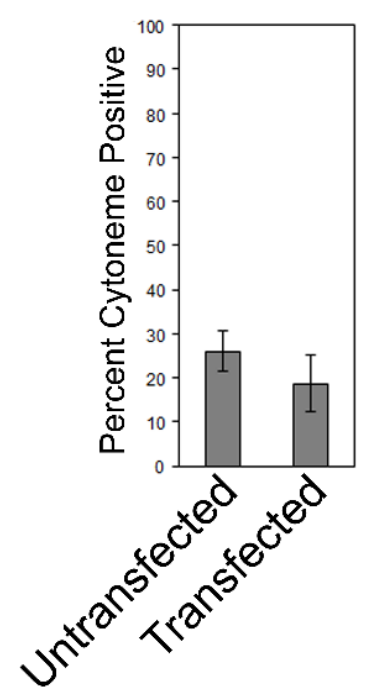

Figure 3-11. Lipid-based transfection effects play no role on cytoneme occurrence. $\mathrm{S} 2$ cells subjected to mock transfections were compared to untransfected S2 cells. Fields of S2 cells stained with Actin and alpha-Spectrin were analyzed for the presence of cytonemes. Graph represents the average of three independent experiments with error bars representing s.e.m. 
a documented, non-functional mutant from the literature which harbors mutations within the GXXXD RND transporter motifs predicted within transmembranes four and ten of Disp (referred to as TM4/10). Unfortunately, dual mutations of the TM4/10 protein significantly affected expression or protein stability in S2 cells and as an alternative we attempted mutation of the motifs individually. It has been demonstrated that RND transporters utilize both GXXXD motifs in cooperation and that disruption of one ablates function of the transporter (69). Furthermore, the fourth transmembrane GXXXD motif is important in cargo selectivity of RND transporter containing protein in bacteria (71). As such, we targeted the fourth transmembrane GXXXD motif in Disp for mutation. In Disp proteins of the fly, fish, rat, mouse and human, the transmembrane four GXXXD motif contains two aspartate residues indicative that Disp possibly transports organic molecules (Figure 3-12 and (71)). In order to ablate the antiporter function carried out by this type of RND transporter, both aspartic acid residues were mutated to alanine. Expression of the transmembrane four GXXXD mutant (referred to as TM4 from this point) produced comparable protein levels to Disp by detection by HA antiserum (Figure 3-13). Furthermore, localization of the TM4 protein was similar to DispHA. In Figure 3-14, TM4 protein (green) localizes to the plasma membrane of the cell where it colocalizes with Hh (magenta) protein. Notably, the TM4 mutant is able to localize to extended cytonemes similar to DispHA Figure 3-14, TM4 panel v. Disp panel). With these findings, we next wanted to verify that disruption of the transmembrane four GXXXD motif of the RND domain in Disp would disable functionality as observed with the TM4/10 mutant and predicted based on bacterial RND transporter protein studies.

To test the functionality of the TM4 mutant, a modified form of the traditional $\mathrm{Hh}$ pathway luciferase reporter assay in C18 cells was used $(26,116)$. Detailed in Figure 3-15, two sets of cells are generated with producing cell pathway components in one while the Hh responsive reporter and normalization reporters are in the other. This assay allows testing Disp mutant functionality in the presence or absence of endogenous Disp by co-transfecting disp 3'UTR specific dsRNA within the producing cells. Once the cells are combined, reporter cells are exposed to ligand to activate the reporter gene, and the results from this assay measure pathway activation as a readout of Disp functionality.

The TM4 mutant was tested using this functional assay in the presence or absence of endogenous Disp. In this assay, the functionality of Disp is measured by the production of a Firefly Luciferase driven by Hh pathway activation. Using a constitutively expressed Renilla Luciferase as a normalization control, the ratios from the two luciferase signals are then presented as reporter activity relative to control. As such, introduction of exogenous Hedgehog to the endogenous pool of Disp increases the relative reporter activity to approximately 5 fold (Figure 3-16, light grey bars - column 1 v. column 2). This response can be inhibited by removing the endogenous pool of Disp with the disp 3 'UTR specific dsRNA evidenced by the decrease to almost baseline levels in the Hh with disp 3'UTR specific dsRNA sample (Figure 3-16, column 2 - light grey bar v. dark grey bar). Co-transfection of Disp and Hh to the endogenous pool of Disp increased the activity level to $\sim 15$ fold, suggesting an additive effect of exogenous Disp to the Hh sample with the endogenous Disp pool (Figure 3-16, light bars - column 3 compared to 2). Demonstrating the specificity of the dsRNA, exogenous expression of Disp with $\mathrm{Hh}$ is able to rescue the removal of the endogenous Disp pool using the 3'UTR 


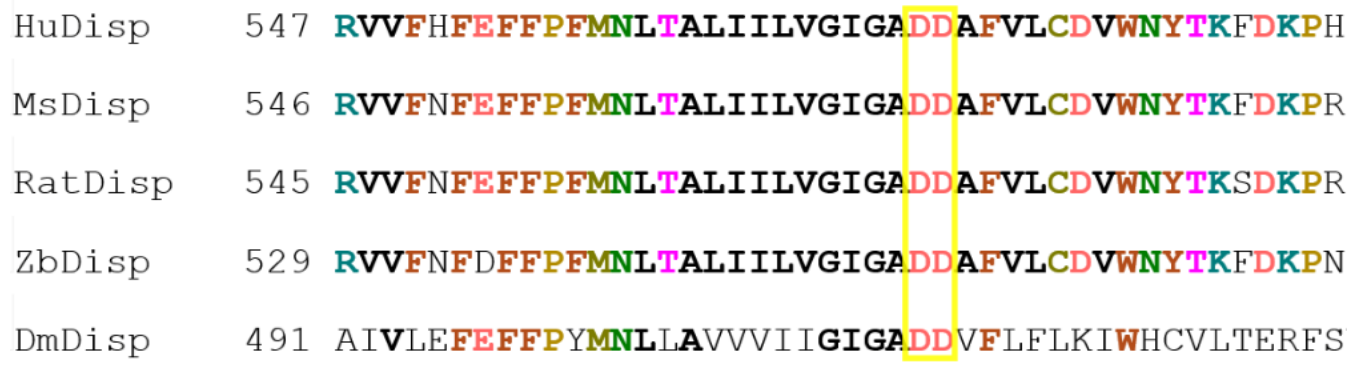

Figure 3-12. Disp alignment of the GXXXD transmembrane four containing region.

An amino acid alignment of Disp proteins from a variety of species show the highly conserved TM4 GXXXD motif. The aspartic acids important for facilitating antiporter function are encased in a yellow box. Amino acid numbers for the respective species is listed on the left.

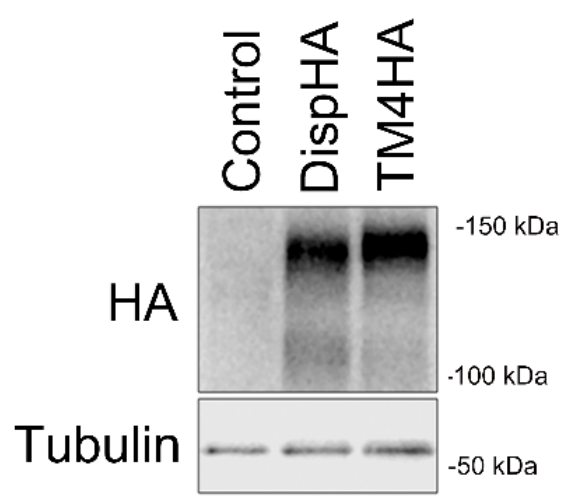

Figure 3-13. Disp TM4HA mutant has comparable protein levels to DispHA. S2 cells expressing wild-type or the TM4 mutant were lysed and protein expression was measured by Western Blot. There was similar expression levels between the two proteins. HA antiserum was used to detect Disp while Tubulin serves as the loading control. 

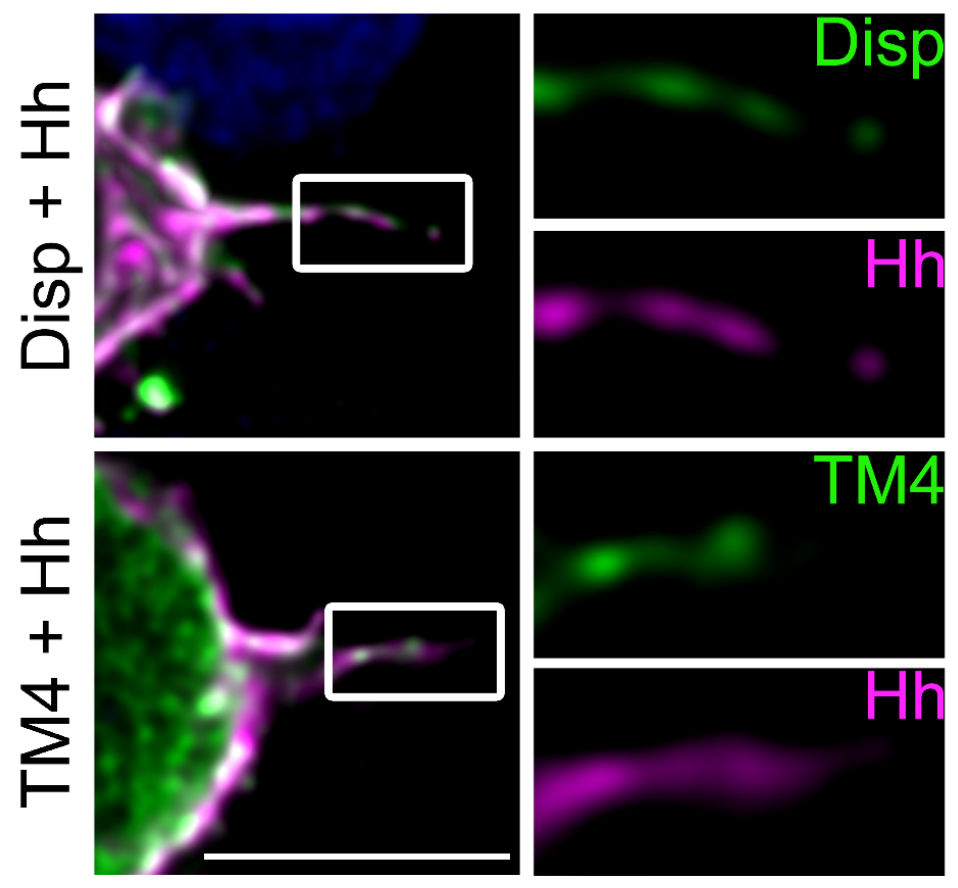

Figure 3-14. Disp TM4 mutant localizes similarly to wild-type Disp.

S2 cells co-expressing Hh (green) with either wild-type or the TM4 mutant (pink) were compared in their localization. There was no differences in the localization between these two proteins. Images were taken at $63 \mathrm{X}$. Scale bar represents $3 \mu \mathrm{m}$.

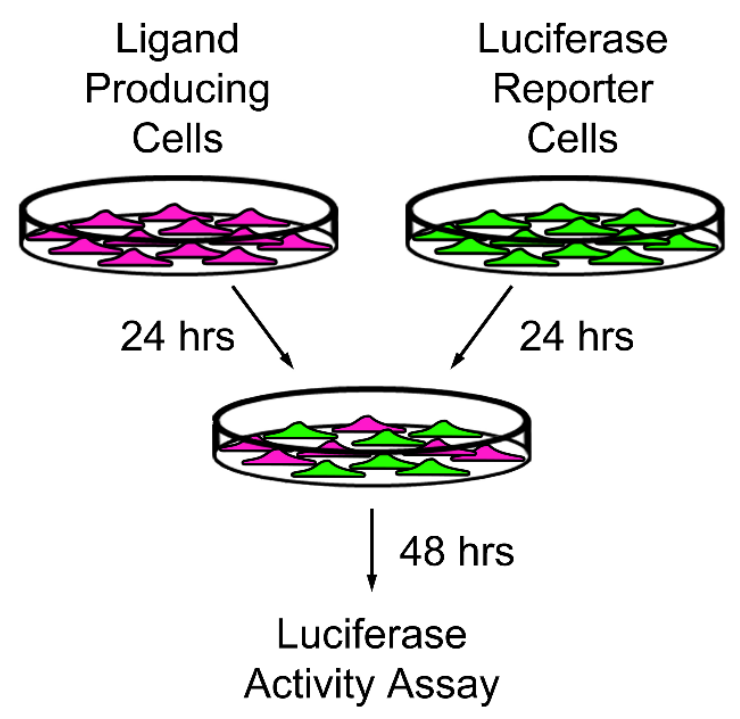

Figure 3-15. Co-culture reporter assay design.

This cartoon diagram illustrates the protocol for performing the Co-Culture Reporter Assay used in these studies. 


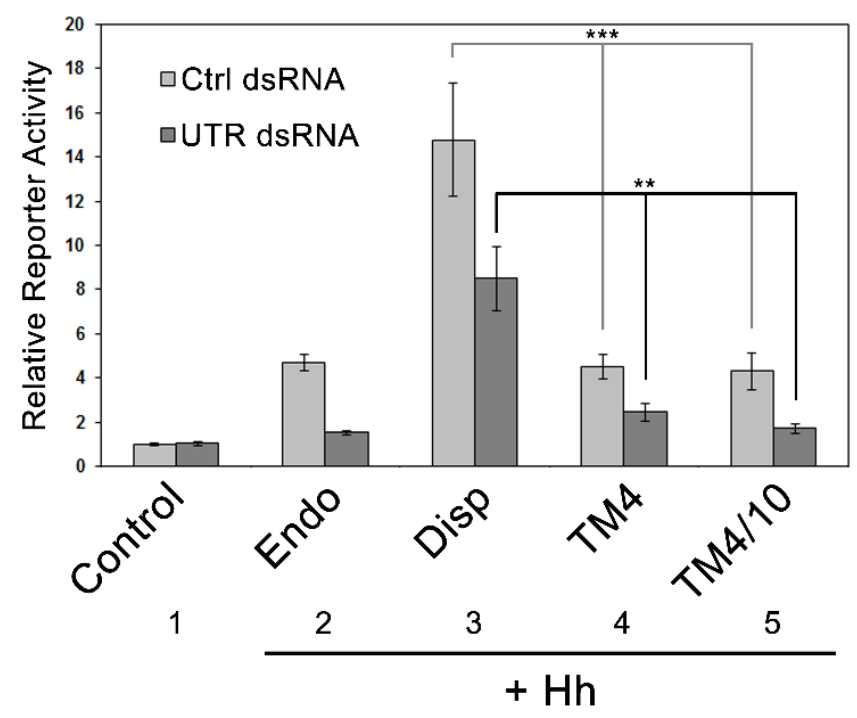

Figure 3-16. Co-culture reporter assay reveals TM4 mimics non-functional TM4/TM10.

Introduction of 3'UTR dsRNA targeting disp can be rescued by wild-type, but not the TM4 or TM4/TM10 double mutant. Graph represents the average of multiple experiments with error bars corresponding to s.e.m. ${ }^{* *} \mathrm{p} \leq 0.01 * * * \mathrm{p} \leq 0.001$. 
specific dsRNA which is lacking in the Disp expression constructs (Figure 3-16, dark grey bars, column 2 v. 3). The disparity between Disp and Hh co-expression with and without disp specific dsRNA is likely reflective of the loss of the endogenous pool of Disp protein. Compared to the wild-type counterpart, both the TM4 and TM4/10 mutants were unable to additively increase the Hh response or to rescue loss of endogenous Disp protein in this assay (Figure 3-16, light grey bars - column 3 v. $4 \& 5$ and dark grey bars - column 3 compared to $4 \& 5$ ). Based on these results, we concluded that the fourth transmembrane GXXXD motif is necessary for Disp function.

With the combined results from protein expression, localization, and functionality, we wanted to use the TM4 mutant as a control for cytoneme occurrence. By using this mutant, both expression of a membrane protein and the requirement of Disp functionality for increases in cytoneme occurrence were tested. As in previous experiments, the GFP control induced a low occurrence rate at approximately $20 \%$ (Figure 3-17). Expression of Hh, Disp, and Disp with Hh all increased cytoneme occurrence to a similar rate of approximately 60 percent. The TM4 mutant alone was unable to induce a significant increase in cytoneme occurrence compared to the GFP control (Figure 3-17). Interestingly, co-expression of the TM4 mutant with Hh ablated the increase seen when Hh was expressed alone suggesting TM4 exhibits dominant activity in this assay (Figure 3-17).

By controlling for transfection and non-specific effects of exogenous membrane protein expression we can confidently conclude that the Hh pathway components are altering the level of cytoneme occurrence. To investigate the mechanism behind this increase we began ruling out common effects of the pathway activation.

\section{Analysis of Density and Signaling on Cytoneme Occurrence}

The Hh pathway can function as a mitogen in many cellular contexts (125). Taking this into account with the report of Hh specific cytonemes growing towards sources of the Drosophila FGF molecule, Branchless, we wanted to test whether cell density played a role in the occurrence rates observed. If the mitogenic capability of the Hh pathway was influencing cytoneme occurrence we would expect increases in cell density would universally increase occurrence levels. To test this, we plated GFP, Hh, Disp, or $\mathrm{Hh}+$ Disp expressing cells at increasing concentrations from 250k (very sparse) to one million cells per chamber of a 4-well chamber slide. One million cells per well of the 4-well chamber slide is the normal plating density for the previous cytoneme occurrence experiments. While there were slight increases seen with cytoneme occurrence for the GFP control these values failed to reach statistical significance (Figure 3-18). This alone indicates that cytoneme occurrence is not purely due to the cell density and that additional factors induce cytoneme occurrence. Concurrent with previous findings, Hh pathway components increased the occurrence rates at the higher densities.

With a wide variety of concentration-dependent transcriptional targets, it is possible that activation of $\mathrm{Hh}$ signaling by soluble release triggered the production of an unknown factor which aided increases in cytoneme occurrence at higher densities 


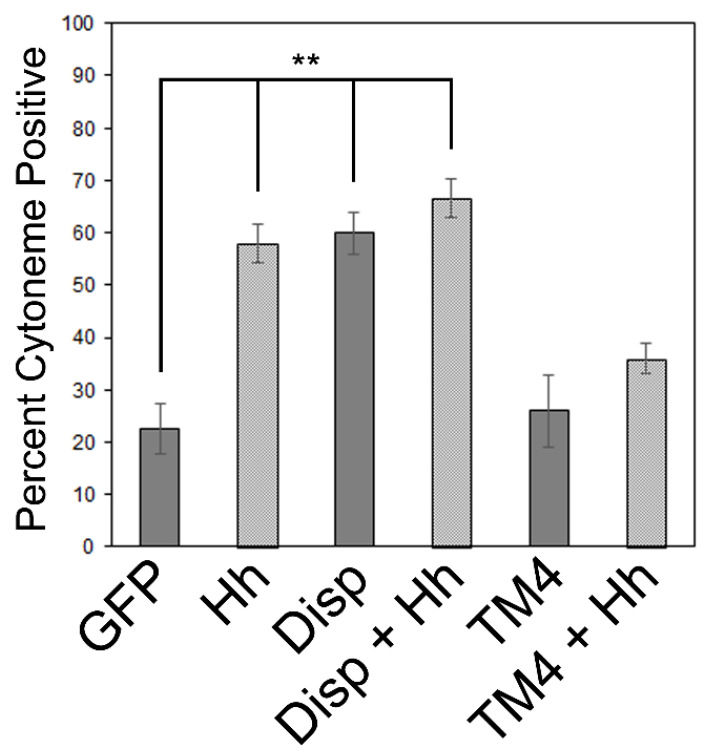

Figure 3-17. The membrane protein control, TM4, fails to increase cytoneme occurrence.

S2 cells transfected with GFP, Hh, Disp, TM4, or Hh with Disp/TM4 mutant were assayed for cytoneme occurrence. The TM4 mutant fails to increase cytoneme occurrence alone and inhibits Hh induction when co-expressed. The graph represents the average of three independent experiments with s.e.m. error bars. $* * \mathrm{p} \leq 0.01$.

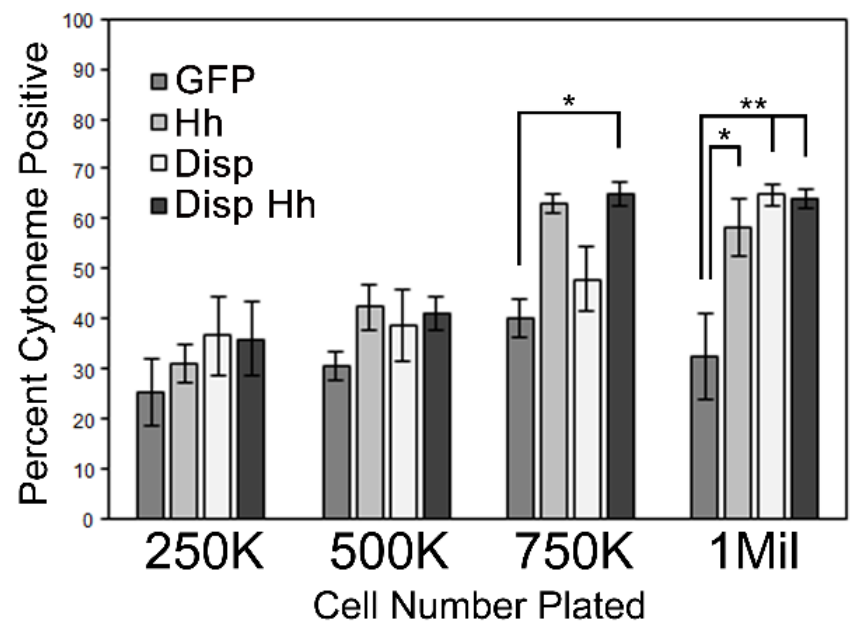

Figure 3-18. Increasing density does not significantly affect GFP cytoneme occurrence.

S2 cells plated at the indicated densities were assayed for cytonemes. Density had no significant effect on cytoneme occurrence of GFP cell. Density at 1 million corresponds to densities of previous experiments. The cytoneme occurrence average of three independent experiments is graphed here with s.e.m. as error bars. $* \mathrm{p} \leq 0.05 * * \mathrm{p} \leq 0.01$. 
$(49,126)$. Supporting this possibility, co-expression of TM4 restricted Hh within the cell compared to wild type Disp (Figure 3-14, Hh panels). As such, TM4 failed to rescue loss of Disp in the co-culture reporter assay (Figure 3-16, dark grey bars -3 v. 4). This evidence supports that the release Hh to the neighboring cells could induce an additional factor needed to increase cytoneme occurrence.

To test this, we used conditioned media collected from cells expressing GFP, Hh, and a Hh mutant lacking the cholesterol modification (Referred to as $\mathrm{HhN}$ and (59)). The mutational truncation of the $\mathrm{HhN}$ molecule which prevents the cholesterol modification subsequently allows large amounts of the ligand to be secreted into the media compared to Hh while maintaining competency to induce Hh pathway signaling $(59,88)$. Once collected, we applied the conditioned medias to GFP expressing cells plated at a 1 million per well density in an attempt to increase in cytoneme occurrence in GFP expressers.

In this assay the level of pathway activation was prescreened by checking Fused protein phosphorylation status in cellular lysates. Downstream of the essential signal transducer Smoothened, Fused is phosphorylated in response to signaling activity (127). The Fused phosphorylation status is a tool used to measure endogenous Hh pathway activity levels. In previous experiments, Hh consistently increased cytoneme occurrence and as such the level of Fused phosphorylation in this population of cells would indicate the level of signaling activity necessary to produce the additional unknown co-factor. Fused phosphorylation levels are elevated in Hh expressing cell populations compared to GFP cell population detected by Western blot using a Fused specific antiserum (Figure 3-19, left: lane 1 v. 2 - arrow head indicates phosphorylated form). HhN producing cells also induce a similar level of pathway activity compared to Hh expressing cells (Figure 3-19, left: lane 2 compared to lane 3). Application of $\mathrm{Hh}$ or $\mathrm{HhN}$ conditioned media to GFP receiving cells caused increased Fused phosphorylation, but not when control conditioned media was applied (Figure 3-19, left: lanes 4-6 v. lane 1). While there was a phosphorylation increase in cells treated with $\mathrm{Hh}$ or $\mathrm{HhN}$ condition media, only $\mathrm{HhN}$ conditioned media was able to induce the Fused phosphorylation level of receiving cell populations to a level comparable to Hh expressing cell populations (Figure 3-19, left: lane 6 compared to lane 2).

Having established that cells receiving $\mathrm{HhN}$ conditioned media had Hh pathway activation levels similar to Hh producing cell samples, we then determined the rates of cytoneme occurrence within the populations of receiving cells. GFP expressing cells treated with the conditioned media were processed with MEM-fix then imaged and analyzed for the presence of cytonemes. Consistent with a lack of pathway activation dictating a failure to increase cytoneme occurrence, receiving cells of control media had baseline level cytoneme occurrence of approximately 30 percent (Figure 3-19, right). Contradictory to this relationship, GFP receiving cells treated with $\mathrm{HhN}$ conditioned media also had cytoneme occurrence levels comparable to GFP expressing control cells. This result suggests that Hh pathway activity does not induce the additional factor needed to increase cytoneme occurrence. As such, cytoneme occurrence in previous experiments must be caused, at least in part, by an intrinsic mechanism due to Hh or Disp. 

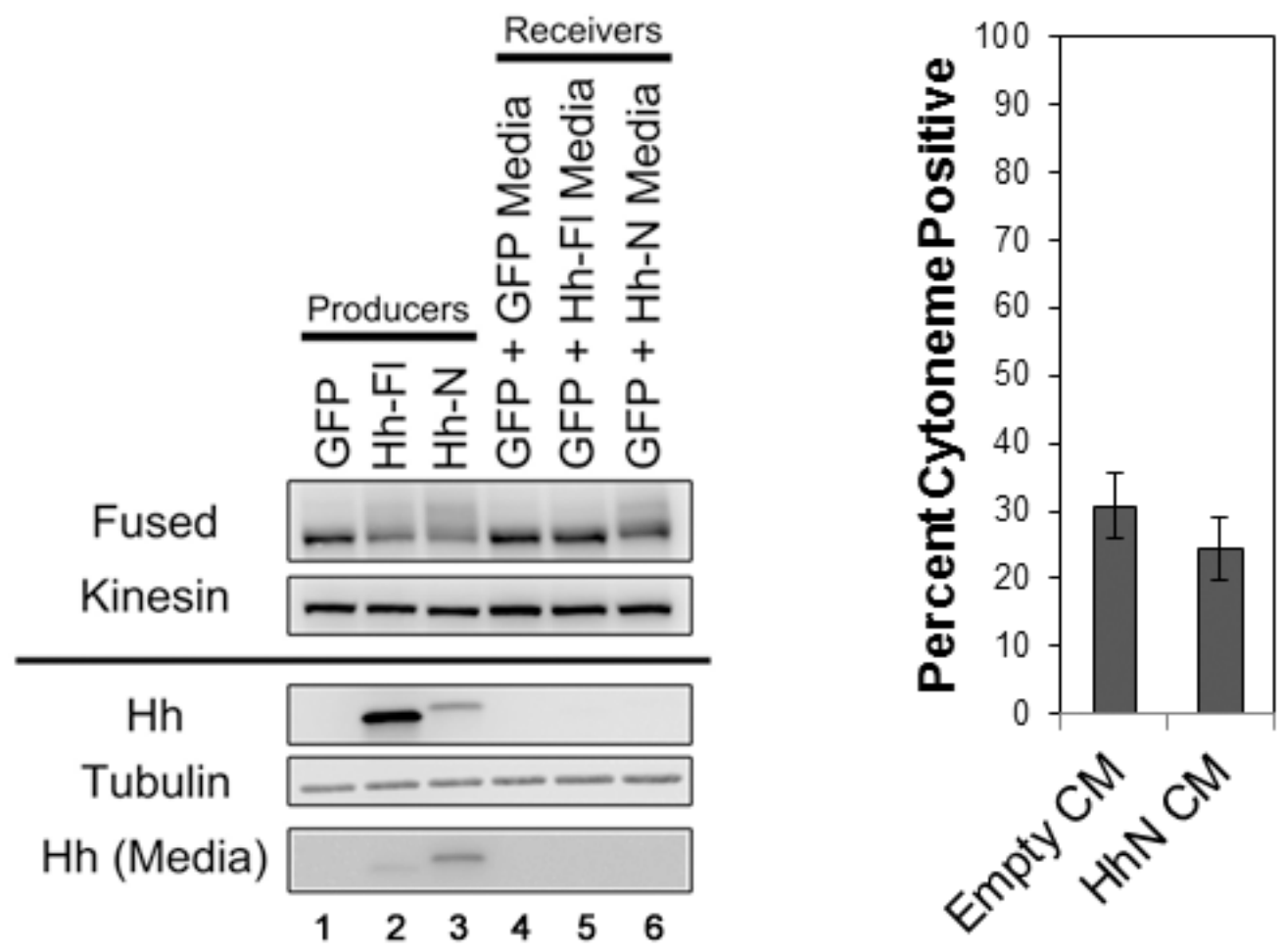

Figure 3-19. Pathway activity within receiving cells does not influence cytoneme occurrence.

Using S2 cell lysates, the Western Blot for Fused phosphorylation (arrow head) indicated similar levels of pathway activation in $\mathrm{Hh}$ producers and $\mathrm{HhN}$ conditioned media receiving cells. Cytoneme occurrence measurements from GFP positive receiving cells treated with the listed conditioned media show no significant difference in occurrence. Representative Western blot was probed with anti-Fused and loading control antiKinesin. Corresponding Western detects $\mathrm{Hh}$ in the lysate and media using anti-Hh and Tubulin serves as the loading control. The occurrence graph plots the average of three experiments with s.e.m. for error bars. 


\section{Investigating Hh Lipidation on Cytoneme Outgrowth}

We began investigating the intrinsic mechanism by probing the requirement of $\mathrm{Hh}$ lipid modifications. Disp is likely expressed in these cells demonstrated by the ability to release cholesterol modified Hh into conditioned media (Figure 3-19 - Left - Hh blot: media lane $1 \mathrm{v} 2$ ). As such, if Disp is involved in cytoneme mediated Hh transport we hypothesized that the cholesterol modification would be required to increase cytoneme occurrence in this intrinsic mechanism. This requirement of cholesterol in cytoneme transport would then be consistent with the genetic data that Disp is required for the long range transport of the Hh ligand.

To investigate this requirement, S2 cells expressing GFP, Hh or HhN were treated with MEM-fix and the localization of the Hh proteins was first compared. As observed previously, Hh localized to the cell membrane and outgrown cytonemes (Figure 3-20, top). Similar to $\mathrm{Hh}, \mathrm{HhN}$ was found at the cell membrane but was also largely concentrated in intracellular punctate. A small portion of the $\mathrm{HhN}$ protein was found in an extended cytoneme albeit at a significantly lower abundance than the dually lipidated form. The cytoneme occurrence rates of $\mathrm{HhN}$ were then determined. Hh expressing cells increased cytoneme occurrence to approximately $75 \%$ in these experiments while GFP expressing cell populations only had approximately $35 \%$ with a cytoneme. Consistent with our hypothesis, there was a significant difference between $\mathrm{Hh}$ and $\mathrm{HhN}$ populations in which approximately $30 \%$ of $\mathrm{HhN}$ cells had a cytoneme (Figure 3-21). This result supports the hypothesis that Disp is involved in cytoneme-mediated Hh transport.

To test whether Disp regulated the cytoneme occurrence increase in $\mathrm{Hh}$ expressing cell populations, Disp was knocked down before expression of either mCherry or Hh in S2 cells. The efficiency of the Disp knockdown was measured by Western blot detecting the endogenous Disp protein in membrane fractions of cell lysates using Disp specific antiserum (Figure 3-22). Treatment with disp 3'UTR specific dsRNA reduced endogenous protein levels compared to treatment with control dsRNA (Figure 3-22, lanes $3 \& 5$ compared to $2 \& 4$, respectively - bracket indicated Disp protein). Consistent with loss of Disp, Hh protein accumulated in Disp knockdown samples (Figure 3-22, lane $5 \mathrm{v}$. lane 4 of Hh blot). With the reduction of Disp protein levels indicated by a loss of Disp protein as well an accumulation of Hh within the cells indicated by western blot, the cells were then assayed for their cytoneme occurrence level. Reduction of Disp in mCherry expressing cells using dsRNA had no significant effect on basal cytoneme occurrence levels: all populations had approximately $25 \%$ with cytonemes (Figure 3-23, mCherry Untreated v. mCherry + Ctrl dsRNA v. mCherry + disp dsRNA). Conversely, Hh-induced cytoneme occurrence levels at $\sim 60 \%$ were significantly reduced to near baseline levels at $\sim 30 \%$ when exposed to disp 3'UTR specific dsRNA (Figure 3-23, Hh + Ctrl dsRNA v. Hh + disp dsRNA).

With these data taken together, these studies provide strong evidence that Disp regulates Hh induced cytoneme occurrence levels in this $\mathrm{S} 2$ in vitro cytoneme system. In order to investigate the mechanism by which Disp increased cytoneme occurrence we turned back to live imaging. 

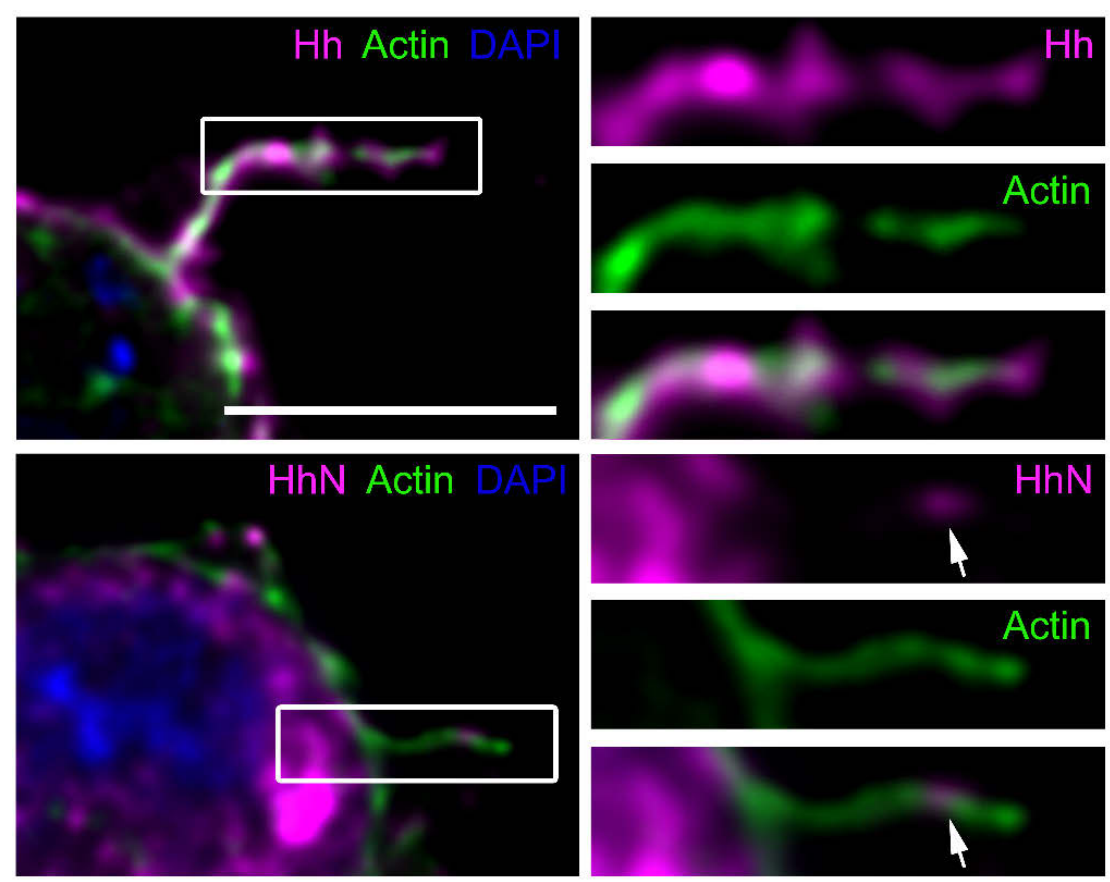

Figure 3-20. HhN fails to enrich in cytonemes compared to dually lipidated Hh. Cytonemes from $\mathrm{Hh}$ and $\mathrm{HhN}$ expressing cells were imaged and the localization of the two molecules was compared. Hh abundantly localizes throughout outgrown cytonemes. $\mathrm{HhN}$ is found within cytonemes but fails to enrich in the structures.

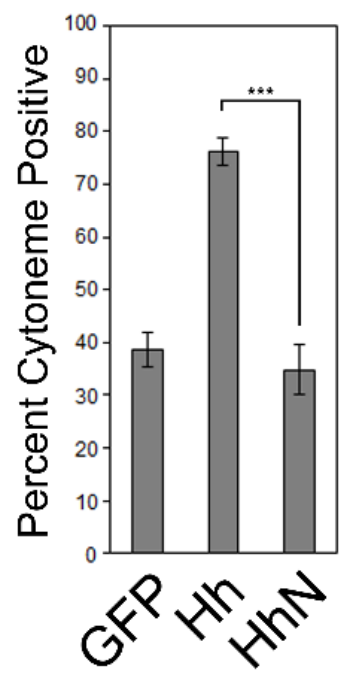

Figure 3-21. HhN producers do not match Hh cytoneme occurrence levels. $\mathrm{S} 2$ cells transfected with GFP, Hh, or HhN were analyzed for their level of cytoneme occurrence. Hh significantly increased cytoneme occurrence compared to $\mathrm{HhN}$ in producing cells. $* * * \mathrm{p} \leq 0.001$. 


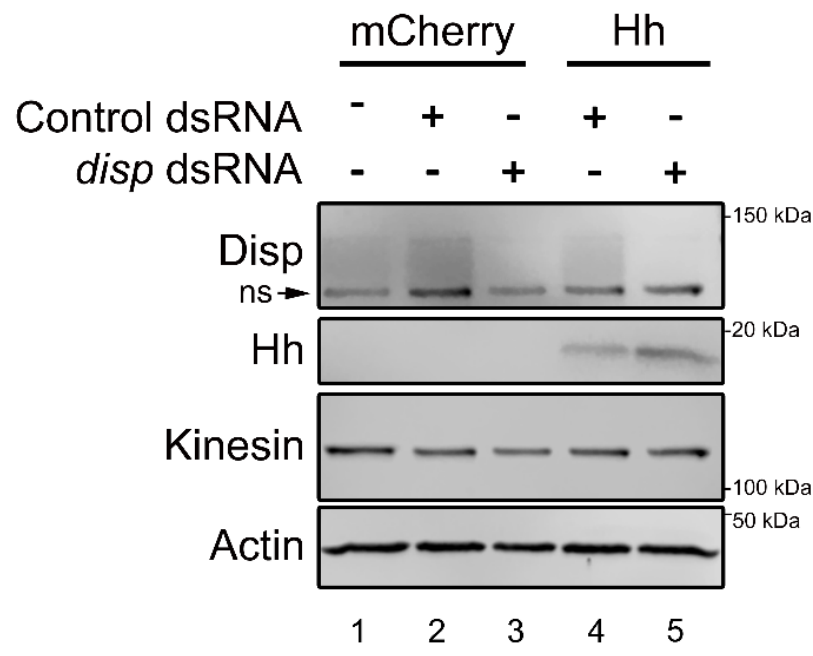

Figure 3-22. Endogenous Disp knockdown is verified using anti-Disp antibody. The representative Western blot of S2 cell membrane lysates detects specific signal that is reduced in disp 3'UTR ${ }^{\prime} R R A$ treated lanes. Indicative of successful Disp knockdown, Hh levels within the lysates increase. Kinesin serves as a high molecular weight loading control. Tubulin serves as a low molecular weight loading control.

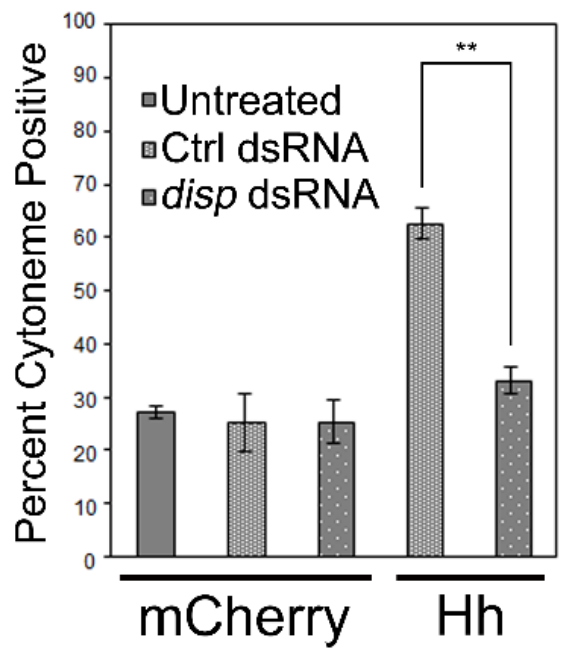

Figure 3-23. Knockdown of Disp in S2 cells ablates Hh induced cytoneme occurrence.

S2 cells expressing either mCherry or Hh were treated with Control or disp 3'UTR dsRNA before assaying for cytoneme occurrence. Treatment with disp specific dsRNA blocked the increase in cytoneme occurrence seen with Hh expression. Graph represents the average of multiple experiments pooled together. Bars represent s.e.m. ${ }^{* *} \mathrm{p} \leq 0.01$. 


\section{Live Imaging of GFP and Disp-mCherry (+) S2 Cytonemes}

The cytoneme occurrence assays performed all utilize fixed cells. Therefore, the images obtained are snap shots of what is occurring while the cells are living. Based on this fact, increases in occurrence by Disp were likely allowed a higher percentage of cells to be captured while extending a cytoneme. This is likely due to a Disp-dependent mechanism by which cytonemes are either stabilized once outgrown, grown at a higher frequency than GFP expressing cells, or a combination of both. To determine which was occurring, S2 cells were co-transfected with GFP and a C-terminal fluorescent mCherry tagged Disp and examined in live imaging. Cytonemes from cells positive for these two markers were measured and revealed that the average duration of cytonemes was almost three times longer than cells co-expressing GFP and CD8-mCherry $(\sim 235$ second -+ 33.12 seconds, $n=12$, and Movie 2 ). This increase in overall duration was likely aided by a decreased retraction rate of $3.98 \mu \mathrm{m} / \mathrm{min}(-+0.67 \mu \mathrm{m} / \mathrm{min}$ and $\mathrm{n}=11)$. In contrast, growth rates were similar to control measurements at $6.53 \mu \mathrm{m} / \mathrm{min}(-+0.87 \mu \mathrm{m} / \mathrm{min}$ and $\mathrm{n}=12$ ). Table 3-1 summarizes the live imaging data.

In combination of fixed and live imaging data, these findings support that the increases in cytoneme occurrence by $\mathrm{Hh}$ are likely due to a cytoneme stabilizing mechanism requiring Disp. While S2 cytonemes serve a robust role in investigating cytoneme biology, it was essential to verify that effects on cytonemes observed in this system are recapitulated in vivo.

\section{Validating In Vitro Findings in Drosophila Wing Imaginal Discs}

Turning to the Drosophila wing imaginal disc was the obvious choice in the progression of these studies. Cytonemes characteristics were originally defined in this system and since then it has served as a model organ for interrogating mechanisms controlling cytoneme-mediated morphogen transport. To these ends, we generated transgenic flies for $U A S$-GFP, -disp, and the-TM4 mutant. As such, Engrailed (en)-Gal4 recombinant flies expressing CD8-RFP were crossed to these UAS fly lines and examined for alterations in cytoneme biology. The UAS driver, en-gal4, is compartmentally restricted to the posterior portion of the wing disc where the Hh ligand is endogenously produced. The highest level of signaling occurs at the border and tapers off further into the anterior compartment. As such, the anterior/posterior (A/P) border between the two compartments was ideal for examination. Consistent with work presented in this study as well as previous published findings, CD8-RFP positive control cell cytonemes were present at the basolateral surface of the A/P border (Figure 3-24). Expression of $U A S$-dispHA resulted in a similar, if not slightly increased, density of CD8RFP cytonemes at the basolateral A/P border (Figure 3-25). Conversely, expression of the TM4 mutant had a negative effect on the CD8-RFP cytoneme density at the basolateral A/P border (Figure 3-26). With these results, we concluded that the S2 cytoneme system faithfully recapitulated cytoneme biology and that Hh-mediated transport through cytonemes is regulated by Disp. 
Table 3-1. Cytoneme live imaging growth rates and duration.

\begin{tabular}{lcc}
\hline \multicolumn{1}{c}{ Measure } & mCD8-mCherry & Disp-mCherry \\
\hline Avg. growth rate $(\mu \mathrm{m} / \mathrm{min})$ & $6.03(-/+0.61)$ & $6.53(-/+0.87)$ \\
Avg. retraction rate $(\mu \mathrm{m} / \mathrm{min})$ & $7.53(-/+1.01)$ & $3.98(-/+0.67)$ \\
Avg. total duration $(\mathrm{sec})$ & $77.50(-/+7.91)$ & $234.54(-/+33.12)$ \\
\hline
\end{tabular}

Note. Compilation of measurements from live imaging experiments of S2 cells coexpressing cytoplasmic GFP with mCD8-mCherry or Disp-mCherry proteins.

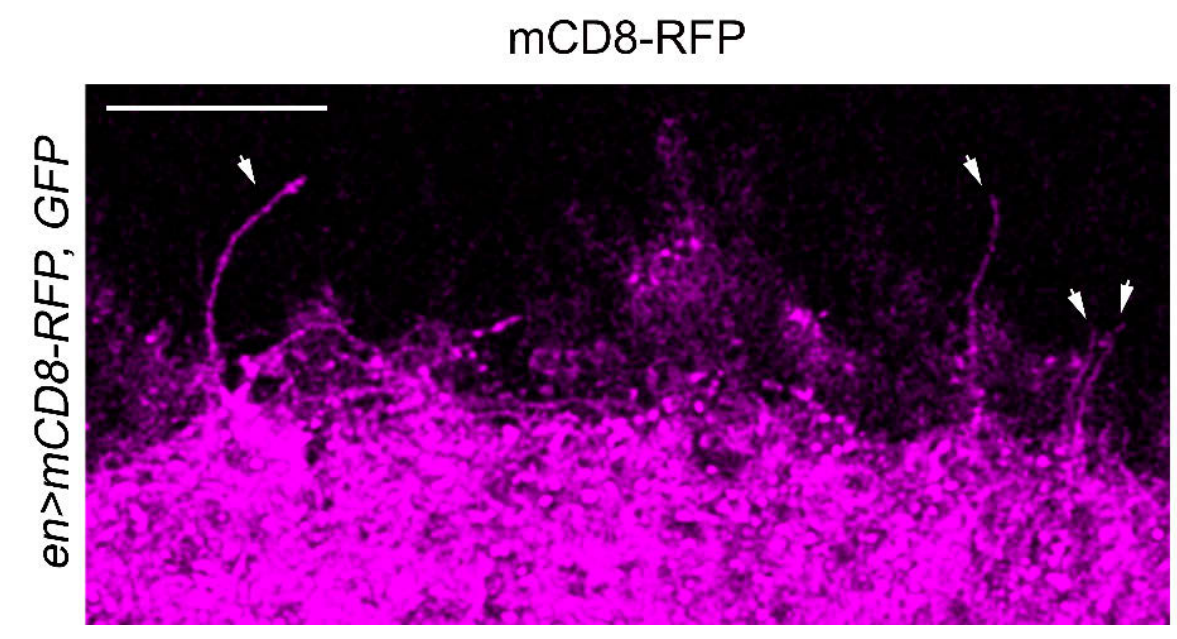

Figure 3-24. Wing discs expressing GFP and mCD8-RFP extend cytonemes into the anterior signaling compartment.

Wing discs from third instar larva were harvested and prepped using MEM-Fix. Cytonemes were present at the anterior/posterior (A/P) border. Representative image is shown $(\mathrm{n}=6)$. Scale bar represents $10 \mu \mathrm{m}$. Images were taken at 40X magnification. 


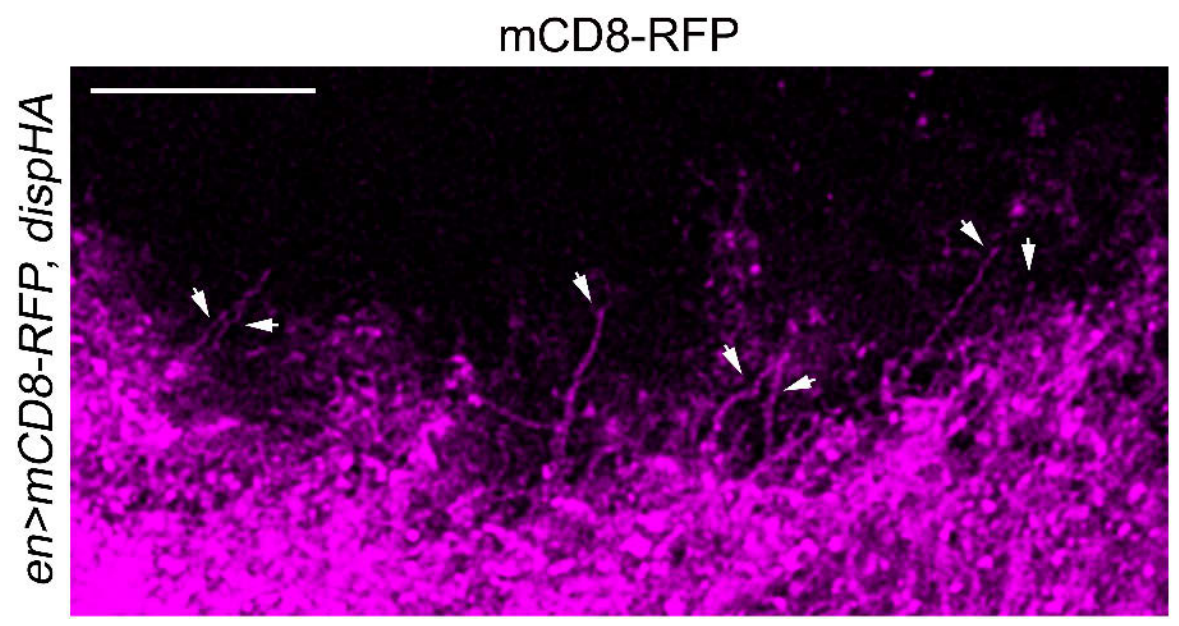

Figure 3-25. Wing discs expressing Disp and mCD8-RFP extend cytonemes into the anterior compartment.

Third instar larval wing discs were harvested and prepped using MEM-Fix. Cytonemes were observed at the A/P border. Representative image shown $(\mathrm{n}=5)$. Scale bar represents $10 \mu \mathrm{m}$. Images were taken at $40 \mathrm{X}$ magnification.

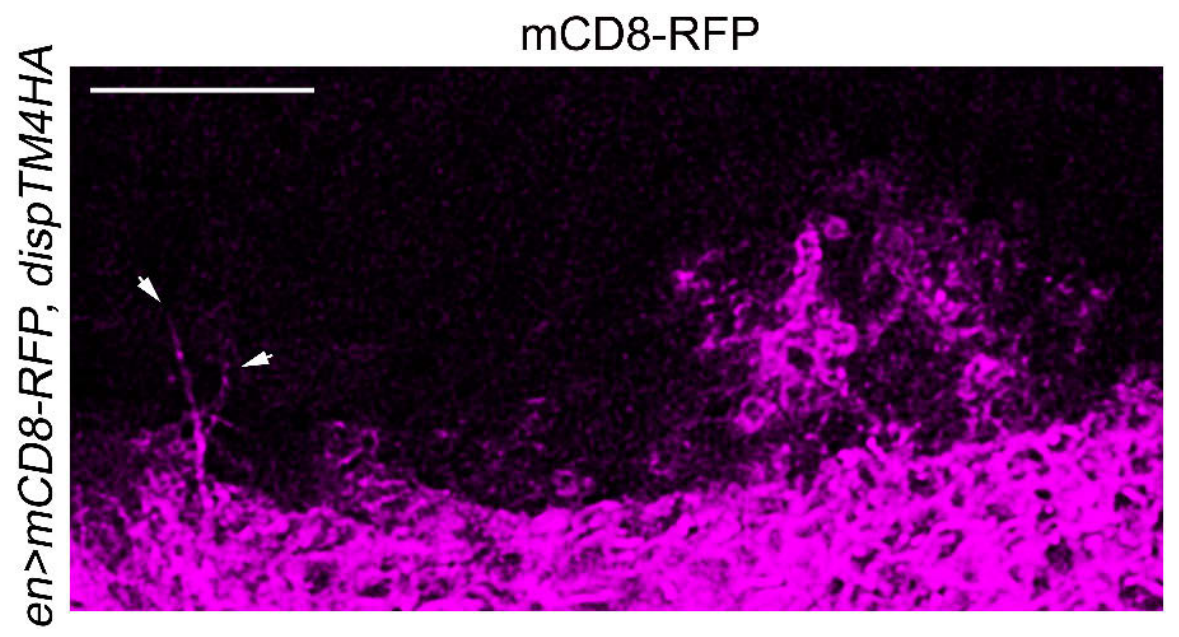

Figure 3-26. Wing discs expressing TM4 and mCD8-RFP sparsely produce cytonemes into the anterior compartment.

Wing discs of third instar larva were processed as discussed. Cytonemes were observed at the A/P border. Representative image shown $(n=6)$. Scale bar represents $10 \mu \mathrm{m}$. Images were taken at $40 \mathrm{X}$ magnification. 


\section{CHAPTER 4. DISP CLEAVAGE REGULATES RELEASE OF THE HEDGEHOG PATHWAY LIGAND}

While much of the previously discussed work interrogates the role played by Disp in cytoneme-mediated Hh transport, the second aim of these studies was to identify novel regulatory mechanisms facilitating Disp function in Hh release. From our studies discussed previously we verified that mutation of the TM4 GXXXD motif disabled the functionality of Disp in vitro. In the Western blot in Figure 3-13, HA antiserum detected two protein bands, one at $\sim 145 \mathrm{kDa}$ and the other at $\sim 110 \mathrm{kDa}$, for both Disp and the TM4 mutant. With the slower migrating, larger molecular weight species matching the predicted molecule weight of Disp, the faster migrating, lower molecular weight band was an unexpected species. Prior publications made no mention of a lower molecular weight protein band in any organism. Furthermore, there are no documented splice variants for the disp transcript and the expression of Disp protein was driven by a synthetic vector containing full length Disp cDNA.

\section{Disp Protein Banding Pattern Correlates with Activity}

In Figure 3-13, a comparison between the $\sim 110 \mathrm{kDa}$ species of Disp and TM4 mutant indicated a decrease of the lower molecular weight species with TM4 mutant expression. This experiment was repeated multiple times with consistent findings with a reduced lower molecular weight species detected with expression of the TM4 mutant. We know that the TM4 mutant is functionally deficient based on the co-culture reporter assay from Figure 3-16 (light grey bars - column 3 v. 4). As such, this indicated that presence of the lower band correlated with functional activity. Based on this correlation, we hypothesized that the $\sim 110 \mathrm{kDa}$ form of Disp was important to for Hh release.

To begin addressing this hypothesis, we sought to determine the identity of the lower molecular weight form of Disp. Initial experiments were first aimed at examining the maturation process of transmembrane proteins. This is a complicated process involving many regulatory steps to ensure proper membrane orientation, folding, and trafficking to their final destinations. One of the first post translational modifications in this process involves the glycosylation of Asparagine residues which primarily helps with protein folding in the Endoplasmic Reticulum (128). The glycosylation process is a fairly well defined sequence in which simple sugars are often modified into more complex forms as membrane and secreted proteins move along the secretory route. With membrane proteins, simple sugars often indicate ER localization, while the more complex are associated with post-ER compartments like the Golgi or further along in the secretory pathway.

As an initial hypothesis, we proposed that the lower form was an underglycosylated form of the Disp protein. This under-glycosylated form would indicate the ER resident pool of Disp before more complex glycosylation was added to assist in proper folding of the protein. We speculated that as sugars were added the protein 
migration through SDS-page gels would slow to yield the higher $\sim 145 \mathrm{kDa}$ molecular weight protein species.

To test this, enzymes that differentially cleave sugar species were utilized. When cell lysates from Disp expressing cells were treated with the Endoglycosidase H (Endo$\mathrm{H})$ enzyme, which targets only simple sugars added in the ER, both upper and lower bands shifted slightly with the upper species giving rise to a faster migrating band around $\sim 125 \mathrm{kDa}$ (Figure 4-1, lane 1 v. 2). The production of this band below the higher molecular weight protein form suggested the upper band contained an ER resident pool $(116,128)$. Treatment with the Peptide:N-Glycosidase F (PNGase F) enzyme, which targets all sugar modifications, further collapsed the lower species as well as reduced the upper band to a similar level of the Endo-H resistant species at $\sim 125 \mathrm{kDa}$ (Figure 4-1, lane 3). Evidenced by a pronounced shift with PNGase F, the lower band harbors complex glycosylations indicating the lower form is most likely a post-ER protein species (Figure 4-1, lane 3). Taken together, the lower species band seen is not an underglycosylated form. While there is a shift in the lower band, it has been previously described that mature Drosophila protein glycosylations can contain a form of sugar called paucimannosidic, which can be clipped by the Endo-H enzyme, that do not form in mammals (116).

With glycosylation ruled out and the indication that the lower band is a mature protein form, we wanted to rule out that the lower form resulted from nonspecific proteolysis during cell lysis preparation. To do so, DispHA-expressing cells were lysed using boiling SDS sample buffer. The combination of SDS and heat effectively denatures the majority of proteins ablating their function as lysis is performed. Similar to previous lysis methods, SDS lysis isolated both protein species (Figure 4-2). This indicated that the lower species was produced before cell lysis.

Notably, when detecting the endogenous Disp protein it was observed that the lower band was relatively similar in abundance to the upper form (Figure 4-3, dark: lane 1, $\sim 140 \mathrm{kDa}$ species compared to $\sim 110 \mathrm{kDa}$ species). Conversely, exogenous expression resulted in the larger molecular weight band being the predominant species detected (Figure 4-3, light: lane 3, upper v. lower species). Based on this consistent pattern with over expression, we postulated that this was due to a mechanism similar to an enzyme being the limiting reagent in a reaction. Moreover, the substrate of an enzymatic reaction would build up when continually added with no additional enzyme provided. As such, we hypothesized that the lower species was a physiological cleavage product of the higher molecular weight band.

\section{Estimating the Cleavage Site of Drosophila Dispatched}

To investigate whether this was a cleavage product we began by estimating where in the protein cleavage might be occurring. Since the HA epitope specific antibody and the antibody directed against the fourth large extracellular loop detected both protein bands that eliminated the majority of the amino acids towards the $\mathrm{C}$-terminus. With that in mind and by using estimated molecular weights from the deglycosylated products, the 


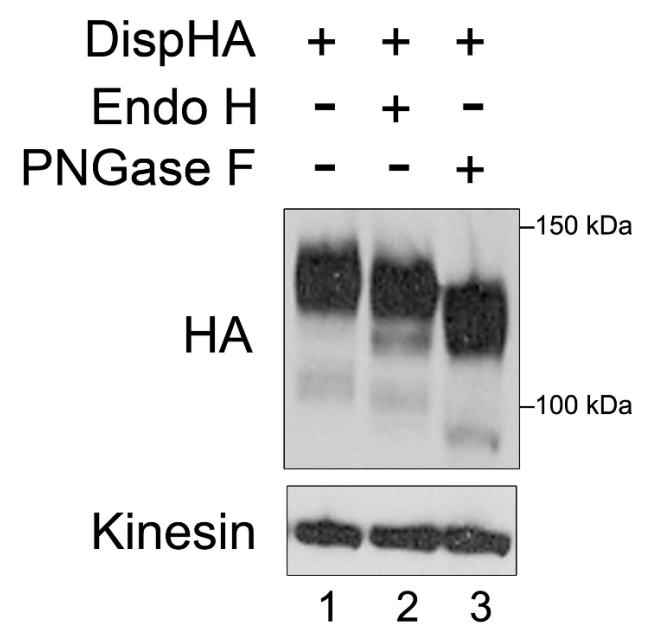

Figure 4-1. Glycosylation analysis of Disp reveals mature glycosylation on lower molecular weight species.

$\mathrm{Cl} 8$ membrane cell lysates were treated with glycosylation removing enzymes EndoH and PNGase-F. Removal of simple sugars with EndoH cause a slight downshift in both bands with a distinct band resolving from the upper species. Treatment with PNGase-F collapsed both species further with the larger species equally the EndoH resolved band. Representative Western is shown of probing for the HA epitope tag on Disp and Kinesin serves as the loading control.

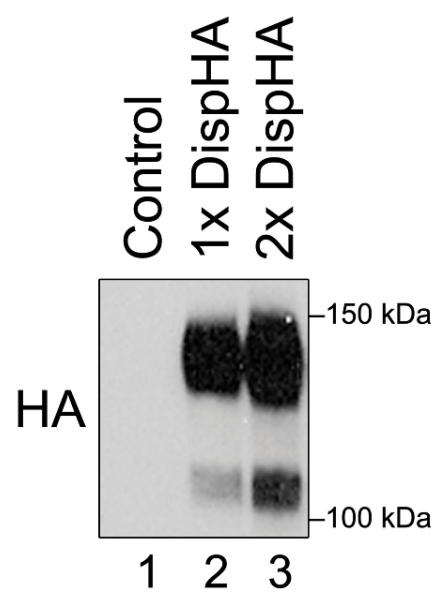

Figure 4-2. SDS lysis of Cl8 cells expressing Disp mimic banding pattern.

C18 cells transfected with Disp were lysed using 4X SDS sample buffer. Increasing amounts of lysate were loaded on the gel before Western blotting to reveal presence of the lower molecular weight species. Representative Western shows HA antibody detection of Disp. 


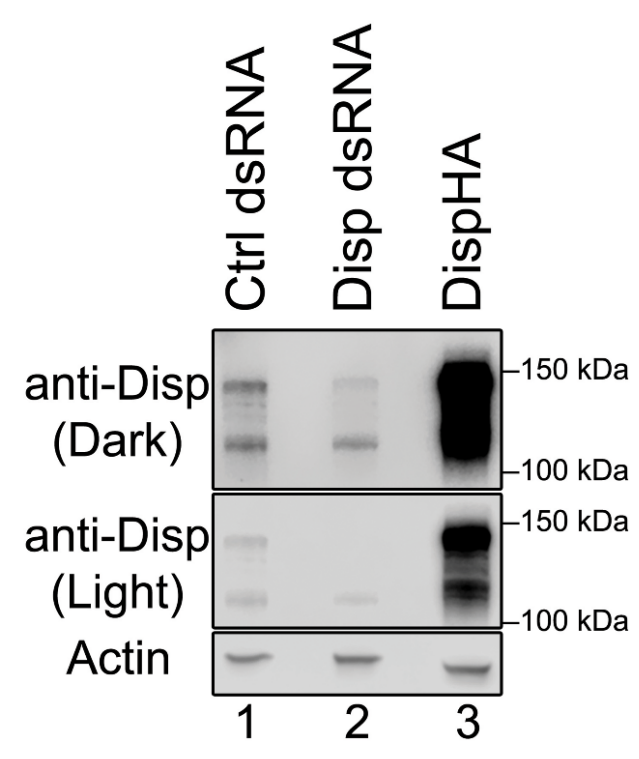

Figure 4-3. Endogenous Disp banding is similar to exogenous protein banding. Membrane lysates isolated from Cl8 cells treated with control or disp 3'UTR specific dsRNA or Disp expressing cl8 cells reveal similar banding pattern. The lower endogenous band is higher in abundance while the exogenous Disp bands are approximately equal. Western is representative of multiple experiments where Disp was detected using the Disp antibody and Kinesin serves as the loading control. 
site of cleavage was predicted to reside within the first extracellular loop (Figure 4-4, black triangle). To confirm this, a V5-epitope tag was inserted after V108 within the first loop closer to the N-terminus of the Drosophila DispHA protein (Figure 4-4, yellow V5 box). By western, probing with a V5 antibody produced a single upper band as was seen with the endogenous and exogenous proteins but lacked the lower $\sim 110 \mathrm{kDa}$ species (Figure 4-5, V5 upper). Consistent with the cleavage hypothesis, an approximately $30 \mathrm{kDa}$ band was detected corresponding to the expected size of a cleaved N-terminal fragment (Figure 4-5, V5 lower). Notably, insertion of the V5 tag within the first extracellular loop did not affect Disp function indicated by the depletion of intracellular lysate detected by Western blot (Figure 4-5, Hh blot: lane 6 compared to lane 8). With these results taken together with the detection of both bands by two independent antibodies we were confident that the higher molecular weight form was being cleaved to produce the lower molecular weight species.

Before proceeding further, we wanted to determine if the production of the lower species was a conserved event. Since TM4 mutant was inefficiently cleaved and deficient in releasing $\mathrm{Hh}$ based on our functional assays, cleavage could be important for $\mathrm{Hh}$ release. If correct, the same cleavage event should be present in Disp from other organisms.

\section{Testing Conservation of the Disp Lower Species Production}

To survey the conservation of this event, an insect expression construct was generated for HA-epitope tagged mouse Disp (mDisp) and subsequently tested by Western blot for the presence of a lower species using HA antiserum. In Figure 4-6, a similar banding pattern was observed when over expressing mDisp protein in cl8 cells albeit at higher molecular weights $(\sim 175 \mathrm{kDa}$ and $\sim 145 \mathrm{kDa})$. The mDisp protein is estimated at $\sim 170 \mathrm{kDa}$ based on amino acid composition. If cleavage occurred in a similar area, the resulting product could be within the size range of the lower molecular weight species based on topological prediction software (SOSUI). With the production of the lower molecular weight species of mDisp protein in Drosophila cells and the similarity in predicted region of cleavage this suggests cleavage is likely a conserved event. With this possibility of a conserved cleavage, we sought to identify the $\mathrm{N}$-terminus of the lower band by Edman degradation, which would indicate the exact amino acid position of cleavage.

\section{Identifying the N-Terminus of the Lower Molecular Weight Disp}

Fly Disp was exogenously expressed in $\mathrm{Cl} 8$ cells before the membrane fraction of the cells were biochemically isolated. Disp proteins were subsequently biochemically purified and enriched by immunoprecipitation. The purified protein was then run on an SDS-PAGE gel and transferred to nitrocellulose membranes. Once transferred, the purified proteins were stained with coomassie blue and the corresponding lower band was excised and sent for Edman degradation analysis. Results from the fly protein were largely uninformative, but did reveal the presence of a proline as either a first or a second 


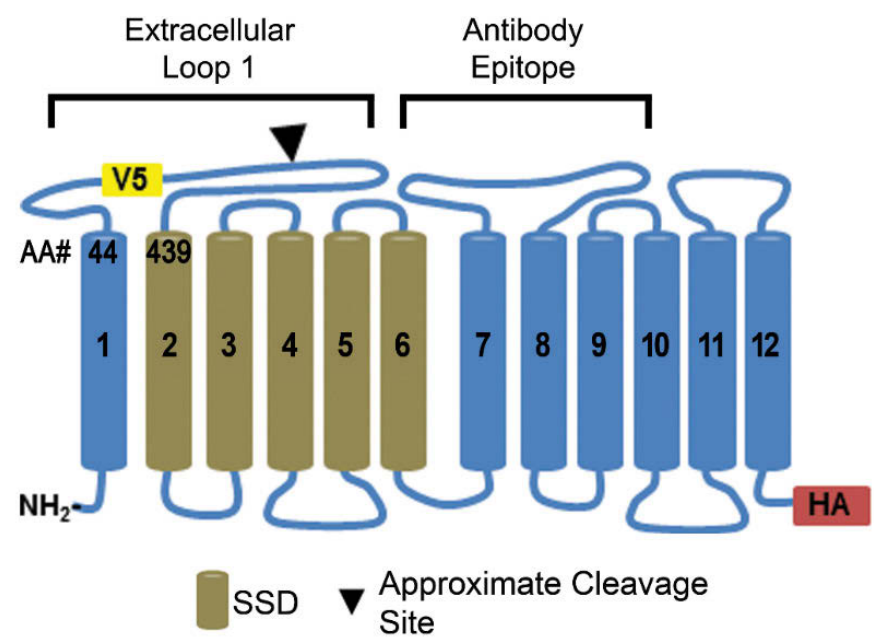

Figure 4-4. Estimation of cleavage site: Diagram.

Cartoon diagram shows the predicted arrangement of transmembrane domains of the Drosophila Disp protein (SOSUI Prediction). C-terminal HA tag, internal V5 tag, Disp antibody epitope region, estimated cleavage site, and the position of the RND motifs are denoted.

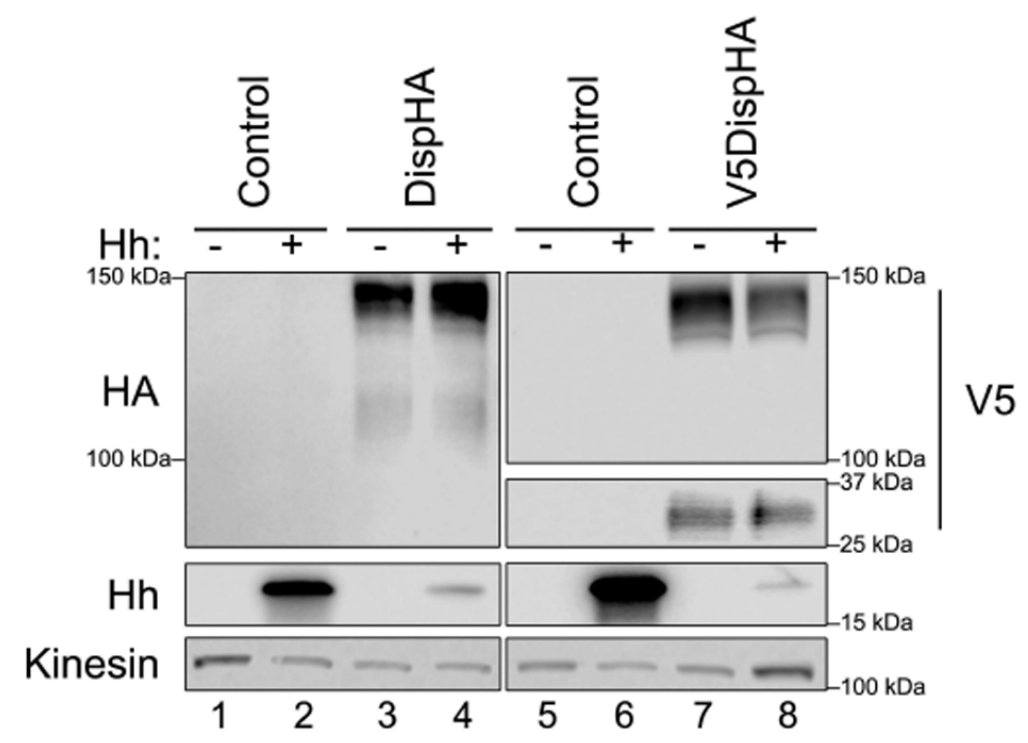

Figure 4-5. Hh release assay with double-tagged Disp reveals $30 \mathrm{kDa}$ fragment. Membrane lysates from $\mathrm{Cl} 8$ cells expressing the single or double-tagged Disp alone or with Hh were isolated and subjected to Western Blotting. Probing with V5 epitope antiserum revealed the lack of the lower molecular weight band detected with Disp or HA epitope antiserum and additionally the presence of an $\sim 30 \mathrm{kDa}$ fragment corresponding to the approximate molecular weight of a cleaved product. The single and double tagged versions of Disp are both functional in depleting Hh from cell lysates. This is a representative Western blot of multiple experiments performed by Daniel Stewart. 


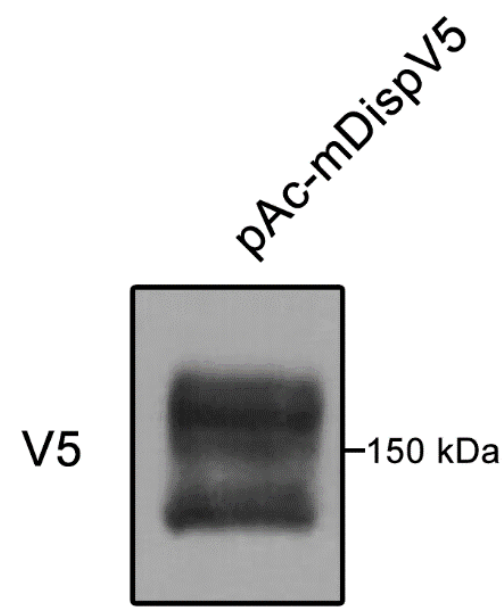

Figure 4-6. Cl8 cells expressing a C-terminal V5-tagged mDisp produce similar banding pattern.

Membrane lysates from c18 cells expressing a carboxy terminal tagged V5 mDisp construct were probed with V5 antiserum by Western blot. A similar banding pattern was observed for mDisp protein where two distinct molecular weight species were detected $(\sim 175 \mathrm{kDa}$ and $\sim 140 \mathrm{kDa})$. 
amino terminal residue. In a collaborative effort with Dr. Daniel Stewart, the mouse Disp (mDisp) Edman degradation analysis was performed with HEK-293T cell produced Disp protein and was successful. The newly formed $\mathrm{N}$-terminus by cleavage was identified as EVDWNF. Sequence analysis of the mDisp protein revealed the presence of a Furin proprotein convertase family dibasic cleavage motif (characterized as $[\mathrm{R} / \mathrm{K}]-[\mathrm{X}]^{(0,2,4,6)}$ $[\mathrm{R} / \mathrm{K}]$ with cleavage occurring after the second Arginine) juxtaposed to the $\mathrm{N}$-terminal sequence of the lower form (Figure 4-7, blue marks motif with green representing cleavage site and (129-131)). The fly protein shared little sequence conservation to the mouse Furin family cleavage site save the presence of the dibasic Arginine group (Figure 4-7). Consistent with the limited fly Disp Edman degradation data there was a proline at the second position from the dibasic arginine group (Figure 4-7). Based on these findings, we hypothesized that the protease responsible for Disp cleavage belonged to the Furin family of proprotein convertases.

The Furin family is a conserved serine protease family present in a variety of organisms from Yeast to Humans (131). These proteases function as proprotein convertases, which convert typically inactive proteins (referred to as proproteins) into their functional protein form (130-135). A large number of substrates for the Furin family are cleaved after $[\mathrm{R}]-[\mathrm{R}]$ or $[\mathrm{K}]-[\mathrm{R}]$ sites while a minority can be cleaved after a $[\mathrm{H}]-[\mathrm{R}]$ stretch (136). Following the dibasic cleavage site, typically a polar amino acid with a preference for asparagine or glutamic acid is present followed by an aliphatic amino acid with isoleucine, valine, or leucine preferred (135). In the fly protein, the amino acid sequence of $[\mathrm{R}]-[\mathrm{R}]-[\mathrm{Q}]-[\mathrm{P}]$ is present which fits the characteristics of a typical Furin family cleavage site containing a dibasic amino acid group $([R]-[R])$ followed by a polar amino acid ([Q]) and then an aliphatic ([P]). In this context, it is possible that the large molecular weight species of Disp is a proprotein which is cleaved to form the lower molecular weight species as the functional form.

\section{Mutational and Pharmacological Inhibition to Block Disp Cleavage}

If Disp is a substrate for a Furin family member, disruption of the cleavage site or chemical inhibition of the Furin family should inhibit production of the lower species. To test this, the Arginine residues were mutated to Alanine to disrupt cleavage. Unfortunately, there was an enhancement of cleavage when the double Arginines were mutated, referred to as DispCS, compared to wild-type (Figure 4-8). With previous reports of possible compensation by additional Furin motifs in Notch, multiple mutations were made throughout the region targeting basic amino acids (134). Consistent with this, cleavage was only eliminated once the entire region containing theoretical compensatory sites and identified site were removed in the fly cleavage site deletion mutant (Disp $\Delta \mathrm{CS}$ ) (Figure 4-9, lower band species: lane 1 compared to 4). To ensure that disruption of cleavage by deletion of the cleavage site region allowed for proper membrane protein trafficking, the glycosylation status of the Disp $\Delta$ CS mutant was assessed. Treatment with Endo $\mathrm{H}$ and PNGase F yielded identical Disp higher molecular weight products of the Disp $\Delta$ CS compared to wild-type (Figure 4-9, upper band: lane 2 v. 5 and 3 v. 6). This data is supportive that the fly Disp protein is cleaved by a Furin family proprotein convertase and that the Disp $\Delta \mathrm{CS}$ mutant likely matures similar to Disp. 


\section{dDisp 225 TLPTDGWADMH ....RRQ . . . . PIEGFFCD zDisp 247 SHQDDRWSKDHYDRKKRQAEWDFSKDSFFCD mDisp 263 SHRDDRWSDDHHERERREVDWNFQKDSFFCD hDisp 264 SHRDDRWSDDHYEREKREVDWNFHKDSGGCD}

Figure 4-7. Cleavage site sequence diagram.

A protein sequence alignment between multiple species of Disp protein reveals conservation of the predicted Furin cleavage motif (denoted by blue line). Cleavage position is marked by a green verticle line.

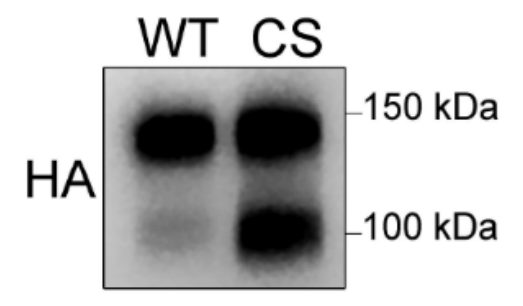

Figure 4-8. Mutation of fly Edman site fails to inhibit production of cleavage product.

Cl8 cells expressing Disp mutant proteins were lysed and the membrane fractions were isolated. Mutation of the Arginine residues at 236 and 237 together failed to inhibit cleavage of the protein based on detection by Western blot. HA epitope antiserum was used to detect the Disp mutant construct. 


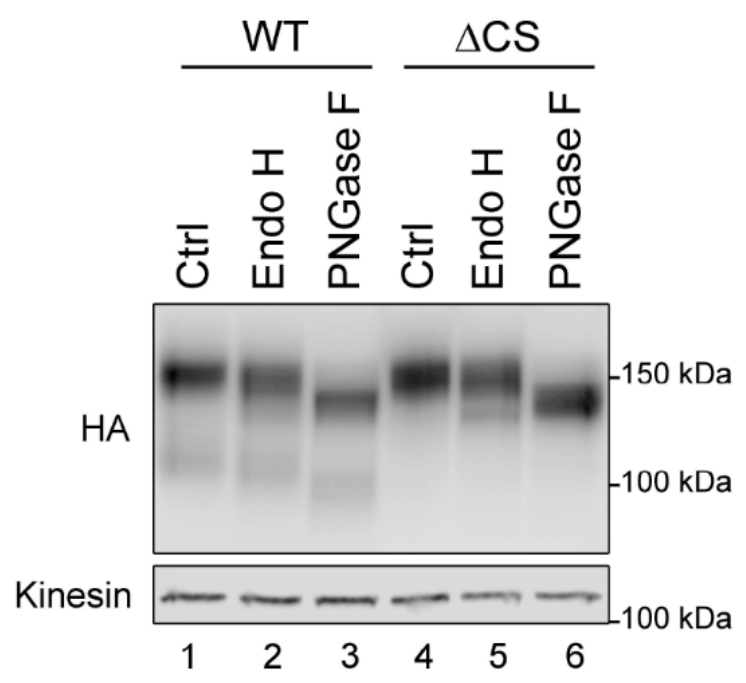

Figure 4-9. Targeting an upstream region from predicted site ablates Disp cleavage.

Deletion of the 209-238 AA region blocked cleavage completely. Deletion of the cleavage region does not impair post-ER trafficking. Disp proteins were detected using HA epitope antiserum and Kinesin serves as the loading control for this representative Western blot. 
As a second approach to support Disp cleavage by the Furin family, previously established pharmacological inhibitors of Furin family members were tested (132). The chemical inhibitors of the Furin family proteolytic function most likely serve as pseudosubstrates for the Furin active site (135). C18 cells stably expressing the double-tagged version of Disp were treated with Furin Inhibitor I (chloromethylketone) at increasing concentrations from $6.25 \mu \mathrm{m}$ to $50 \mu \mathrm{m}$. The highest dosage was reported as effective in inhibiting other cleavage events perpetrated by the Furin family in Drosophila (132). In Figure 4-10, while overall levels of Disp were reduced in treated samples the densitometry ratio between the two species was slightly elevated compared to DMSO vehicle control. This ratio increase indicates that the amount of either the upper band is increasing, the amount of the lower band is decreasing, or a combination of the two suggesting that cleavage is being inhibited.

These results taken together support the hypothesis that the Furin proprotein convertases is responsible for cleavage of Disp. To interrogate the functional importance of Disp cleavage, efforts were focused on determining what functional effect the lack of cleavage caused.

\section{In Vivo Analysis of the $\Delta$ CS Mutant}

To determine whether cleavage deficient Disp would impact function in vivo, transgenic flies for the Disp $\Delta$ CS mutant were produced and tested. Dr. Suresh Marada performed the crosses for expression of Disp and the Disp $\Delta$ CS mutant using the wing specific driver apterous (ap)-Gal4. Wings from the ap-Gal4>dispWT animals had a pronounced blistering of the adult wing, typical of overactive Hh signaling in the wing

(Figure 4-11). Conversely, Disp $\Delta \mathrm{CS}$ expression largely resulted in normal wings with a small occurrence of a curved wing (shown in Figure 4-11). This result suggested that Disp expression had an additive effect on the amount of Hh signaling within the wing imaginal disc. The Disp $\Delta$ CS mutant was unable to do so, suggesting that the protein was deficient in release of the Hh ligand for additional pathway activation. Notably, Disp $\Delta C S$ failed to inhibit the endogenous protein evidenced by the relatively normal adult wing suggesting that the lack of cleavage likely altered Disp function in a non-dominant manner perhaps through a mislocalization of the mutant protein.

To investigate this possibility, we examined the localization of the Disp $\Delta C S$ mutant in polarized cells in vivo. As mentioned previously, the path Hh takes in polarized wing imaginal disc cells before release involves internalization from the apical surface followed by relocalization back apically or to the basolateral surface $(54,55)$. Knowing that Furin and Furin2 in Drosophila are expressed in the wing imaginal disc, we hypothesized that Disp cleavage by Furin may influence the trafficking process for $\mathrm{Hh}$ release (133). While the wing imaginal disc is commonly used to study morphogen transport, the Drosophila Ovary is often used to study polarization and the trafficking of proteins (137). Furthermore, Furin and Furin2 are also expressed in the ovary (132). As such, to test the hypothesis that Furin-mediated cleavage could influence trafficking, Disp transgenes were driven by a Drosophila ovary follicle cell driver: c204-Gal4. The Drosophila follicle cells within the ovary are arranged in a single polarized layer of 


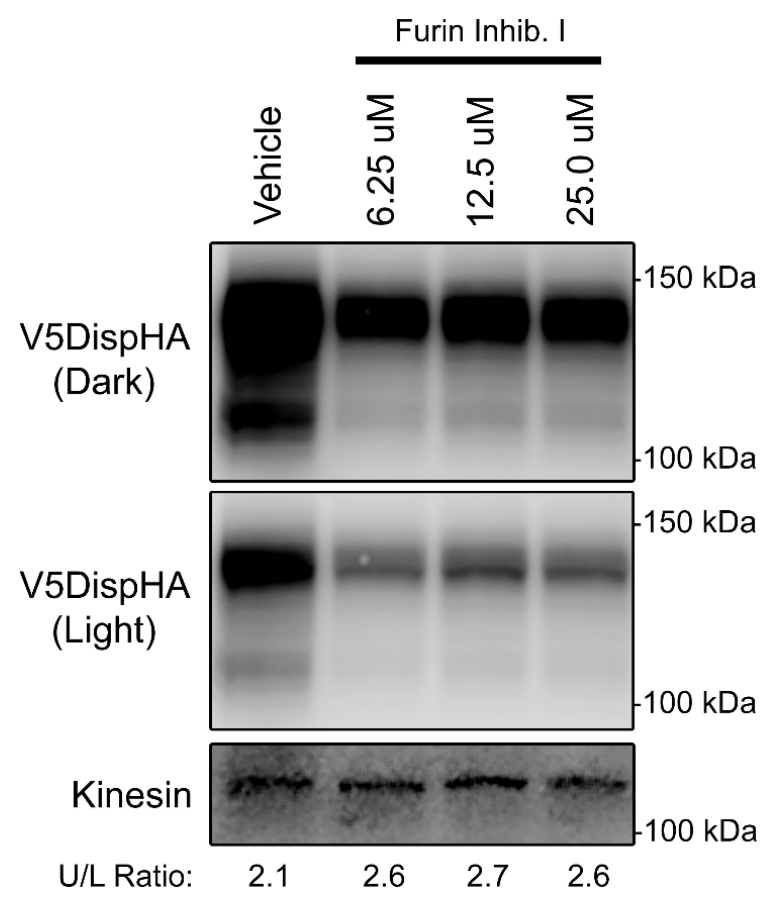

Figure 4-10. Furin inhibitor I retards production of lower Disp molecular weight species.

Membrane fractions from Cl8 cells expressing Disp treated with vehicle or the polyArginine, Furin Inhibitor II compound were examined by Western Blot. Treatment with the compound resulted in a decrease in overall protein levels. The ratio between upper and lower molecular weight species is slightly altered in inhibitor treated samples based on densitometry. Representative Western blot using HA epitope antiserum is shown. 


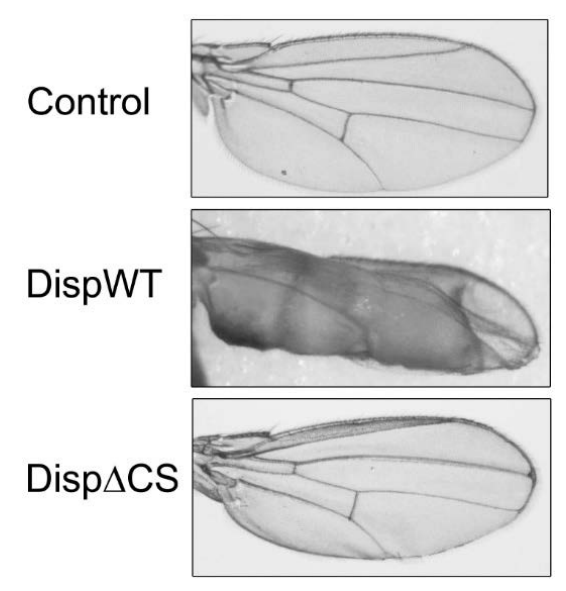

Figure 4-11. Expression of Disp $\Delta C S$ in the wing fails to induce blistering. Wings from adult flies expressing either wild-type or Disp $\Delta$ CS under the control of apterous-Gal4 were collected and examined. Disp expressing flies had a severely blistered wing phenotype typical of overactive Hh signaling. Conversely, Disp $\Delta \mathrm{CS}$ mutant expressing fly wings were largely indistinguishable from control wings with a few wings exhibiting a slight curling. Fly crosses were performed by Suresh Marada. 
columnar epithelium with the apical surface surrounding the egg containing lumen. The expression of Disp in these cells mimicked localization observed previously in the wing imaginal disc (54). A minor portion of the Disp protein (green) localized to the apical surface, marked by F-Actin (red), while the majority concentrated to the basolateral surface of follicle cells as indicated by V5 and HA-epitope staining (Figure 4-12, left). Detection of the N-terminal V5 epitope tag of the V5DispHA protein revealed a portion of apical puncta lacking HA staining. This suggests the smaller N-terminal cleaved species separates from the C-terminal portion of the Disp protein. In contrast to the organization seen with the wild-type protein, Disp $\Delta$ CS was largely distributed at random throughout the cell with no concentration in one region compared to another (Figure 4-12, right). These data are consistent with the hypothesis that Furin family mediated cleavage of Disp results in proper membrane localization, or recycling, for Hh release.

In conclusion, the discussed results evidence the novel finding of an essential regulatory mechanism governing Disp function. While the mechanism remains to be clarified, these studies have identified the first conserved regulatory protein partner modulating the activity of the only conserved protein dedicated to the trafficking and release of the required developmental morphogen Hedgehog. 

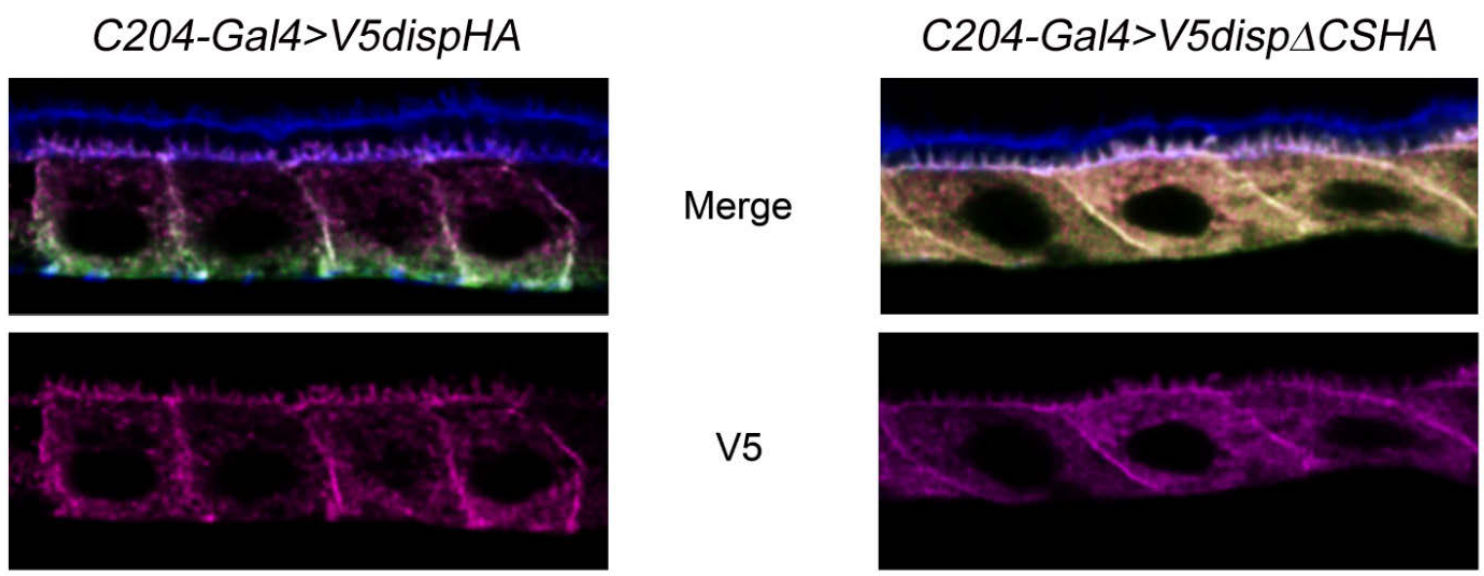

V5
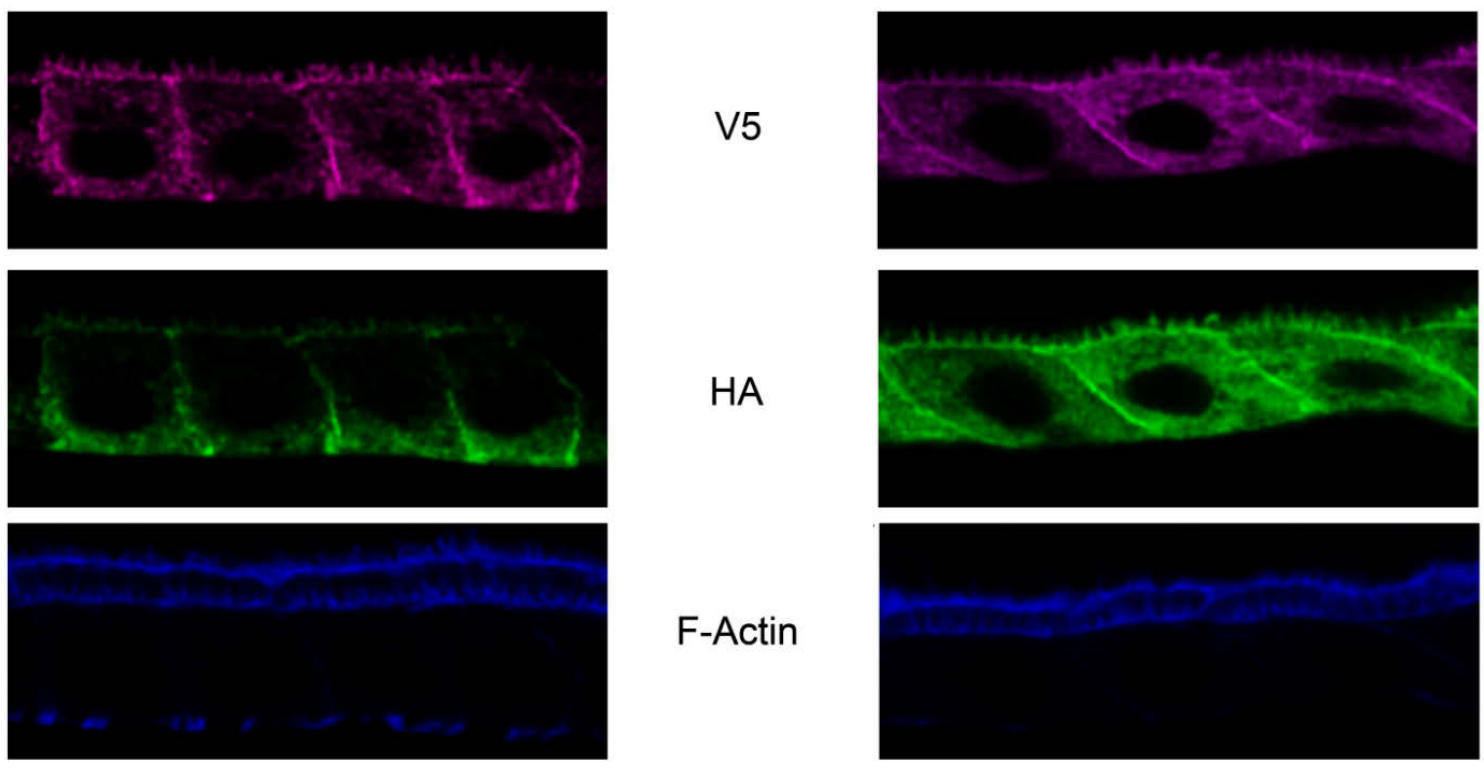

F-Actin

Figure 4-12. Polarized follicle cells in the Drosophila ovary reveal Disp $\Delta$ CS trafficking defect.

Using a follicle cell specific driver within the Drosophila ovary, transgenes for control, Disp, and Disp $\Delta$ CS we expressed and analyzed. The HA (green) signal of V5DispHA localized primarily to the basolateral surface of the follicle cells with a small population present near the apical surface. Distribution of the HA (green) signal for V5Disp $\Delta$ CSHA was markedly different in comparison with the majority of the protein dispersed across the cell. F-Actin serves as an apical surface marker. Drosophila ovaries were prepared and stained by Suresh Marada. 


\section{CHAPTER 5. DISCUSSION}

In this work, we performed traditional confocal and super resolution imaging on cytonemes from cultured Drosophila S2 cells using a modified electron microscopy fixative we named MEM-fix. Through the use of MEM-fix the thin, fragile cytonemes from several cell types were maintained for study using traditional immunofluorescent techniques. This allowed the modification of proteins through standard cell biology techniques to interrogate the regulatory and functional mechanisms of cytonememediated Hh delivery. By these efforts we identified a requirement of Disp in this direct form of delivery as well as a novel cytoneme-stabilizing functionality which likely facilitates the transport of $\mathrm{Hh}$ to receiving cells at large distances. The results from our in vitro system were indicative of cytoneme biology in transgenic Drosophila supporting that our analysis of cultured cells could serve as a reliable system for mechanistically interrogating cytoneme regulation and function in morphogen transport.

In a somewhat fortuitous event, these studies into regulatory and functional mechanisms facilitating cytoneme-mediated Hh transport identified a novel regulation in which the Disp protein is proteolytically cleaved to facilitate release. We identified the cleavage site and interrogated the protease family responsible for the cleavage. Through mutational and pharmacological inhibition of cleavage, we provide evidence that the Furin family of proprotein convertases is responsible. Analysis in two Drosophila tissues revealed that cleavage of Disp by the Furin family is important for Hh release and likely controls the proper localization of the Disp protein to the apical and basolateral surfaces in polarized cells.

Described as un-fixable since their discovery in 1999, cytonemes have remained a poorly studied mechanism of morphogen transport. As such, very few papers exist examining their function in the transport of the Hh morphogen. While Disp and Hh were documented to localize to cytonemes, no modulation of cytoneme biology was attributed to either protein. Within these studies we provide evidence that the essential regulator of $\mathrm{Hh}$ release, Dispatched, stabilizes cytonemes induced by the cholesterol-modified $\mathrm{Hh}$ ligand. This is the first study to demonstrate that these proteins can modulate cytoneme behavior. However, these results contradict previous findings in the wing imaginal disc where exogenous Hh expression failed to influence cytoneme biology by increasing cytoneme stabilization. A number of possible explanations exist based on the data presented in this study. This difference could be due to the difference in Disp protein present in imaginal wing disc cells compared to the S2 cells used in these studies. Our finding that knockdown of endogenous Disp ablated the ability of Hh to induce cytoneme occurrence supports this possibility in that Disp functions as the limiting component in Hh-induced cytoneme transport. A second explanation could be that the cleavage status of Disp in wing imaginal disc cells could influence the ability to produce a cytoneme. The reduced level of cleavage in the TM4 mutant which acted in a dominant manner in the cytoneme occurrence assay gives evidence to this possibility. Regardless, Disp is likely the essential component at the center of this discrepancy. 
The mechanism Disp employs to influence cytoneme biology is still unclear. Although, data obtained from live imaging analysis of GFP or Disp expressing cells suggests Disp facilitates a stabilization of outgrown cytonemes. The retraction rates of Disp-expressing cells were almost two times slower likely increasing the overall duration of outgrown cytonemes. In a previous study another Hh pathway component, Interference hedgehog (Ihog), was able to stabilize outgrown cytonemes of the wing disc and has been known to be important for $\mathrm{Hh}$ transport throughout the tissue $(54,96)$. As such, we speculate that this stabilization might occur through the interaction between Disp and Ihog with direct or indirect modulation to actin polymerization machinery maintaining outstretched extensions.

Evidence supporting additional protein partners, in addition to Ihog, facilitating Disp induced cytoneme occurrence comes from our cytoneme occurrence studies testing the effects of density. We found that Disp and Hh required a higher cell density in order to induce cytoneme occurrence. This could indicate cooperativity between cytoneme producing cells and the surrounding cells either by providing a short lived, distance limited signal to induce cytoneme outgrowth or by acting as a scaffold once cytonemes encounter the cell surface of neighbors. The data presented further suggest that production of this additional factor was independent of Hh signaling. Evidence supporting these possibilities include the ability of FGF to promote cytoneme directionality and the inability of cytonemes to grow past cells lacking heparin sulfate proteoglycans $(54,96,105,109)$. While FGF has been shown to control directionality of Hh specific cytonemes it is unclear whether the molecule promotes occurrence. Future studies into this area are needed to determine this attribute of FGF. The knockdown of enzymes responsible for HSPGs blocking cytoneme progression through the wing imaginal disc is evidence which supports outgrown cytonemes are being stabilized on cellular scaffolding of neighboring cells. Furthermore, Ihog has been shown to interact with HSPGs on the membranes of surrounding cells supporting the possibility that Disp and Ihog would cooperate to increase cytoneme duration. Investigations into the link between additional protein factors, like Ihog, facilitating cytoneme stabilization through a variety of possibilities would further expand our limited knowledge on the mechanisms controlling cytoneme-mediated Hh transport.

Along this line of reasoning, our studies identifying Furin as a Disp regulatory protein raises a significant amount of questions. While Furin proprotein convertases have been implicated in regulating the BMP and Notch signaling pathways, no apparent link to Hedgehog signaling is reported. As such, our studies provide the first evidence that a Furin family member can influence $\mathrm{Hh}$ signaling at the level of $\mathrm{Hh}$ release by cleaving Disp. The evidence from the wings of transgenic disp flies suggest that cleavage of Disp by the Furin family activates Disp to release Hh. If true, loss of the Furin responsible for cleavage should have significant effects on development with Hh specific phenotypes apparent. Consistent with this, knockout mice of Furin family members, Furin and PACE4, in vertebrates are embryonic lethal with significant craniofacial phenotypes (131).

While the recycling of Hh and Disp from the apical surface was identified as an integral portion of proper Hh release in previous reports, no apparent mechanism was 
identified of this Disp-dependent process. However, we now know that cleavage and activation of the protein is important in the proper trafficking of Disp to these surfaces. In future studies, understanding the consequence of cleavage on cytoneme occurrence could be informative in this process. Cytonemes within the wing imaginal disc are primarily projected from the basolateral surface $(54,96,114)$. Failure of the Disp $\Delta$ CS to concentrate to this area leads to the speculation that Disp $\Delta \mathrm{CS}$ will likely be unable to facilitate cytoneme stabilization. This proposal is supported by the localization of the Furin proprotein convertase to the basolateral surface in Madin-Darby Canine Kidney Epithelial (MDCK) cells, which is consistent with reports of Canine Disp localization in these same cells $(72,138)$. However, it is unknown whether this particular cell line can produce cytonemes. It is our hope that through the use of MEM-fix and the information presented here these unknowns can be clarified. 


\section{LIST OF REFERENCES}

1. Ingham PW, McMahon AP. Hedgehog signaling in animal development: paradigms and principles. Genes \& development. 2001;15(23):3059-87. Epub 2001/12/04. doi: 10.1101/gad.938601. PubMed PMID: 11731473.

2. Taipale J, Beachy PA. The Hedgehog and Wnt signalling pathways in cancer. Nature. 2001;411(6835):349-54. Epub 2001/05/18. doi: 10.1038/35077219. PubMed PMID: 11357142.

3. Lum L, Beachy PA. The Hedgehog response network: sensors, switches, and routers. Science. 2004;304(5678):1755-9. Epub 2004/06/19. doi:

10.1126/science.1098020. PubMed PMID: 15205520.

4. Chiang C, Litingtung Y, Harris MP, Simandl BK, Li Y, Beachy PA, Fallon JF. Manifestation of the limb prepattern: limb development in the absence of sonic hedgehog function. Developmental biology. 2001;236(2):421-35. Epub 2001/07/31. doi: 10.1006/dbio.2001.0346. PubMed PMID: 11476582.

5. Ekker SC, Ungar AR, Greenstein P, von Kessler DP, Porter JA, Moon RT, Beachy PA. Patterning activities of vertebrate hedgehog proteins in the developing eye and brain. Current biology. 1995;5(8):944-55. Epub 1995/08/01. PubMed PMID: 7583153.

6. Farzan SF, Singh S, Schilling NS, Robbins DJ. The adventures of sonic hedgehog in development and repair. III. Hedgehog processing and biological activity. American journal of physiology Gastrointestinal and liver physiology. 2008;294(4):G844-9. Epub 2008/02/02. doi: 10.1152/ajpgi.00564.2007. PubMed PMID: 18239057; PMCID: 2694571.

7. Therond PP. Release and transportation of Hedgehog molecules. Current opinion in cell biology. 2012;24(2):173-80. Epub 2012/03/01. doi: 10.1016/j.ceb.2012.02.001. PubMed PMID: 22366329.

8. Jiang J, Hui CC. Hedgehog signaling in development and cancer. Developmental cell. 2008;15(6):801-12. doi: 10.1016/j.devcel.2008.11.010. PubMed PMID: 19081070 .

9. Nusslein-Volhard C, Wieschaus E. Mutations affecting segment number and polarity in Drosophila. Nature. 1980;287(5785):795-801. Epub 1980/10/30. PubMed PMID: 6776413.

10. Varjosalo M, Taipale J. Hedgehog: functions and mechanisms. Genes \& development. 2008;22(18):2454-72. doi: 10.1101/gad.1693608. PubMed PMID: 18794343. 
11. Ingham PW, Nakano Y, Seger C. Mechanisms and functions of Hedgehog signalling across the metazoa. Nature reviews genetics. 2011;12(6):393-406. Epub 2011/04/20. doi: 10.1038/nrg2984. PubMed PMID: 21502959.

12. Morata G. How Drosophila appendages develop. Nature reviews molecular cell biology. 2001;2(2):89-97. doi: 10.1038/35052047. PubMed PMID: 11252967.

13. Blair SS. Compartments and appendage development in Drosophila. BioEssays: news and reviews in molecular, cellular and developmental biology. 1995;17(4):299-309. doi: 10.1002/bies.950170406. PubMed PMID: 7741723.

14. Guillen I, Mullor JL, Capdevila J, Sanchez-Herrero E, Morata G, Guerrero I. The function of engrailed and the specification of Drosophila wing pattern. Development. 1995;121(10):3447-56. Epub 1995/10/01. PubMed PMID: 7588077 .

15. Struhl G, Basler K. Organizing activity of wingless protein in Drosophila. Cell. 1993;72(4):527-40. Epub 1993/02/26. PubMed PMID: 8440019.

16. Ho KS, Scott MP. Sonic hedgehog in the nervous system: functions, modifications and mechanisms. Current opinion in neurobiology. 2002;12(1):5763. Epub 2002/02/28. PubMed PMID: 11861165.

17. Thomas C, Ingham PW. Hedgehog signaling in the Drosophila eye and head: an analysis of the effects of different patched trans-heterozygotes. Genetics. 2003;165(4):1915-28. Epub 2004/01/06. PubMed PMID: 14704176; PMCID: 1462905 .

18. Dansereau DA, Lasko P. The development of germline stem cells in Drosophila. Methods in molecular biology. 2008;450:3-26. doi: 10.1007/978-1-60327-2148_1. PubMed PMID: 18370048; PMCID: PMC2729445.

19. Crozatier M, Glise B, Vincent A. Patterns in evolution: veins of the Drosophila wing. Trends in genetics. 2004;20(10):498-505. doi: 10.1016/j.tig.2004.07.013. PubMed PMID: 15363904.

20. Johnson RL, Grenier JK, Scott MP. patched overexpression alters wing disc size and pattern: transcriptional and post-transcriptional effects on hedgehog targets. Development. 1995;121(12):4161-70. Epub 1995/12/01. PubMed PMID: 8575316.

21. Tsuneizumi K, Nakayama T, Kamoshida Y, Kornberg TB, Christian JL, Tabata T. Daughters against dpp modulates dpp organizing activity in Drosophila wing development. Nature. 1997;389(6651):627-31. Epub 1997/10/23 22:33. doi: 10.1038/39362. PubMed PMID: 9335506. 
22. Zecca M, Basler K, Struhl G. Direct and long-range action of a wingless morphogen gradient. Cell. 1996;87(5):833-44. Epub 1996/11/29. PubMed PMID: 8945511.

23. Cadigan KM, Fish MP, Rulifson EJ, Nusse R. Wingless repression of Drosophila frizzled 2 expression shapes the Wingless morphogen gradient in the wing. Cell. 1998;93(5):767-77. Epub 1998/06/18. PubMed PMID: 9630221.

24. Hsiung F, Ramirez-Weber FA, Iwaki DD, Kornberg TB. Dependence of Drosophila wing imaginal disc cytonemes on Decapentaplegic. Nature. 2005;437(7058):560-3. Epub 2005/09/24. doi: 10.1038/nature03951. PubMed PMID: 16177792.

25. Felsenfeld AL, Kennison JA. Positional signaling by hedgehog in Drosophila imaginal disc development. Development. 1995;121(1):1-10. PubMed PMID: 7867491 .

26. Carroll CE, Marada S, Stewart DP, Ouyang JX, Ogden SK. The extracellular loops of Smoothened play a regulatory role in control of Hedgehog pathway activation. Development. 2012;139(3):612-21. doi: 10.1242/dev.075614. PubMed PMID: 22223683; PMCID: PMC3252357.

27. Jia J, Amanai K, Wang G, Tang J, Wang B, Jiang J. Shaggy/GSK3 antagonizes Hedgehog signalling by regulating Cubitus interruptus. Nature. 2002;416(6880):548-52. doi: 10.1038/nature733. PubMed PMID: 11912487.

28. Capdevila J, Guerrero I. Targeted expression of the signaling molecule decapentaplegic induces pattern duplications and growth alterations in Drosophila wings. The EMBO journal. 1994;13(19):4459-68. Epub 1994/10/03. PubMed PMID: 7925288; PMCID: 395378.

29. Ho KS, Suyama K, Fish M, Scott MP. Differential regulation of Hedgehog target gene transcription by Costal2 and Suppressor of Fused. Development. 2005;132(6):1401-12. Epub 2005/03/08. doi: 10.1242/dev.01689. PubMed PMID: 15750186 .

30. Muenke M. Finding genes involved in human developmental disorders. Current opinion in genetics \& development. 1995;5(3):354-61. Epub 1995/06/01. PubMed PMID: 7549431.

31. Roessler E, Muenke M. Holoprosencephaly: a paradigm for the complex genetics of brain development. Journal of inherited metabolic disease. 1998;21(5):481-97. Epub 1998/09/05. doi: 10.1023/A:1005406719292. PubMed PMID: 9728329.

32. Jacob L, Lum L. Deconstructing the hedgehog pathway in development and disease. Science. 2007;318(5847):66-8. Epub 2007/10/06. doi: 10.1126/science.1147314. PubMed PMID: 17916724. 
33. Roessler E, Muenke M. The molecular genetics of holoprosencephaly. American journal of medical genetics Part C, Seminars in medical genetics. 2010;154C(1):52-61. Epub 2010/01/28. doi: 10.1002/ajmg.c.30236. PubMed PMID: 20104595; PMCID: 2815021.

34. Solomon BD, Gropman A, Muenke M. Holoprosencephaly Overview. In: Pagon RA, Bird TD, Dolan CR, Stephens K, Adam MP, editors. GeneReviews. Seattle (WA)1993.

35. Geng X, Oliver G. Pathogenesis of holoprosencephaly. The Journal of clinical investigation. 2009;119(6):1403-13. doi: 10.1172/JCI38937. PubMed PMID: 19487816; PMCID: PMC2689134.

36. Gorlin RJ. Nevoid basal cell carcinoma (Gorlin) syndrome. Genetics in medicine: official journal of the American College of Medical Genetics. 2004;6(6):530-9. doi: 10.109701.GIM.0000144188.15902.C4. PubMed PMID: 15545751.

37. Jones EA, Sajid MI, Shenton A, Evans DG. Basal cell carcinomas in gorlin syndrome: a review of 202 patients. J Skin Cancer. 2011;2011:217378. doi: 10.1155/2011/217378. PubMed PMID: 21152126; PMCID: PMC2998699.

38. Evans DG, Farndon PA. Nevoid Basal Cell Carcinoma Syndrome. In: Pagon RA, Adam MP, Ardinger HH, Wallace SE, Amemiya A, Bean LJH, Bird TD, Ledbetter N, Mefford HC, Smith RJH, Stephens K, editors. GeneReviews(R). Seattle (WA)1993.

39. Biesecker LG. Pallister-Hall Syndrome. In: Pagon RA, Adam MP, Ardinger HH, Wallace SE, Amemiya A, Bean LJH, Bird TD, Ledbetter N, Mefford HC, Smith RJH, Stephens K, editors. GeneReviews(R). Seattle (WA)1993.

40. Ma Y, Erkner A, Gong R, Yao S, Taipale J, Basler K, Beachy PA. Hedgehogmediated patterning of the mammalian embryo requires transporter-like function of dispatched. Cell. 2002;111(1):63-75. Epub 2002/10/10. PubMed PMID: 12372301 .

41. Jeong Y, Leskow FC, El-Jaick K, Roessler E, Muenke M, Yocum A, Dubourg C, Li X, Geng X, Oliver G, Epstein DJ. Regulation of a remote Shh forebrain enhancer by the Six3 homeoprotein. Nature genetics. 2008;40(11):1348-53. Epub 2008/10/07. doi: 10.1038/ng.230. PubMed PMID: 18836447; PMCID: 2648611.

42. Geng X, Acosta S, Lagutin O, Gil HJ, Oliver G. Six3 dosage mediates the pathogenesis of holoprosencephaly. Development. 2016;143(23):4462-73. doi: 10.1242/dev.132142. PubMed PMID: 27770010; PMCID: PMC5201039.

43. Ding Q, Motoyama J, Gasca S, Mo R, Sasaki H, Rossant J, Hui CC. Diminished Sonic hedgehog signaling and lack of floor plate differentiation in Gli2 mutant mice. Development. 1998;125(14):2533-43. PubMed PMID: 9636069. 
44. Mo R, Freer AM, Zinyk DL, Crackower MA, Michaud J, Heng HH, Chik KW, Shi XM, Tsui LC, Cheng SH, Joyner AL, Hui C. Specific and redundant functions of Gli2 and Gli3 zinc finger genes in skeletal patterning and development. Development. 1997;124(1):113-23. PubMed PMID: 9006072.

45. Matise MP, Epstein DJ, Park HL, Platt KA, Joyner AL. Gli2 is required for induction of floor plate and adjacent cells, but not most ventral neurons in the mouse central nervous system. Development. 1998;125(15):2759-70. PubMed PMID: 9655799.

46. Hahn H, Wojnowski L, Zimmer AM, Hall J, Miller G, Zimmer A. Rhabdomyosarcomas and radiation hypersensitivity in a mouse model of Gorlin syndrome. Nature medicine. 1998;4(5):619-22. PubMed PMID: 9585239.

47. Bose J, Grotewold L, Ruther U. Pallister-Hall syndrome phenotype in mice mutant for Gli3. Human molecular genetics. 2002;11(9):1129-35. PubMed PMID: 11978771.

48. Goodrich LV, Milenkovic L, Higgins KM, Scott MP. Altered neural cell fates and medulloblastoma in mouse patched mutants. Science. 1997;277(5329):1109-13. Epub 1997/08/22. PubMed PMID: 9262482.

49. Barakat MT, Humke EW, Scott MP. Learning from Jekyll to control Hyde: Hedgehog signaling in development and cancer. Trends in molecular medicine. 2010;16(8):337-48. Epub 2010/08/11. doi: 10.1016/j.molmed.2010.05.003. PubMed PMID: 20696410.

50. Robinson G, Parker M, Kranenburg TA, Lu C, Chen X, Ding L, Phoenix TN, Hedlund E, Wei L, Zhu X, Chalhoub N, Baker SJ, Huether R, Kriwacki R, Curley N, Thiruvenkatam R, Wang J, Wu G, Rusch M, Hong X, Becksfort J, Gupta P, Ma J, Easton J, Vadodaria B, Onar-Thomas A, Lin T, Li S, Pounds S, Paugh S, Zhao D, Kawauchi D, Roussel MF, Finkelstein D, Ellison DW, Lau CC, Bouffet E, Hassall T, Gururangan S, Cohn R, Fulton RS, Fulton LL, Dooling DJ, Ochoa K, Gajjar A, Mardis ER, Wilson RK, Downing JR, Zhang J, Gilbertson RJ. Novel mutations target distinct subgroups of medulloblastoma. Nature.

2012;488(7409):43-8. doi: 10.1038/nature11213. PubMed PMID: 22722829; PMCID: PMC3412905.

51. Taylor MD, Northcott PA, Korshunov A, Remke M, Cho YJ, Clifford SC, Eberhart CG, Parsons DW, Rutkowski S, Gajjar A, Ellison DW, Lichter P, Gilbertson RJ, Pomeroy SL, Kool M, Pfister SM. Molecular subgroups of medulloblastoma: the current consensus. Acta Neuropathol. 2012;123(4):465-72. doi: 10.1007/s00401-011-0922-z. PubMed PMID: 22134537; PMCID: PMC3306779.

52. Muller P, Rogers KW, Yu SR, Brand M, Schier AF. Morphogen transport. Development. 2013;140(8):1621-38. Epub 2013/03/28. doi: 10.1242/dev.083519. PubMed PMID: 23533171. 
53. Caspary T, Garcia-Garcia MJ, Huangfu D, Eggenschwiler JT, Wyler MR, Rakeman AS, Alcorn HL, Anderson KV. Mouse Dispatched homolog1 is required for long-range, but not juxtacrine, Hh signaling. Current biology. 2002;12(18):1628-32. Epub 2002/10/10. PubMed PMID: 12372258.

54. Callejo A, Bilioni A, Mollica E, Gorfinkiel N, Andres G, Ibanez C, Torroja C, Doglio L, Sierra J, Guerrero I. Dispatched mediates Hedgehog basolateral release to form the long-range morphogenetic gradient in the Drosophila wing disk epithelium. Proceedings of the National Academy of Sciences of the United States of America. 2011;108(31):12591-8. Epub 2011/06/22. doi: 10.1073/pnas.1106881108. PubMed PMID: 21690386; PMCID: 3150953.

55. D'Angelo G, Matusek T, Pizette S, Therond PP. Endocytosis of Hedgehog through dispatched regulates long-range signaling. Developmental cell. 2015;32(3):290-303. doi: 10.1016/j.devcel.2014.12.004. PubMed PMID: 25619925 .

56. Porter JA, Young KE, Beachy PA. Cholesterol modification of hedgehog signaling proteins in animal development. Science. 1996;274(5285):255-9. Epub 1996/10/11. PubMed PMID: 8824192.

57. Chamoun Z, Mann RK, Nellen D, von Kessler DP, Bellotto M, Beachy PA, Basler K. Skinny hedgehog, an acyltransferase required for palmitoylation and activity of the hedgehog signal. Science. 2001;293(5537):2080-4. Epub 2001/08/04. doi: 10.1126/science.1064437. PubMed PMID: 11486055.

58. Peters C, Wolf A, Wagner M, Kuhlmann J, Waldmann H. The cholesterol membrane anchor of the Hedgehog protein confers stable membrane association to lipid-modified proteins. Proceedings of the National Academy of Sciences of the United States of America. 2004;101(23):8531-6. doi: 10.1073/pnas.0308449101. PubMed PMID: 15163793; PMCID: PMC423228.

59. Burke R, Nellen D, Bellotto M, Hafen E, Senti KA, Dickson BJ, Basler K. Dispatched, a novel sterol-sensing domain protein dedicated to the release of cholesterol-modified hedgehog from signaling cells. Cell. 1999;99(7):803-15. Epub 2000/01/05. PubMed PMID: 10619433.

60. Kawakami T, Kawcak T, Li YJ, Zhang W, Hu Y, Chuang PT. Mouse dispatched mutants fail to distribute hedgehog proteins and are defective in hedgehog signaling. Development. 2002;129(24):5753-65. Epub 2002/11/08. PubMed PMID: 12421714.

61. Nakano Y, Kim HR, Kawakami A, Roy S, Schier AF, Ingham PW. Inactivation of dispatched 1 by the chameleon mutation disrupts Hedgehog signalling in the zebrafish embryo. Developmental biology. 2004;269(2):381-92. Epub 2004/04/28. doi: 10.1016/j.ydbio.2004.01.022. PubMed PMID: 15110707. 
62. Kuwabara PE, Labouesse M. The sterol-sensing domain: multiple families, a unique role? Trends in Genetics. 2002;18(4):193-201. doi: Doi 10.1016/S01689525(02)02640-9. PubMed PMID: ISI:000174770300011.

63. Espenshade PJ, Li WP, Yabe D. Sterols block binding of COPII proteins to SCAP, thereby controlling SCAP sorting in ER. Proceedings of the National Academy of Sciences of the United States of America. 2002;99(18):11694-9. Epub 2002/08/24. doi: 10.1073/pnas.182412799. PubMed PMID: 12193656; PMCID: 129331.

64. Brown MS, Goldstein JL. Cholesterol feedback: from Schoenheimer's bottle to Scap's MELADL. Journal of lipid research. 2009;50 Suppl:S15-27. Epub 2008/11/01. doi: 10.1194/jlr.R800054-JLR200. PubMed PMID: 18974038; PMCID: 2674699.

65. Sever N, Yang T, Brown MS, Goldstein JL, DeBose-Boyd RA. Accelerated degradation of HMG CoA reductase mediated by binding of insig-1 to its sterolsensing domain. Molecular cell. 2003;11(1):25-33. PubMed PMID: 12535518.

66. Patterson M. Niemann-Pick Disease Type C. In: Pagon RA, Adam MP, Ardinger HH, Wallace SE, Amemiya A, Bean LJH, Bird TD, Ledbetter N, Mefford HC, Smith RJH, Stephens K, editors. GeneReviews(R). Seattle (WA)1993.

67. Strutt H, Thomas C, Nakano Y, Stark D, Neave B, Taylor AM, Ingham PW. Mutations in the sterol-sensing domain of Patched suggest a role for vesicular trafficking in Smoothened regulation. Current biology. 2001;11(8):608-13. Epub 2001/05/23. PubMed PMID: 11369206.

68. Ohsaki Y, Sugimoto Y, Suzuki M, Hosokawa H, Yoshimori T, Davies JP, Ioannou YA, Vanier MT, Ohno K, Ninomiya H. Cholesterol depletion facilitates ubiquitylation of NPC1 and its association with SKD1/Vps4. Journal of cell science. 2006;119(Pt 13):2643-53. Epub 2006/06/08. doi: 10.1242/jcs.02993. PubMed PMID: 16757520.

69. Tseng TT, Gratwick KS, Kollman J, Park D, Nies DH, Goffeau A, Saier MH, Jr. The RND permease superfamily: an ancient, ubiquitous and diverse family that includes human disease and development proteins. J Mol Microbiol Biotechnol. 1999;1(1):107-25. PubMed PMID: 10941792.

70. Nikaido H, Takatsuka Y. Mechanisms of RND multidrug efflux pumps. Biochimica et biophysica acta. 2009;1794(5):769-81. doi: 10.1016/j.bbapap.2008.10.004. PubMed PMID: 19026770; PMCID: PMC2696896.

71. Nies DH. Efflux-mediated heavy metal resistance in prokaryotes. FEMS Microbiol Rev. 2003;27(2-3):313-39. PubMed PMID: 12829273. 
72. Etheridge LA, Crawford TQ, Zhang S, Roelink H. Evidence for a role of vertebrate Disp1 in long-range Shh signaling. Development. 2010;137(1):133-40. Epub 2009/12/22. doi: 10.1242/dev.043547. PubMed PMID: 20023168; PMCID: 2796928.

73. Marigo V, Davey RA, Zuo Y, Cunningham JM, Tabin CJ. Biochemical evidence that patched is the Hedgehog receptor. Nature. 1996;384(6605):176-9. doi: 10.1038/384176a0. PubMed PMID: 8906794.

74. Chen Y, Struhl G. Dual roles for patched in sequestering and transducing Hedgehog. Cell. 1996;87(3):553-63. PubMed PMID: 8898207.

75. Torroja C, Gorfinkiel N, Guerrero I. Patched controls the Hedgehog gradient by endocytosis in a dynamin-dependent manner, but this internalization does not play a major role in signal transduction. Development. 2004;131(10):2395-408. Epub 2004/04/23. doi: 10.1242/dev.01102. PubMed PMID: 15102702.

76. Taipale J, Cooper MK, Maiti T, Beachy PA. Patched acts catalytically to suppress the activity of Smoothened. Nature. 2002;418(6900):892-7. Epub 2002/08/23. doi: 10.1038/nature00989. PubMed PMID: 12192414.

77. Alcedo J, Ayzenzon M, Von Ohlen T, Noll M, Hooper JE. The Drosophila smoothened gene encodes a seven-pass membrane protein, a putative receptor for the hedgehog signal. Cell. 1996;86(2):221-32. PubMed PMID: 8706127.

78. van den Heuvel M, Ingham PW. smoothened encodes a receptor-like serpentine protein required for hedgehog signalling. Nature. 1996;382(6591):547-51. Epub 1996/08/08. doi: 10.1038/382547a0. PubMed PMID: 8700230.

79. Mukhopadhyay S, Rohatgi R. G-protein-coupled receptors, Hedgehog signaling and primary cilia. Seminars in cell \& developmental biology. 2014;33:63-72. doi: 10.1016/j.semcdb.2014.05.002. PubMed PMID: 24845016; PMCID: PMC4130902.

80. Dominguez M, Brunner M, Hafen E, Basler K. Sending and receiving the hedgehog signal: control by the Drosophila Gli protein Cubitus interruptus. Science. 1996;272(5268):1621-5. Epub 1996/06/14. PubMed PMID: 8658135.

81. Tabata T, Kornberg TB. Hedgehog is a signaling protein with a key role in patterning Drosophila imaginal discs. Cell. 1994;76(1):89-102. Epub 1994/01/14. PubMed PMID: 8287482.

82. Torroja C, Gorfinkiel N, Guerrero I. Mechanisms of Hedgehog gradient formation and interpretation. Journal of neurobiology. 2005;64(4):334-56. Epub 2005/07/26. doi: 10.1002/neu.20168. PubMed PMID: 16041759. 
83. Eaton S. Release and trafficking of lipid-linked morphogens. Current opinion in genetics \& development. 2006;16(1):17-22. Epub 2005/12/21. doi: 10.1016/j.gde.2005.12.006. PubMed PMID: 16364628.

84. Porter JA, von Kessler DP, Ekker SC, Young KE, Lee JJ, Moses K, Beachy PA. The product of hedgehog autoproteolytic cleavage active in local and long-range signalling. Nature. 1995;374(6520):363-6. Epub 1995/03/23. doi: 10.1038/374363a0. PubMed PMID: 7885476.

85. Pepinsky RB, Zeng C, Wen D, Rayhorn P, Baker DP, Williams KP, Bixler SA, Ambrose CM, Garber EA, Miatkowski K, Taylor FR, Wang EA, Galdes A. Identification of a palmitic acid-modified form of human Sonic hedgehog. The Journal of biological chemistry. 1998;273(22):14037-45. PubMed PMID: 9593755.

86. Stegman MA, Vallance JE, Elangovan G, Sosinski J, Cheng Y, Robbins DJ. Identification of a tetrameric hedgehog signaling complex. The Journal of biological chemistry. 2000;275(29):21809-12. Epub 2000/05/29. doi: 10.1074/jbc.C000043200. PubMed PMID: 10825151.

87. Zeng X, Goetz JA, Suber LM, Scott WJ, Jr., Schreiner CM, Robbins DJ. A freely diffusible form of Sonic hedgehog mediates long-range signalling. Nature. 2001;411(6838):716-20. Epub 2001/06/08. doi: 10.1038/35079648. PubMed PMID: 11395778 .

88. Chen MH, Li YJ, Kawakami T, Xu SM, Chuang PT. Palmitoylation is required for the production of a soluble multimeric Hedgehog protein complex and longrange signaling in vertebrates. Genes \& development. 2004;18(6):641-59. Epub 2004/04/13. doi: 10.1101/gad.1185804. PubMed PMID: 15075292; PMCID: 387240 .

89. Goetz JA, Suber LM, Zeng X, Robbins DJ. Sonic Hedgehog as a mediator of long-range signaling. BioEssays: news and reviews in molecular, cellular and developmental biology. 2002;24(2):157-65. Epub 2002/02/09. doi: 10.1002/bies.10056. PubMed PMID: 11835280.

90. Panakova D, Sprong H, Marois E, Thiele C, Eaton S. Lipoprotein particles are required for Hedgehog and Wingless signalling. Nature. 2005;435(7038):58-65. Epub 2005/05/06. doi: 10.1038/nature03504. PubMed PMID: 15875013.

91. Willnow TE, Hammes A, Eaton S. Lipoproteins and their receptors in embryonic development: more than cholesterol clearance. Development. 2007;134(18):323949. Epub 2007/08/28. doi: 10.1242/dev.004408. PubMed PMID: 17720693.

92. Eugster C, Panakova D, Mahmoud A, Eaton S. Lipoprotein-heparan sulfate interactions in the Hh pathway. Developmental cell. 2007;13(1):57-71. Epub 2007/07/05. doi: 10.1016/j.devcel.2007.04.019. PubMed PMID: 17609110. 
93. Eaton S. Multiple roles for lipids in the Hedgehog signalling pathway. Nature reviews molecular cell biology. 2008;9(6):437-45. Epub 2008/05/27. doi: 10.1038/nrm2414. PubMed PMID: 18500255.

94. Palm W, Swierczynska MM, Kumari V, Ehrhart-Bornstein M, Bornstein SR, Eaton S. Secretion and signaling activities of lipoprotein-associated hedgehog and non-sterol-modified hedgehog in flies and mammals. PLoS biology. 2013;11(3):e1001505. doi: 10.1371/journal.pbio.1001505. PubMed PMID: 23554573; PMCID: PMC3595218.

95. Weisgraber KH. Apolipoprotein E: structure-function relationships. Adv Protein Chem. 1994;45:249-302. PubMed PMID: 8154371.

96. Gradilla AC, Gonzalez E, Seijo I, Andres G, Bischoff M, Gonzalez-Mendez L, Sanchez V, Callejo A, Ibanez C, Guerra M, Ortigao-Farias JR, Sutherland JD, Gonzalez M, Barrio R, Falcon-Perez JM, Guerrero I. Exosomes as Hedgehog carriers in cytoneme-mediated transport and secretion. Nature communications. 2014;5:5649. doi: 10.1038/ncomms6649. PubMed PMID: 25472772.

97. McCarthy RA, Barth JL, Chintalapudi MR, Knaak C, Argraves WS. Megalin functions as an endocytic sonic hedgehog receptor. The Journal of biological chemistry. 2002;277(28):25660-7. doi: 10.1074/jbc.M201933200. PubMed PMID: 11964399.

98. McCarthy RA, Argraves WS. Megalin and the neurodevelopmental biology of sonic hedgehog and retinol. Journal of cell science. 2003;116(Pt 6):955-60. PubMed PMID: 12584240.

99. Beachy PA, Hymowitz SG, Lazarus RA, Leahy DJ, Siebold C. Interactions between Hedgehog proteins and their binding partners come into view. Genes \& development. 2010;24(18):2001-12. Epub 2010/09/17. doi: 10.1101/gad.1951710. PubMed PMID: 20844013; PMCID: 2939362.

100. Parchure A, Vyas N, Ferguson C, Parton RG, Mayor S. Oligomerization and endocytosis of Hedgehog is necessary for its efficient exovesicular secretion. Molecular biology of the cell. 2015;26(25):4700-17. doi: 10.1091/mbc.E15-090671. PubMed PMID: 26490120; PMCID: PMC4678025.

101. Looze C, Yui D, Leung L, Ingham M, Kaler M, Yao X, Wu WW, Shen RF, Daniels MP, Levine SJ. Proteomic profiling of human plasma exosomes identifies PPARgamma as an exosome-associated protein. Biochemical and biophysical research communications. 2009;378(3):433-8. doi: 10.1016/j.bbrc.2008.11.050. PubMed PMID: 19028452; PMCID: PMC2633355.

102. Morales CR, Zeng J, El Alfy M, Barth JL, Chintalapudi MR, McCarthy RA, Incardona JP, Argraves WS. Epithelial trafficking of Sonic hedgehog by megalin. J Histochem Cytochem. 2006;54(10):1115-27. doi: 10.1369/jhc.5A6899.2006. PubMed PMID: 16801528; PMCID: PMC3957805. 
103. Chuang PT, McMahon AP. Vertebrate Hedgehog signalling modulated by induction of a Hedgehog-binding protein. Nature. 1999;397(6720):617-21. Epub 1999/03/02. doi: 10.1038/17611. PubMed PMID: 10050855.

104. Gradilla AC, Guerrero I. Cytoneme-mediated cell-to-cell signaling during development. Cell and tissue research. 2013. Epub 2013/02/26. doi: 10.1007/s00441-013-1578-x. PubMed PMID: 23435991.

105. Ramirez-Weber FA, Kornberg TB. Cytonemes: cellular processes that project to the principal signaling center in Drosophila imaginal discs. Cell. 1999;97(5):599607. Epub 1999/06/15. PubMed PMID: 10367889.

106. Sherer NM, Mothes W. Cytonemes and tunneling nanotubules in cell-cell communication and viral pathogenesis. Trends in cell biology. 2008;18(9):41420. Epub 2008/08/16. doi: 10.1016/j.tcb.2008.07.003. PubMed PMID: 18703335; PMCID: 2628975.

107. Roy S, Hsiung F, Kornberg TB. Specificity of Drosophila cytonemes for distinct signaling pathways. Science. 2011;332(6027):354-8. Epub 2011/04/16. doi: 10.1126/science.1198949. PubMed PMID: 21493861; PMCID: 3109072.

108. Kornberg T. Pictures in cell biology. Cytonemes. Trends in cell biology. 1999;9(11):434. Epub 2000/01/08. PubMed PMID: 10627154.

109. Sato M, Kornberg TB. FGF is an essential mitogen and chemoattractant for the air sacs of the drosophila tracheal system. Developmental cell. 2002;3(2):195-207. Epub 2002/08/27. PubMed PMID: 12194851.

110. Rojas-Rios P, Guerrero I, Gonzalez-Reyes A. Cytoneme-mediated delivery of hedgehog regulates the expression of bone morphogenetic proteins to maintain germline stem cells in Drosophila. PLoS biology. 2012;10(4):e1001298. Epub 2012/04/18. doi: 10.1371/journal.pbio.1001298. PubMed PMID: 22509132; PMCID: 3317903.

111. Sanders TA, Llagostera E, Barna M. Specialized filopodia direct long-range transport of SHH during vertebrate tissue patterning. Nature.

2013;497(7451):628-32. Epub 2013/04/30. doi: 10.1038/nature12157. PubMed PMID: 23624372; PMCID: 4197975.

112. Sagar, Prols F, Wiegreffe C, Scaal M. Communication between distant epithelial cells by filopodia-like protrusions during embryonic development. Development. 2015;142(4):665-71. doi: 10.1242/dev.115964. PubMed PMID: 25617437.

113. Bischoff M, Gradilla AC, Seijo I, Andres G, Rodriguez-Navas C, GonzalezMendez L, Guerrero I. Cytonemes are required for the establishment of a normal Hedgehog morphogen gradient in Drosophila epithelia. Nature cell biology. 2013;15(11):1269-81. doi: 10.1038/ncb2856. PubMed PMID: 24121526; PMCID: PMC3840581. 
114. Roy S, Huang H, Liu S, Kornberg TB. Cytoneme-mediated contact-dependent transport of the Drosophila decapentaplegic signaling protein. Science. 2014;343(6173):1244624. doi: 10.1126/science.1244624. PubMed PMID: 24385607; PMCID: PMC4336149.

115. Bryant PJ. Filopodia: fickle fingers of cell fate? Current biology. 1999;9(17):R655-7. Epub 1999/10/06. PubMed PMID: 10508575.

116. Marada S, Stewart DP, Bodeen WJ, Han YG, Ogden SK. The unfolded protein response selectively targets active smoothened mutants. Molecular and cellular biology. 2013;33(12):2375-87. doi: 10.1128/MCB.01445-12. PubMed PMID: 23572559; PMCID: PMC3700102.

117. Afshar K, Stuart B, Wasserman SA. Functional analysis of the Drosophila diaphanous FH protein in early embryonic development. Development. 2000;127(9):1887-97. PubMed PMID: 10751177.

118. Muller T, Schumann C, Kraegeloh A. STED microscopy and its applications: new insights into cellular processes on the nanoscale. Chemphyschem: a European journal of chemical physics and physical chemistry. 2012;13(8):1986-2000. doi: 10.1002/cphc.201100986. PubMed PMID: 22374829.

119. Blom H, Widengren J. STED microscopy - towards broadened use and scope of applications. Current opinion in chemical biology. 2014;20:127-33. doi: 10.1016/j.cbpa.2014.06.004. PubMed PMID: 24983537.

120. Felgner PL, Gadek TR, Holm M, Roman R, Chan HW, Wenz M, Northrop JP, Ringold GM, Danielsen M. Lipofection: a highly efficient, lipid-mediated DNAtransfection procedure. Proceedings of the National Academy of Sciences of the United States of America. 1987;84(21):7413-7. PubMed PMID: 2823261; PMCID: PMC299306.

121. van Meer G. Membranes in motion. EMBO reports. 2010;11(5):331-3. Epub 2010/04/17. doi: 10.1038/embor.2010.60. PubMed PMID: 20395954; PMCID: 2868540 .

122. van Meer G, Hoetzl S. Sphingolipid topology and the dynamic organization and function of membrane proteins. FEBS letters. 2010;584(9):1800-5. Epub 2009/10/20. doi: 10.1016/j.febslet.2009.10.020. PubMed PMID: 19837070.

123. van Meer G, de Kroon AI. Lipid map of the mammalian cell. Journal of cell science. 2011;124(Pt 1):5-8. Epub 2010/12/22. doi: 10.1242/jcs.071233. PubMed PMID: 21172818.

124. Dubreuil RR, Maddux PB, Grushko TA, MacVicar GR. Segregation of two spectrin isoforms: polarized membrane-binding sites direct polarized membrane skeleton assembly. Molecular biology of the cell. 1997;8(10):1933-42. PubMed PMID: 9348534; PMCID: PMC25644. 
125. Bailey EC, Scott MP, Johnson RL. Hedgehog signaling in animal development and human disease. Ernst Schering Research Foundation workshop. 2000(29):211-35. Epub 2000/08/16. PubMed PMID: 10943312.

126. Zheng X, Zeng W, Gai X, Xu Q, Li C, Liang Z, Tuo H, Liu Q. Role of the Hedgehog pathway in hepatocellular carcinoma (review). Oncol Rep. 2013;30(5):2020-6. doi: 10.3892/or.2013.2690. PubMed PMID: 23970376.

127. Therond PP, Knight JD, Kornberg TB, Bishop JM. Phosphorylation of the fused protein kinase in response to signaling from hedgehog. Proceedings of the National Academy of Sciences of the United States of America. 1996;93(9):42248. Epub 1996/04/30. PubMed PMID: 8633045; PMCID: 39516.

128. Haltiwanger RS, Lowe JB. Role of glycosylation in development. Annual review of biochemistry. 2004;73:491-537. doi: 10.1146/annurev.biochem.73.011303.074043. PubMed PMID: 15189151.

129. Seidah NG. The proprotein convertases, 20 years later. Methods in molecular biology. 2011;768:23-57. doi: 10.1007/978-1-61779-204-5_3. PubMed PMID: 21805237.

130. Kibirev VK, Osadchuk TV. [Structure and properties of proprotein convertase inhibitors]. Ukr Biokhim Zh (1999). 2012;84(2):5-29. PubMed PMID: 22642118.

131. Scamuffa N, Calvo F, Chretien M, Seidah NG, Khatib AM. Proprotein convertases: lessons from knockouts. FASEB journal: official publication of the Federation of American Societies for Experimental Biology. 2006;20(12):195463. doi: 10.1096/fj.05-5491rev. PubMed PMID: 17012247.

132. Johnson TK, Henstridge MA, Herr A, Moore KA, Whisstock JC, Warr CG. Torso-like mediates extracellular accumulation of Furin-cleaved Trunk to pattern the Drosophila embryo termini. Nature communications. 2015;6:8759. doi: 10.1038/ncomms9759. PubMed PMID: 26508274; PMCID: PMC4640135.

133. Kunnapuu J, Bjorkgren I, Shimmi O. The Drosophila DPP signal is produced by cleavage of its proprotein at evolutionary diversified furin-recognition sites. Proceedings of the National Academy of Sciences of the United States of America. 2009;106(21):8501-6. doi: 10.1073/pnas.0809885106. PubMed PMID: 19433798; PMCID: PMC2689000.

134. Jarriault S, Le Bail O, Hirsinger E, Pourquie O, Logeat F, Strong CF, Brou C, Seidah NG, Isra $1 \mathrm{~A}$. Delta-1 activation of notch-1 signaling results in HES-1 transactivation. Molecular and cellular biology. 1998;18(12):7423-31. PubMed PMID: 9819428; PMCID: PMC109323.

135. Molloy SS, Thomas G. Furin. In: Dalbey R, Sigman D, editors. Co- and Posttranslational Proteolysis of Proteins. 3 ed: Academic Press; 2001. p. 509. 
136. Lipari MT, Li W, Moran P, Kong-Beltran M, Sai T, Lai J, Lin SJ, Kolumam G, Zavala-Solorio J, Izrael-Tomasevic A, Arnott D, Wang J, Peterson AS, Kirchhofer D. Furin-cleaved proprotein convertase subtilisin/kexin type 9 (PCSK9) is active and modulates low density lipoprotein receptor and serum cholesterol levels. The Journal of biological chemistry. 2012;287(52):43482-91. doi: 10.1074/jbc.M112.380618. PubMed PMID: 23135270; PMCID: PMC3527935.

137. Tanentzapf G, Smith C, McGlade J, Tepass U. Apical, lateral, and basal polarization cues contribute to the development of the follicular epithelium during Drosophila oogenesis. The Journal of cell biology. 2000;151(4):891-904. PubMed PMID: 11076972 ; PMCID: PMC2169434.

138. Simmen T, Nobile M, Bonifacino JS, Hunziker W. Basolateral sorting of furin in MDCK cells requires a phenylalanine-isoleucine motif together with an acidic amino acid cluster. Molecular and cellular biology. 1999;19(4):3136-44. PubMed PMID: 10082580; PMCID: PMC84107. 


\section{VITA}

William Joseph Bodeen was born in Memphis, TN in the spring of 1985 . He earned his Bachelors of Science in Natural Sciences from Christian Brothers University in Memphis, TN in December of 2007. He married his wife Rachael Nichole Valenzuela in the spring of 2010 and welcomed their first child Benjamin to the family in the winter of 2015. He is expected to receive his Ph.D. in Biomedical Sciences with a concentration in Cancer and Developmental Biology from the University of Tennessee Health Science Center in May of 2017. 